MARIANA BROLEZZI GOMES TEIXEIRA

\title{
ASPECTOS FISIOLÓGICOS E GENÉTICOS QUE CARACTERIZAM ENTEROBACTÉRIAS ISOLADAS DE CANA-DE-AÇÚCAR OU DE ORIGEM CLÍNICA
}

Dissertação apresentada ao Programa de Pós-Graduação Interunidades em Biotecnologia USP/Instituto Butantan/IPT, para obtenção do Título de Mestre em Biotecnologia. 
MARIANA BROLEZZI GOMES TEIXEIRA

\section{ASPECTOS FISIOLÓGICOS E GENÉTICOS QUE CARACTERIZAM \\ ENTEROBACTÉRIAS ISOLADAS DE CANA-DE-AÇÚCAR OU DE ORIGEM \\ CLÍNICA}

Dissertação apresentada ao Programa de Pós-Graduação Interunidades em Biotecnologia USP/Instituto Butantan/IPT, para obtenção do Título de Mestre em Biotecnologia.

Área de concentração: Biotecnologia

Orientadora: Profa. Dra. Heloiza Ramos Barbosa

Versão original 
DADOS DE CATALOGAÇÅO NA PUBLICAÇÃo (CIP)

Serviço de Biblioteca e Informação Biomédica do

Instituto de Cièncias Biomédicas da Universidade de São Paulo

reproduçăo nåo autortzada pelo autor

Teixeira, Mariana Brolezzi Gomes.

Aspectos fisiológicos e genéticos que caracterizam enterobactérias isoladas de cana-de-açúcar ou de origem clínica / Mariana Brolezzi Gomes Teixeira. - São Paulo, 2014.

Orientador. Profa. Dra. Heloiza Ramos Barbosa.

Dissertaçäo (Mestrado) - Universidade de Säo Paulo. Instituto de Ciências Biomédicas. Programa de Pós-Graduaçäo Interunidades em Biotecnologia USP/IPT/Instituto Butantan. Área de concentraçäo: Microbiologia. Linha de pesquisa: Fisiologia de microrganismos.

Versäo do título para o inglês: Physiological and genetic characteristics that distinguish Enterobacteriaceae from surgarcane and clinical sources.

1. Enterobacteriaceae 2. Filogenia 3. Nitrogenase 4. Cana-deaçúcar 5. Antibióticos 6. Bactérias I. Barbosa, Profa. Dra. Heloiza Ramos II. Universidade de São Paulo. Instituto de Cièncias Biomédicas. Programa de Pós-Graduaçäo Interunidades em Biotecnologia USP/IPT/Instituto Butantan III. Título. 
UNIVERSIDADE DE SÃO PAULO

Programa de Pós-Graduação Interunidades em Biotecnologia Universidade de São Paulo, Instituto Butantan, Instituto de Pesquisas Tecnológicas

Candidato(a): $\quad$ Mariana Brolezzi Gomes Teixeira.

Título da Dissertação: $\quad$ Aspectos fisiológicos e genéticos que caracterizam enterobactérias isoladas de cana-de-açúcar ou de origem clínica.

Orientador(a): $\quad$ Profa. Dra. Heloiza Ramos Barbosa.

A Comissão Julgadora dos trabalhos de Defesa da Dissertação de Mestrado, em sessão pública realizada a ....................................................., considerou

( ) Aprovado(a) ( ) Reprovado(a)

Examinador(a): Assinatura:

Nome:

Instituição:

Examinador(a): Assinatura:

Nome:

Instituição:

Presidente: Assinatura:

Nome:

Instituição: 


\section{CERTIFICADO DE ISENÇÃO}

Certificamos que o Protocolo CEP-ICB N ${ }^{\circ} 633 / 13$ referente ao projeto intitulado: "Aspectos fisiológicos e genéticos que caracterizam bactérias dos gêneros Klebsiella e Enterobacter isoladas de cana-de-acticar ou de casos clinicos bumanos" sob a responsabilidade de Mariana Brolezzi Gomes Teixeira, foi analisado na presente data pela CEUA - COMISSÃo DE ÉTTCA NO USO DE ANIMAIS e pela CEPSH- COMISSÃo DE ÉTICA EM PESQUISA COM SERES HUMANOS, tendo sido deliberado que o referido projeto não utilizará animais que estejam sob a égide da lei 11.794 de 8 de outubro de 2008, nem envolverá procedimentos regulados pela Resolução CONEP n ${ }^{\circ} 466$ de 2012.

São Paulo, 16 de dezembro de 2013.

$$
\text { P) Qunes }
$$

PROF. DR. WOTHAN TAVARES DE L.TMA Coordenador da CEUA - ICB/USP

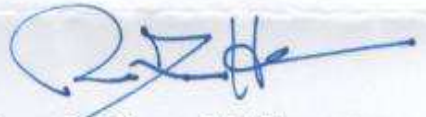

PROF. DR. PAOLO M.A Z.ANOTTO Coordenador da CEPsh - ICB/USP 
Aos meus pais pela dedicação, carinho e paciência com a filha mais bonita deles (eu). 


\section{AGRADECIMENTOS}

À professora Heloiza, pelo ensinamento, orientação e amizade durante todos estes anos.

Aos meus pais, Silvio e Telma, que sempre acreditaram em mim e me apoiaram em todas as decisões da minha vida.

À minha irmã, Fabiana, que, mesmo não sendo a filha mais bonita, me deu um sobrinho absolutamente amável!

Ao meu noivo Marcello, por querer casar comigo... $=\mathrm{D}$

Aos meus avós, Vó Leonor e Vô José (in memorian), pela ajuda na minha criação e por estar sempre presente, e Vó urubu e Vô Pedro pelo carinho.

Aos meus padrinhos ${ }^{2}$ Titia Léa e Tio Valdir, pelo incentivo e apoio.

A todos meus familiares e amigos, eu não seria nada sem vocês. ${ }^{\wedge}$

À Íris, japinha 1, por toda ajuda no laboratório e fora, esse laboratório não seria o mesmo sem você; e ao Zé, que diz que eu pareço a Penélope Cruz.. kkkkkkk

À Simoneusa Japoneusa, que, de tanto perguntarem se ela é minha irmã, eu já a considero como, obrigada mesmo por toda ajuda, pelo ensinamento e paciência com a sua estagiária mais legal... rs.

A todos os colegas do laboratório: Felizpe Ibañez, que sai do país pra fugir da gente e mesmo assim é acordado via Face Time às $6 \mathrm{~h}$ da manhã. Robertuska, que me toma café da manhã no bandex comigo duas vezes no mesmo dia. Linita, que me ensinou a falar espanhol fluentemente, Drikonilda, companheira de breja e o NAD mais bonito da USP, Priscila, japinha 2, que é sempre toda fofa com todos e faz qualquer um sorrir, mesmo nos piores dias. Andrea, por perceber que meu espanhol é mesmo fluente. Leo Gabs Cida, rsrs é muito nome pra uma pessoa só, por ter ajudado a gente por tanto tempo.

Ao Mateus, pelo apoio, amizade e as traduções.

A todos meus amigos, que sempre me apoiam: Eulalia, Priscila, Dani Toth, Láila, Lelê, Cavera pino de boliche, Luciene Nega Diaba, Pilco, Pierre e Gilli.

Ao Prof. Nilton Lincopan, pela ajuda no trabalho, pelas amostras utilizadas aqui, pela amizade e por arrumar sempre uma cerveja escondida nas festas do departamento pra mim. =)

À professora, Eny Floh e sua técnica de laboratório, Amanda, por disponibilizar o laboratório dela, para a realização de alguns experimentos, me ensinarem as técnicas e pela ajuda.

Ao Prof. Beny Spira, que autorizou a utilização do transluminador.

À prof. Márcia, por autorizar a utilização do software Bionumerics.

Aos funcionários da secretaria: Fábia e Marcos, por sempre me ajudar quando necessário.

A CAPES, pelo apoio financeiro e FAPESP pelo financiamento do projeto.

A todos os professores e alunos do departamento.

\section{MUITO OBRIGADA!!}




\section{RESUMO}

Brolezzi M. Aspectos fisiológicos e genéticos que caracterizam Enterobactérias isoladas de cana-deaçúcar ou de origem clínica. [dissertação (Mestrado em Biotecnologia)]. São Paulo: Instituto de Ciências Biomédicas, Universidade de São Paulo; 2014.

Membros da família Enterobacteriaceae são comumente encontrados em simbiose com plantas, promovendo o crescimento vegetal, principalmente, através da redução do nitrogênio atmosférico a amônia, provavelmente devido a transferência deste nitrogênio combinado à planta. Entretanto, enterobacterias são os principais patógenos na medicina humana e veterinária. Estas infecções podem ser adquiridas através de fonts exógenas, incluindo água, fezes, trato intestinal de animais, frutas e vegetais. O objetivo deste estudo é buscar marcadores genéticos e fisiológicos que caracterizem espécies de enterobactérias isoladas de plantas e origem clínica. Enterobactérias isoladas de cana-de-açúcar $(n=24)$ e de origem clínica $(n=15)$ foram submetidas a testes fisiológicos, bioquímicos e genéticos, como: i) análise da capacidade de fixar nitrogênio atmosférico; ii) avaliar a presença do gene nifH; iii) definir o perfil de susceptibilidade a antibióticos; iv) atividade hemolítica; v) produção de substâncias promotoras de crescimento; e, vi) liberação de enzimas extracelulares que favorecem a entrada na planta. A identificação bacteriana foi realizada por MALDI TOF-MS e sequenciamento dos genes $16 S$ rRNA, rpoB and gapA. Árvores filogenéticas foram construídas e a relação clonal foi realizada por ERIC PCR. Para isolados clínicos, a identificação por MALDI TOF-MS mostrou $100 \%$ de correlação com o método molecular, mas essa correlação é reduzida a $75 \%$ em amostras de origem ambiental. Isolados endofíticos e de rizosfera pertencem aos gêneros: Klebsiella, Enterobacter e Kosakonia e os isolados clínicos pertencem aos gêneros: Klebsiella, Enterobacter e Pluralibacter. A atividade da nitrogenase e os perfis de susceptibilidade a antibióticos foram bons marcadores, pois foram os ensaios que mais diferenciaram amostras de origem clínica e ambiental $(p<0.05)$. Amostras ambientais provaram ser melhores fixadores de nitrogênio, enquanto as clínicas exibiram perfil de múltipla resistência a antibióticos. Para o ensaio de redução de acetileno, $87.5 \%$ das amostras ambientais foram positivas, enquanto $20 \%$ das amostras clínicas apresentaram a nitrogenase ativa. $\mathrm{O}$ gene relacionado à fixação de nitrogênio, nifH, foi encontrado em $94 \mathrm{e}$ $40 \%$ das amostras ambientais e clínicas, respectivamente. A produção de hemolisina e fitormônios [ácido indol-3-acético (AIA) e etileno] não foram suficientemente distintivas para caracterizar os grupos, uma vez que, AIA foi produzido em 100 e $83 \%$ dos isolados clínicos e ambientais, respectivamente. O fitormônio etileno foi produzido por aproximadamente $93 \%$ de todas as amostras. Cerca de $80 \%$ de todos os isolados foram capazes de solubilizar fosfato; e pectinase foi produzida por 33 e $46 \%$ das amostras ambientais e clínicas, respectivamente. Por fim, enterobactérias não possuem uma relação clonal, embora a heterogeneidade entre amostras patogênicas e ambientais seja evidente. Atividades metabólicas e fisiológicas altamente conservadas, sustentadas pelo ponto vista genético, permitem a distribuição destas espécies em diferentes ecossistemas, e, em condições favoráveis, esta adaptação pode contribuir para o estabelecimento de processos patogênicos em animais ou simbióticos em plantas. Então, enterobacterias ambientais podem se tornar patogênicas, enquanto isolados clínicos podem se adaptar a condições ambientais.

Palavras-chave: Enterobacteriaceae. Cana-de-açúcar. Fixação biológica de nitrogênio. Antibióticos. Ambiental. Clínica. 


\begin{abstract}
Brolezzi M. Physiological and genetic characteristics that distinguish Enterobacteriaceae from sugarcane and clinical sources. [Master's thesis (Biotechnology)]. São Paulo: Instituto de Ciências Biomédicas, Universidade de São Paulo; 2014.

Members of the Enterobacteriaceae family are commonly found in symbiosis with plants, promoting their growth mainly by the reduction of the atmospheric nitrogen to ammonia, probably due the transference of combined nitrogen to the plant. On the other hand, enterobacterias are major pathogens in human and veterinary medicine. In this regard, mostly associated infections can be acquired from exogenous sources, including water, sewage, intestinal tract of animals, fruits and vegetables. The aim of this study was to characterize physiological and genetic markers that distinguish enterobacterias species isolated from plant food and clinical sources. Enterobacterias isolates from sugarcane $(n=24)$ and clinical samples $(n=15)$ were characterized regarding physiological, biochemical and genetic properties using laboratory assays to: i) verify the ability to fix atmospheric nitrogen; ii) evaluate the presence of the nifH gene; iii) determine the antibiotic susceptibility profile; iv) screen for hemolytic activity; v) production of plant-growth promoting compounds; and, vi) study the release of extracellular enzymes favoring the entry into the host plant. Bacterial identification was made by MALDI TOF-MS and sequencing of the 16S rRNA, rpoB and gapA genes. Phylogenetic trees were constructed and the clonal relatedness was evaluated by ERIC PCR. For clinical isolates, identification by MALDI TOF-MS had $100 \%$ correlation with the molecular method and otherwise this correlation was reduced to $75 \%$ in environmental strains. While, endophytic and rhizosphere isolates belonged to genus Klebsiella, Enterobacter and Kosakonia, clinical isolates belonged to Klebsiella, Enterobacter and Pluralibacter genus. Nitrogenase activity and the antibiotic susceptibility profiles was specific marker, which distinguished clinical and environmental strains $(p<0.05)$. Indeed, environmental strains proved to be best nitrogen fixers whereas clinic strains exhibited a multidrug-resistant profile. In the acetylene reduction assay $87.5 \%$ of the environmental strains were positive, whereas $20 \%$ of the clinic strains had active nitrogenase. In this regard, the nifH gene was found in 94 and $40 \%$ of environmental and clinical isolates, respectively. The production of hemolysin and phytohormones [i.e., indole-3-acetic acid (IAA) and ethylene] were not sufficiently distinguishable to characterize both groups, since IAA was detected in 100 and $83 \%$ of clinical and environmental strains, respectively. Moreover, the ethylene phytohormone was produced by approximately $93 \%$ of all isolates. About $80 \%$ of all isolates were able to solubilize phosphate and pectinase was produced by 33 and $46 \%$ of environmental and clinical strains, respectively. Finally, enterobacterias species were clonally unrelated. Although, heterogeneity of pathogenic and environmental Enterobacteriaceae is evident, highly conserved physiological and metabolic activities are supported on a genetic background that allow a wide distribution along different ecosystems, and in favorable conditions this adaptation could contribute to the establishment of a pathogenic process in animals or symbiosis in plants. So, environmental enterobacterias isolates can become pathogenic, whereas clinical strains can adapt to environmental conditions.
\end{abstract}

Keywords: Enterobacteriaceae. Sugarcane. Biological nitrogen fixation. Antibiotics. Environmental. Clinical. 


\section{LISTA DE ILUSTRAÇÕES}

Figura 1 - Árvore filogenética inferida a partir do alinhamento das sequências do gene $16 \mathrm{~S}$

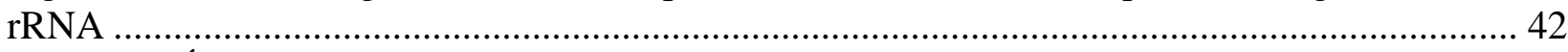

Figura 2 - Árvore filogenética inferida a partir do alinhamento das sequências do gene rpoB .... 43

Figura 3 - Árvore filogenética inferida a partir do alinhamento das sequências concatenadas dos genes $16 \mathrm{~S}$ e $r p o B$

Figura 4 - ERIC-PCR - Dendrograma demonstrando grau de similaridade entre amostras de Klebsiella sp..

Figura 5 - ERIC-PCR - Dendrograma demonstrando grau de similaridade entre amostras de

Enterobacter sp.; Pluralibacter gergoviae e Kosakonia sp.

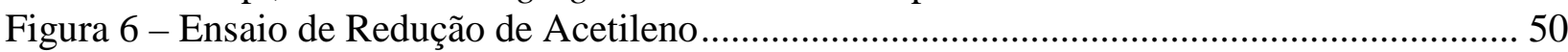

Figura 7 - Análise Estatística - Ensaio de redução de acetileno ................................................... 50

Figura 8 - Produção de etileno....................................................................................... 52

Figura 9 - Análise Estatística - Produção de Etileno .................................................................... 52

Figura 10 - Teste de difusão em disco Amostra de origem ambiental ICB369.......................... 54

Figura 11 - Teste de difusão em disco Amostra de origem clínica C183 …................................ 54

Figura 12 - Proporção de amostras resistentes de isolados ambientais e clínicos ........................ 54

Figura 13 - Análise estatística dos resultados de resistência a diferentes antibióticos.................. 54

Figura 14 - Análise estatística. CIM - Nitrofurantoína ........................................................... 54

Figura 15 - Solubilização de fostato inorgânico - amostra de origem clínica CEG2 …............... 61

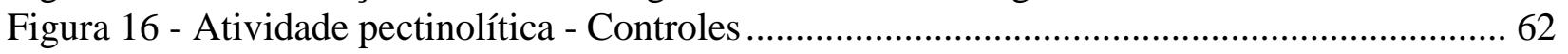

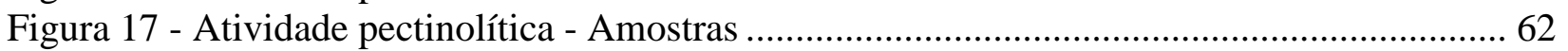

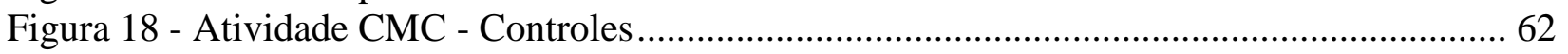

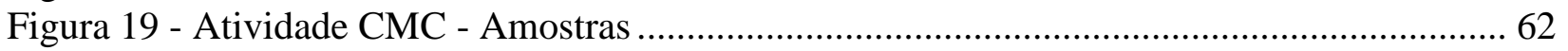

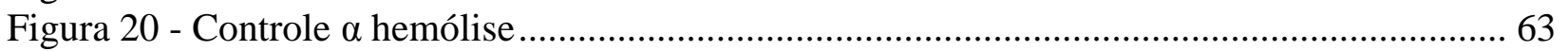

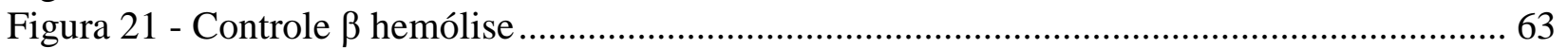

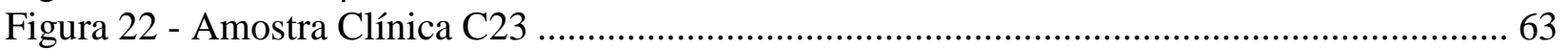

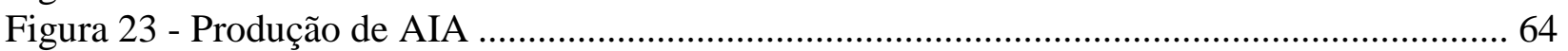

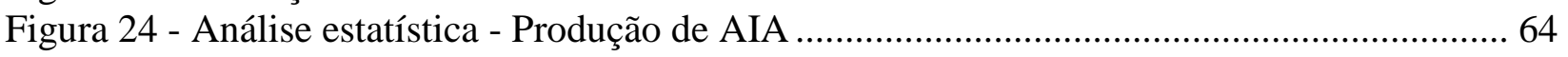




\section{LISTA DE QUADROS}

Quadro 1: Classe de antibióticos, mecanismos de ação, mecanismos de resistência e seus respectivos genes

Quadro 2: Meios de cultura (em g.L-1) para bactérias fixadoras de nitrogênio............................ 28

Quadro 3: Sequência dos primers utilizados para amplificação dos genes $16 \mathrm{~S}$ rRNA e

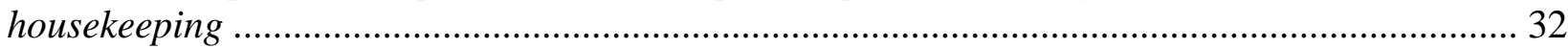

Quadro 4: Sequência dos “primers” utilizados para MLST em Klebsiella pneumoniae. ............. 33

Quadro 5: Iniciadores para amplificação do gene nifH .............................................................. 34

Quadro 6 - Perfil alélico obtido para os isolados de Klebsiella sp............................................. 42

Quadro 7 - Comparação entre resultados obtidos pelos métodos MALDI TOF-MS e análise

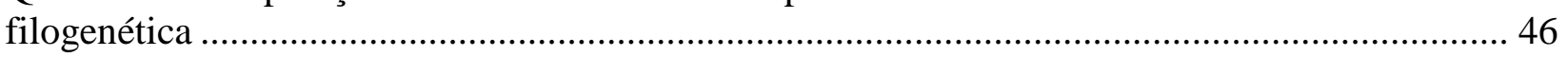

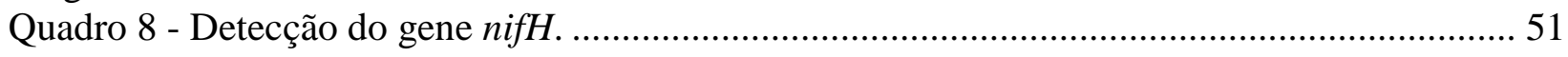

Quadro 9 - Valores de referência para o teste de difusão em disco............................................ 55

Quadro 10 - Resultados individuais para sensibilidade a antibióticos em amostras de origem

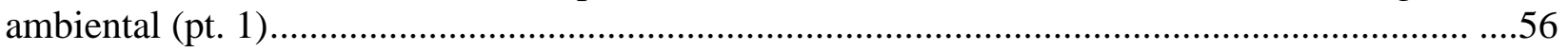

Quadro 11 - Resultados individuais para sensibilidade a antibióticos em amostras de origem

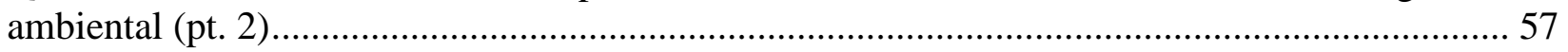

Quadro 12 - Resultados individuais para sensibilidade a antibióticos em amostras de

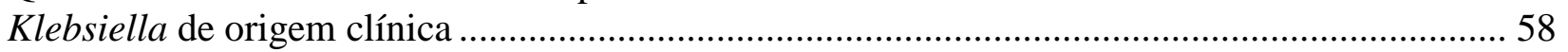

Quadro 13 - Resultados individuais para sensibilidade a antibióticos em amostras de Enterobacter e Pluralibacter de origem clínica..................................................................... 59

Quadro 14 - Transformação e teste de estabilidade dos plasmídios.............................................. 60

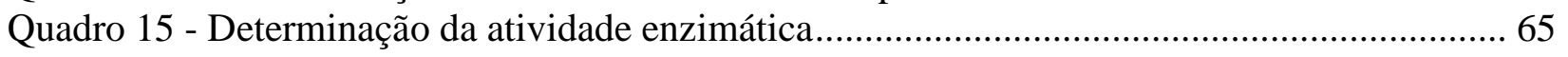




\section{LISTA DE ABREVIATURAS E SIGLAS}

ACC - Ácido 1-carboxílico-1-amino ciclopropano.

AIA - Ácido indol-3-acético.

CMC - Carboximetilcelulose.

DO - Densidade Óptica

FBN - Fixação biológica de Nitrogênio.

HPLC - High-performance liquid chromatography.

IPA - Ácido indol-3-pirúvico.

IAAm - Indolacetamida.

MALDI-TOF MS - Método de ionização e dessorção a laser assistida por matriz.

Met - Metionina.

MLST - Multilocus sequence typing.

PCR - Reação em Cadeia da Polimerase.

QRDR - Quinolone-Resistant Determining Region.

ST - Sequence Types.

Tam - Triptamina.

UFC - Unidades Formadoras de colônia.

UPGMA - Unweighted Pair Group Method with Arithmetic Mean. 


\section{SUMÁRIO}

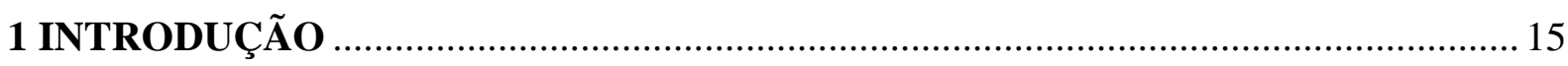

1.1 Membros da família Enterobacteriaceae em hospedeiros vegetais e humanos................. 15

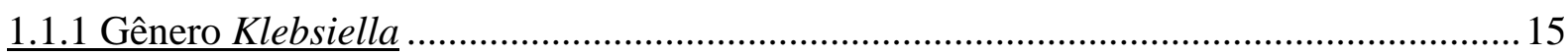

1.1.2 Gênero Enterobacter ........................................................................................... 16

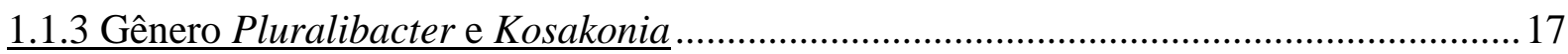

1.2 Características de bactérias associadas às plantas (na rizosfera ou endofíticas). ............ 17

1.3 Características de bactérias associadas a mamíferos, como patógenos oportunistas ......20

1.4 Antibióticos (Mecanismos de ação e mecanismos de resistência) ..................................... 22

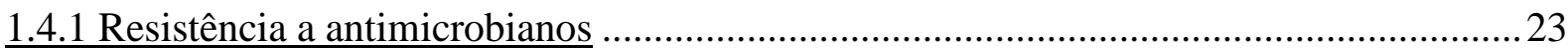

1.4.2 Mecanismos de transferência de material genético entre bactérias ................................24

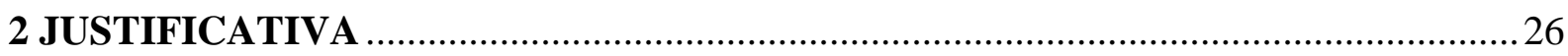

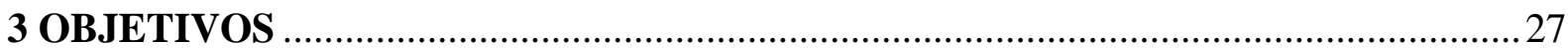

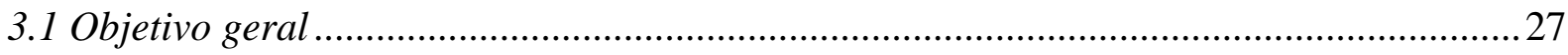

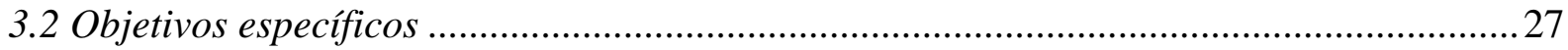

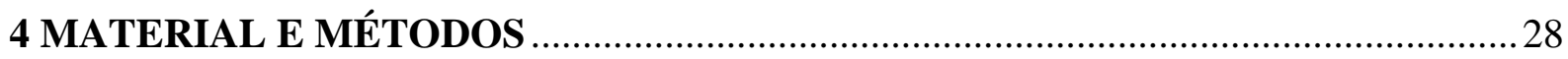

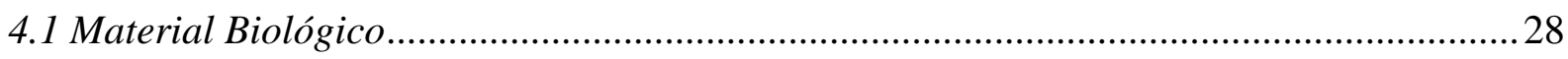

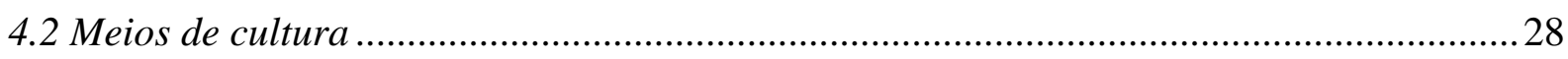

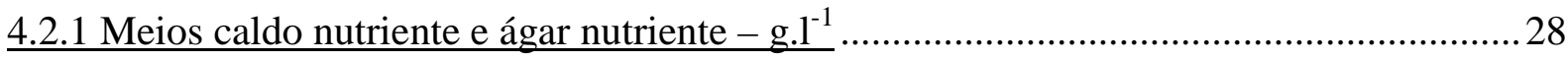

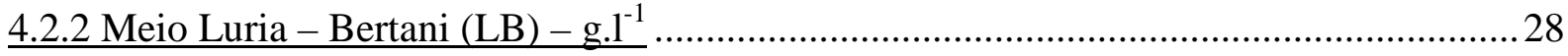

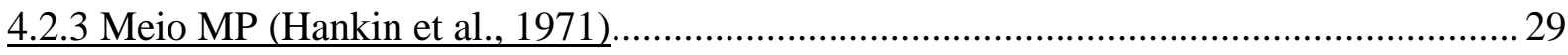

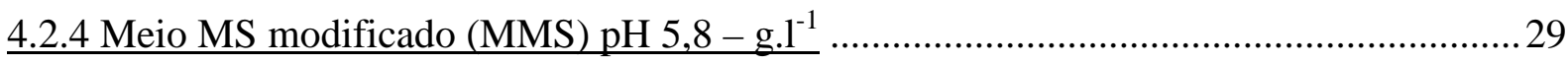

4.2.5 Meios de cultura NFB, JNFB, LGD, LGI e LGIP - g..$^{-1}$ (Döbereiner et al., 1995).........30

4.2.6 Meio ágar fosfato insolúvel - g. $1^{-1}$ (Verma et al., 2001) ................................................ 30

4.2.7 Meio Müeller Hinton - g. $1^{-1}$ (Muller, Hinton., 1941) ................................................... 31

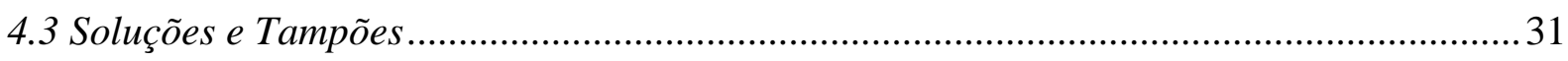

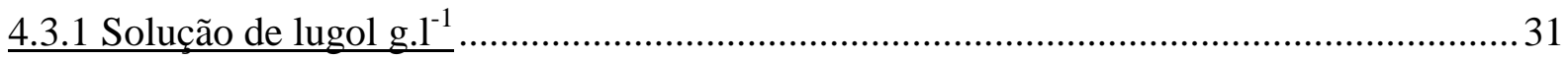

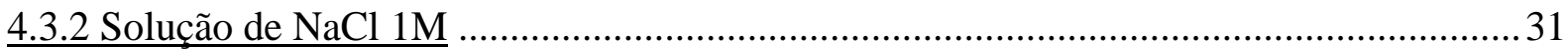

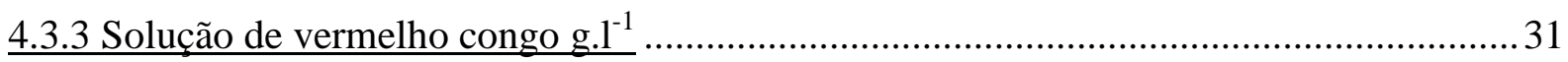

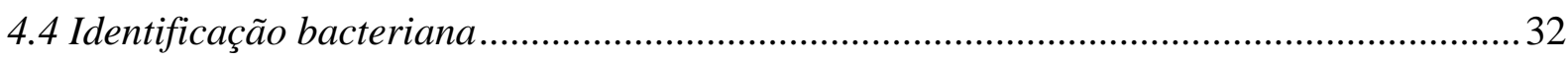

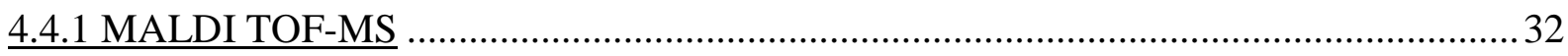

4.4.2 Amplificação e sequenciamento de genes housekeeping. ............................................. 32

4.4.3 Multilocus sequence typing 'MLST' das amostras de Klebsiella sp............................... 34

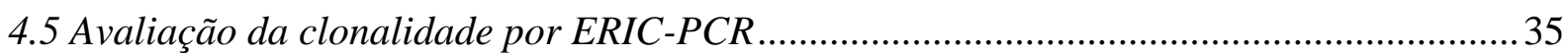

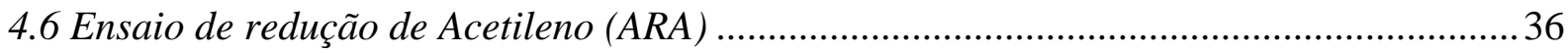

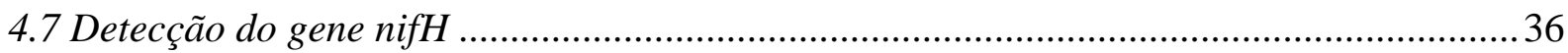


4.8 Produção de Etileno

4.9 Teste de sensibilidade (Difusão em Disco e Concentração Mínima Inibitória) ................. 37

4.10 Transformação das bactérias e teste de estabilidade dos plasmídios ............................... 38

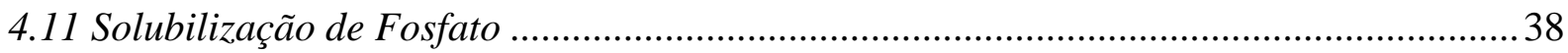

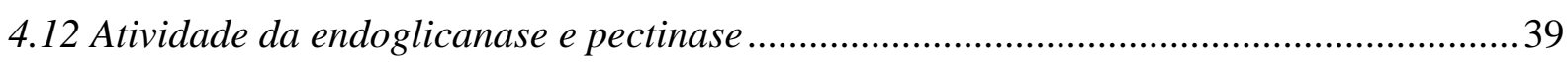

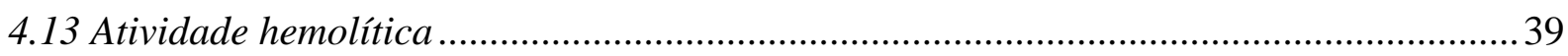

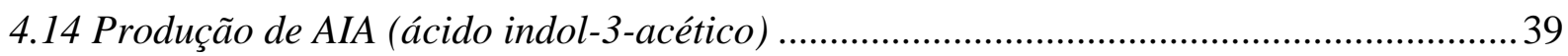

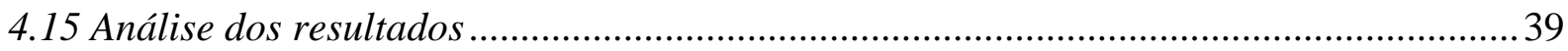

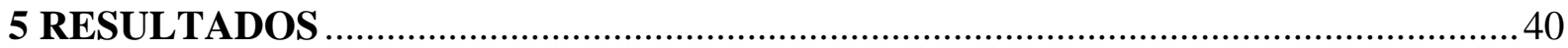

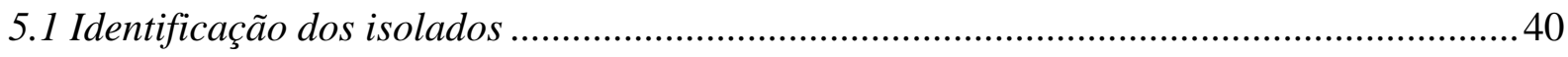

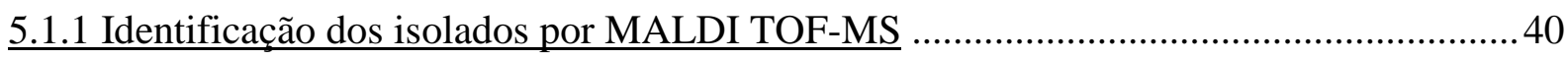

5.1.2 Amplificação dos genes $16 \mathrm{~S}$ rRNA, $r p o B$ e gapA e construção das árvores filogenéticas

5.1.3 MLST (Multilocus sequence typing) das amostras identificadas como Klebsiella sp. ...45

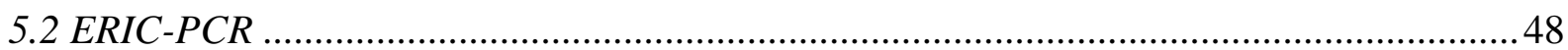

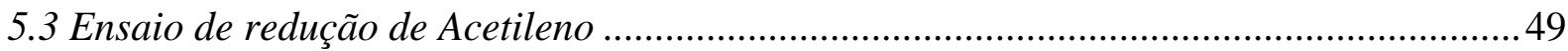

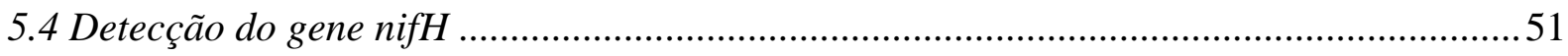

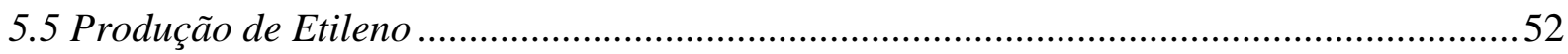

5.6 Sensibilidade a antibióticos por difusão em disco e Concentração Inibitória Mínima ..... 53

5.7 Transformação e teste de estabilidade de plasmídios ........................................................ 60

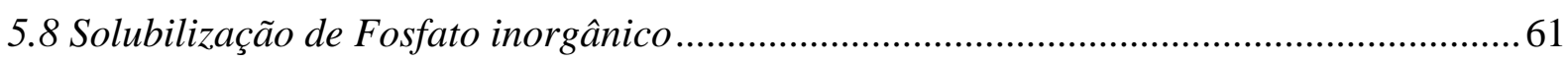

5.9 Determinação da atividade de endoglicanase e pectinase ................................................. 61

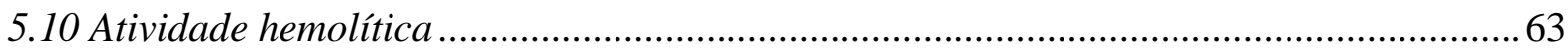

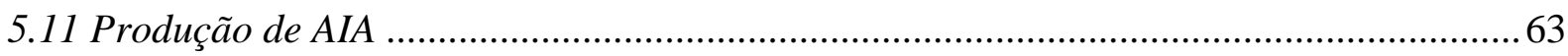

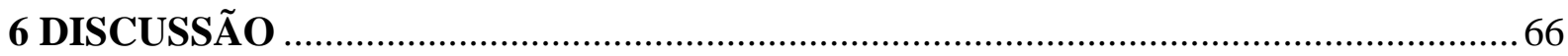

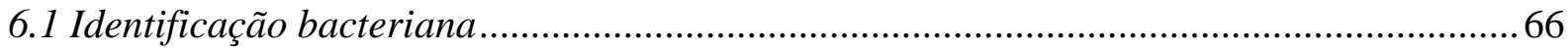

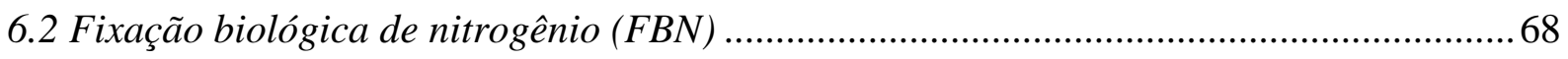

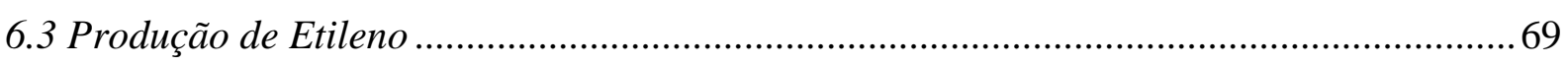

6.4 Sensibilidade a antibióticos e Concentração Inibitória Mínima (CIM)............................ 70

6.5 Transformação e estabilidade dos plasmídios ..................................................................... 71

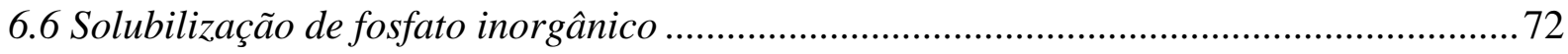

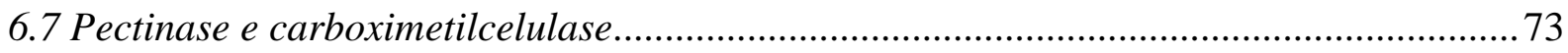

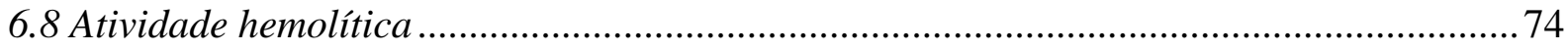

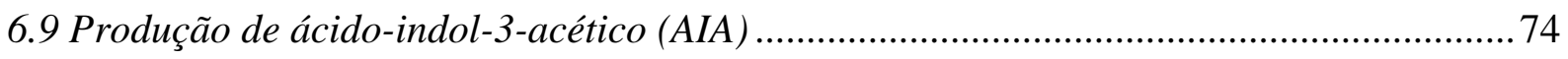

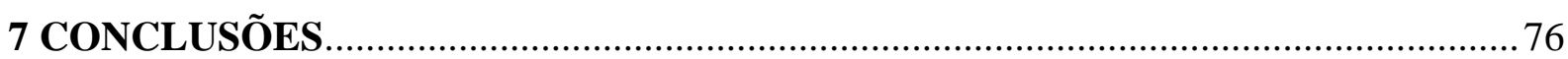

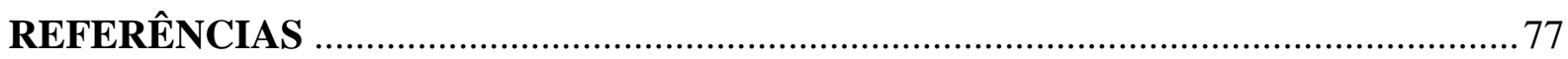




\section{INTRODUÇÃO}

Linhagens bacterianas com potencial valor para a agricultura, promovem o crescimento das plantas e também atuam no controle de fitopatógenos, entretanto, muitas vezes, estas mesmas espécies estão associadas a doenças humanas (Dong et al., 2003).

Por exemplo, Klebsiella pneumoniae subsp. pneumoniae recebe muita atenção devido a associações com doenças em humanos e animais (Wei et al., 2008), mas também é encontrada em associações não patogênicas com espinafre (Lavizzari et al., 2010) e arroz (Zhang et al., 2008) ou em associações patogênicas em abacaxizeiro (Korres et al., 2010). Não está totalmente elucidado como uma espécie poderia ser tão bem sucedida nesses hospedeiros tão diferentes, como frutas e tecido humano, podendo ou não causar sintomas de doença em ambos. A formação de biofilme pode estar relacionada, pois é um dos principais mecanismos de patogenicidade desta espécie (Ohgaki, 1994). Korres et al. (2010) verificaram que isolados clínicos humanos e fitopatogênicos de $K$. pneumoniae subsp. pneumoniae possuem características similares na adesão e formação de biofilmes, apesar da diferença dos substratos originais.

\subsection{Membros da família Enterobacteriaceae em hospedeiros vegetais e humanos.}

Membros da família Enterobacteriaceae são comumente encontrados no solo, água, plantas e animais. Esta família pertence à subdivisão Gamma, filo Proteobacteria é representada pelo menos 44 gêneros e 176 espécies identificadas. Características fenotípicas, hibridização DNA-DNA, análises das sequências dos genes $16 S$ rRNA e outros genes housekeeping têm sido utilizadas no estudo filogenético e identificação das espécies de enterobacterias (Paradis et al., 2005; Pham et al., 2007; Toth et al., 2006). Recentemente, o método de ionização e dessorção a laser assistida por matriz (MALDI-TOF MS) tornou-se um método rápido para a identificação de bactérias em nível de gênero e espécie (van Baar, 2000).

\subsubsection{Gênero Klebsiella}

Originalmente, o gênero Klebsiella, devido à sua importância médica, foi subdividido em três espécies, correspondentes às doenças que causavam: $K$. pneumoniae (pneumonia), $K$. ozaenae (rinite atrófica/ozena) e K. rhinoscleromatis (rinoscleroma). À medida em que a 
taxonomia se tornou cada vez mais refinada, devido ao desenvolvimento de novos métodos, a classificação de espécies, neste gênero, foi continuamente revista. Com o tempo, três classificações principais emergiram, os de Cowan, Bascomb e Ørskov. Países como a GrãBretanha e os antigos países da "Commonwealth of Nations" aderem à classificação de Cowan, enquanto os EUA preferem a classificação de Ørskov. Consequentemente, a mesma bactéria pode ser chamada de $K$. pneumoniae em um país e $K$. aerogenes, em outro. A maioria dos países europeus segue o exemplo americano e reconhece a classificação predominante de Ørskov (Podschun et al., 1996).

No início dos anos 80, isolados ambientais de Klebsiella, foram classificados em táxons provisórios (Gavini et al., 1977). Esses grupos deram origem a quatro novas espécies: $K$. terrigena (Izard et al., 1981), K. ornithinolytica (Sakazaki et al., 1989), K. planticola (Bagley et al., 1981), e K. trevisanii (Ferragut et al., 1983). Em 1986, as duas últimas foram combinadas em uma única espécie, K. planticola, devido à sua similaridade genética (Gavini et al., 1986).

\subsubsection{Gênero Enterobacter}

O gênero Enterobacter foi criado em 1960 para classificar as estirpes previamente identificadas como Aerobacter aerogenes (Cloaca B) e Aerobacter cloacae (Cloaca A) (Hormaeche et al., 1960). A taxonomia deste gênero tem uma história longa e confusa, com várias transferências de espécies nos últimos 20 anos. No final dos anos 80, Erwinia cancerogenus, Erwinia nimipressuralis e Erwinia dissolvens foram transferidas para o gênero Enterobacter (Brenner et al., 1986; Dickey, Zumoff, 1988). Em 1989, Enterobacter agglomerans foi transferido para o novo gênero Pantoea (Gavini et al., 1989). Em 2005, Enterobacter dissolvens foi transferido para subespécie de Enterobacter cloacae, como E. cloacae ssp. dissolvens (Hoffmann et al., 2005). Mais recentemente Enterobacter sakazakii foi transferido para um novo gênero, Cronobacter, com novas espécies que foram definidas a partir deste grupo (Iversen et al., 2008). A maioria das espécies pertencentes ao "complexo $E$. cloacae" são de importância clínica, em comparação com as outras que estão associadas com as plantas, alimentos, solo e água (Manter et al., 2011).

Atualmente, o gênero Enterobacter é um dos maiores grupos da família Enterobacteriaceae, com 20 espécies já descritas e está em rápida expansão, com $50 \%$ das descrições de novas espécies ocorridas na ultima década (Brady et al., 2013). 


\subsubsection{Gênero Pluralibacter e Kosakonia}

Estes grupos foram recentemente criados, espécies deste gênero pertenciam anteriormente ao gênero Enterobacter. Em 2013, foram separados em dois gêneros distintos: Pluralibacter ( $P$. gergoviae e $P$. pyrinus) e Kosakonia (K. cowanii, K. radicincitans, $K$. oryzae e K. arachidis) (Brady et al., 2013).

Espécies destes gêneros, podem ser isoladas a partir de fontes ambientais, incluindo solo e vegetais ou amostras clínicas. Espécies do gênero Kosakonia são descritas promovendo o crescimento das plantas, através da fixação biológica de nitrogênio (Brady et al., 2013).

\subsection{Características de bactérias associadas às plantas (na rizosfera ou endofíticas).}

Determinadas bactérias desta família podem estabelecer interações neutras, patogênicas ou benéficas com vegetais, colonizando a rizosfera ou estabelecendo-se dentro das plantas (Dobbelaere et al., 2003; Marin et al., 1999; Nguyen et al., 1989). No interior de plantas, localizam-se no xilema e espaços intercelulares (Belyavska et al., 1995) sendo a colonização bacteriana da rizosfera altamente influenciada pela espécie da planta devido à diferenças nos exsudados radiculares (Garbeva et al., 2004; Kowalchuk et al., 2002; Smalla et al., 2001). As plantas são frequentemente expostas a uma grande variedade de organismos patogênicos, nãopatogênicos e benéficos devido ao seu estilo de vida séssil. As espécies: Pantoea agglomerans e Erwinia chrysanthemi são os principais fitopatógenos entre eles. Estas espécies são conhecidas por causar perdas significativas em muitas colheitas (Chudasama et al., 2014). Quando a associação é benéfica, a planta desencadeia uma resposta de defesa genérica, que, após um tempo, é suspensa, então bactéria e planta passam a conviver associativamente (Hardoim et al., 2008).

Há relatos de associações benéficas de Klebsiella em batata (Solanum tuberosum), em milho (Zea mays), trigo (Oriza sativa), e outras plantas (Berg et al., 2005; Chelius, Triplett 2000; Mehnaz et al., 2001). Enterobacter cloaceae também foi encontrada no interior de raízes de milho (Hinton et al., 1995), na rizosfera de arroz (Shen et al., 1996) e, em cana de açúcar, associada à parte externa das raízes (Graciolli, 1983). Recentemente foi identificada uma nova espécie do gênero Enterobacter isolada do interior de cana-de-açúcar, sendo nomeada como Enterobacter sacchari (Zhu et al., 2013). 
Quando na rizosfera, os microrganismos se nutrem do exudato das raízes e quando endofíticos, além de nutrientes, também se beneficiam da proteção do interior das plantas. Os microrganismos, por sua vez, liberam substâncias que atuam diretamente como promotoras de crescimento vegetal podendo produzir fitormônios, disponibilizar nutrientes essenciais (como nitrogênio e fósforo) e proteger a planta indiretamente por apresentar ação antagonista contra organismos fitopatogênicos (Van Loon et al., 1998; Whipps, 2001). Por desempenharem estas funções, esses microrganismos apresentam importante papel na rizosfera e equivalem a cerca de $35 \%$ de bactérias cultiváveis (Opelt et al., 2004). A maioria das espécies de rizobactérias que emergem como patógenos humanos pertence ao grupo de antagonistas (Fravel, 1988).

São várias as competências que tornam linhagens da família Enterobacteriaceae adaptadas à planta, entre elas, pode-se citar, a capacidade de fixar nitrogênio (Ferrara, 2010; Oliveira, 2009; Zhao et al., 2006). O nitrogênio é um elemento essencial para os seres vivos, pois é componente de proteínas e ácidos nucléicos, entre outras moléculas. Em plantas, o nitrogênio participa diretamente na produção de biomassa, pois é um dos componentes da clorofila, além de exercer grande influência no crescimento vegetal por meio de fitormônios nitrogenados (Buchanan et al., 2002). Este elemento é encontrado em abundância na atmosfera $(78 \%)$, porém em uma forma quimicamente muito estável $\left(\mathrm{N}_{2}\right)$; somente organismos procariontes diazotróficos conseguem, com um elevado custo energético, tornar esse nitrogênio disponível, reduzindo-o a amônia $\left(\mathrm{NH}_{3+}\right)$ (Zhao et al., 2006). A redução de $\mathrm{N}_{2}$ é realizada especificamente por uma enzima complexa, a nitrogenase, composta pela dinitrogenase redutase e pela dinitrogenase. Esta enzima, às custas de ATP, quebra a tripla ligação que une os dois átomos de $\mathrm{N}_{2}$ transformando-os em amônia. A fixação biológica de nitrogênio é um processo que requer a expressão de um conjunto de genes denominados genes nif (nitrogen fixing), os quais codificam substâncias envolvidas diretamente no processo de fixação biológica de nitrogênio (FBN) (Dobbelaere et al., 2003).

$\mathrm{O}$ estudo da genética de K. pneumoniae levou à descoberta de 20 genes envolvidos na FBN. Nestes microrganismos, os genes nif encontram-se organizados em 7-9 "operons", ocupando uma região de aproximadamente $24 \mathrm{~Kb}$ entre os genes shiA e hisD (Arnold et al., 1988). Desses 20 genes nif, 14 foram encontrados na maioria das bactérias diazotróficas. O gene nifH codifica a unidade estrutural da dinitrogenase redutase e os genes nifD e nifK, as subunidades estruturais da dinitrogenase. Os genes nif, principalmente o gene nif $\mathrm{H}$, têm sido utilizados como marcadores no estudo de organismos fixadores de nitrogênio (Poly et al., 2001). 
A verdadeira contribuição de substâncias nitrogenadas produzidas pelo processo de FBN, por bactérias endofíticas, ainda não está completamente elucidada. Algumas variedades de cana-de-açúcar podem ser supridas em cerca de $60 \%$ das necessidades de nitrogênio pela FBN, o que sugere uma transferência de nitrogênio combinado da bactéria diazotrófica para a planta. (Boddey et al., 2003; Döbereiner, 1997).

Outra característica desses microrganismos associados a plantas é a produção de substâncias promotoras do crescimento vegetal. Dentre elas estão o fitormônio ácido indol-3acético (AIA), uma auxina idêntica à vegetal, que desempenha importante papel na coordenação do desenvolvimento e crescimento de plantas. AIA atua na regulação de extensão, divisão, diferenciação vascular, formação de raízes, dominância apical e tropismos (Napier et al., 1995). Linhagens de Klebsiella e Enterobacter são capazes de liberar AIA em meio de cultura (Ferrara, 2010; Liba et al., 2006; Ryu, Patten, 2008). Patten e Glick (1996) descreveram o AIA produzido por bactérias como promotor de crescimento vegetal ou como indicador de patogenicidade, ou seja, concentrações ótimas podem estimular o crescimento enquanto altas concentrações podem indicar uma resposta de defesa.

O triptofano é a substância precursora do AIA e os microrganismos podem utilizar-se de várias vias para fazer essa transformação. As vias mais caracterizadas são a do ácido indol-3pirúvico (IPA), a da triptamina (Tam) e a da indolacetamida (IAAm) (Koga et al., 1991; Patten, Glick, 1996; Spaepen et al., 2007).

O fitormônio etileno também é um potente modulador do desenvolvimento e crescimento da planta, desempenhando um papel central no metabolismo celular e seu efeito depende de sua concentração e da sensibilidade da planta (Pierik et al., 2006). Sabe-se que microrganismos capazes de sintetizar etileno a partir de metionina, podem ser patogênicos ou não. O etileno e seu precursor, ácido 1-carboxílico-1-amino ciclopropano (ACC) atuam da mesma forma na planta (Zhang et al., 2008). Quando as plantas são submetidas a condições de estresse respondem com uma superprodução de etileno que pode retardar o crescimento vegetal, causar danos teciduais ou facilitar a infecção por microrganismos patogênicos (Glick et al., 2007). Este hormônio é também produzido em resposta a patógenos, causando reação de necrose do tecido vegetal, para isolar o foco da doença. $\mathrm{O}$ etileno mostrou-se fundamental para a defesa da planta em casos de doenças causadas por fungos do solo, que normalmente não são patogênicos, mas se tornam por razões desconhecidas (Hamond-Kosack, Jones, 2000).

O Fósforo (P) é um elemento pouco disponível na natureza porque é geralmente encontrado na forma combinada com outros íons ou com matéria orgânica, o que explica sua 
baixa solubilidade. Através de ácidos orgânicos, produzidos por bactérias rizosféricas, o fosfato torna-se solúvel e prontamente assimilável pelos vegetais (Kim et al., 1997; Lifishitz et al., 1987).

Várias linhagens de Klebsiella e Enterobacter isoladas de cana-de-açúcar mostraram-se potencialmente capazes de contribuir com o crescimento vegetal, pois fixaram $\mathrm{N}_{2}$, excretaram AIA, etileno e aminoácidos (Ferrara, 2010). Experimentos de co-cultura com Klebsiella sp. (isolada de cana-de-açúcar) e calos (células indiferenciadas) de Saccharum sp., realizados em meio isento de fonte de nitrogênio combinado evidenciaram que a associação foi favorável para a planta pois aumentou o conteúdo protéico dos calos em $75 \%$. Este fato mostra um importante potencial de contribuição das bactérias ao vegetal: a transferência para o vegetal da fonte de nitrogênio fixado pela bactéria (Martins, 2014). K. oxytoca, isolada de sementes de arroz, demonstrou ser uma bactéria promotora de crescimento vegetal, aumentando a massa fresca das plantas (23-28\%), a produção de clorofila (23\%) e o comprimento de raiz e parte aérea (Jha et al., 2007)

Ichiwaki (2012) inoculou uma linhagem de Enterobacter spp. (ICB481) em plântulas de cana de açúcar (vegetal induzido de células indiferenciadas) e observou aumento de proteínas totais em todas as plântulas inoculadas quando comparadas com o controle. As plântulas inoculadas com esta cepa, que não receberam nenhum tipo de adubação, apresentaram parâmetros de crescimento equivalentes aos de plântulas tratadas com fertilizantes orgânicos ou convencionais (NPK).

A rizosfera, devido ao alto conteúdo de nutrientes, é um habitat muito favorável ao desenvolvimento de grande quantidade de bactérias incluindo aquelas dotadas de traços antagonistas, defendendo os hospedeiros por desencadear mecanismos como: antibiose: produção de antibióticos, biossurfactantes e toxinas; competição por sítios de colonização e por nutrientes; degradação de substâncias tóxicas produzidas por outros patógenos; e degradação de estruturas dos patógenos (Barbosa et al., 2011). Vários gêneros, incluindo Enterobacter, Klebsiella, Burkholderia, Pseudomonas, Stenotrophomonas são capazes de estabelecer interações bivalentes, ou seja, manter associações benéficas com plantas e causar patogênese em mamíferos (Berg et al., 2005).

\subsection{Características de bactérias associadas a mamíferos, como patógenos oportunistas}

Quando associadas a animais, bactérias da família Enterobacteriaceae podem causar moléstia, porém, por serem oportunistas, só o fazem em indivíduos severamente debilitados, 
imunocomprometidos ou que sofrem de fibrose cística. Como agravante, mais de uma linhagem pode colonizar simultaneamente um mesmo paciente (Parke, Gurian-Sherman, 2001; Steinkamp et al., 2005). Entre os membros desta família, isolados de Klebsiella pneumoniae, Enterobacter spp., Serratia marcescens, Citrobacter freundii e Morganella morganii emergiram como as principais causas de infecções hospitalares por bactérias Gramnegativas (Bell et al., 2007; Jones, 2003; Kiffer et al., 2005).

Os passos da patogênese incluem invasão, colonização, crescimento e o estabelecimento da virulência, que é a capacidade relativa do patógeno em causar doença (Köthe et al., 2003). A presença de receptores, o reconhecimento e aderência a células e outros mecanismos facilmente desenvolvidos por essas bactérias, como biofilmes, juntamente com a falta de defesa do hospedeiro, podem desencadear a patogenicidade (Hacker et al., 2003) Por isso, é particularmente difícil a identificação de fatores de virulência nesses microrganismos (Alonso, Martinez, 1999; Rahme et al., 1995).

Dong et al. (2003) verificou que Klebsiella pneumoniae endofítica não apresenta os fatores de virulência presentes no isolado clínico da mesma espécie, como por exemplo, a produção de sideróforos e a presença de pili. A produção de sideróforos e enzimas extracelulares, por exemplo, caracterizam a mesma bactéria tanto como benéfica ou como patógena, dependendo do hospedeiro. Os sideróforos são substâncias que apresentam alta afinidade pelo ferro, elemento muito importante para o crescimento e metabolismo bacteriano. Quando em humanos, os sideróforos bacterianos são capazes de retirar o ferro das proteínas carreadoras (hemoglobina, transferrina e lactoferrina) e transportar para o citoplasma bacteriano (Tan et al., 1999). No solo, os sideróforos disponibilizam este elemento para o ambiente externo ou para o hospedeiro, auxiliando no crescimento da planta e além disso, descontaminando o solo de metais pesados, pois liga-se a estes, tornando-os assimiláveis para as plantas (Rajkumar et al., 2010). Algumas estruturas como fímbrias garantem a adesão bacteriana tanto em humanos como em fungos fitopatógenos; mutantes com modificações nessas estruturas foram incapazes de reconhecer hospedeiros humanos ou fúngicos (Dörr et al., 1998).

O aparecimento de estirpes resistentes a múltiplos agentes quimioterápicos criou sérios problemas no tratamento dessas infecções, enfatizando a importância de controlar a propagação de microorganismos dentro de hospitais (Hirsch, Tam, 2010; Lincopan et al., 2006; Salzman, Klemm, 1967). 


\subsection{Antibióticos (Mecanismos de ação e mecanismos de resistência)}

Os antibióticos abaixo citados são os mais indicados na terapia às infecções por Enterobactérias (Coelho et al., 2007). O quadro 1 indica os mecanismos de ação e de resistência destes antimicrobianos.

$\beta$-lactâmicos - Pertencem a esse grupo as penicilinas, cefalosporinas, amoxilinas, cefamixinas, oxicefamixinas, ampicilinas, amidinopenicilinas, carbapênicos, ácido clavulânico, sulbactam e os antibióticos monobactâmicos. Elas provocam a lise osmótica celular ao se ligarem e inibirem as transpeptidases de membrana, responsáveis pela síntese do peptideoglicano (Andrade, 2002).

Aminoglicosídeos- são antimicrobianos bactericidas que compreendem o grupo da estreptomicina, neomicina, canamicina, tobramicina e a gentamicina (Spinosa et al., 2002). São extraídos de actinomicetos do grupo Streptomyces. Possuem estruturas químicas complexas, porém pequenas, derivadas de açúcares e um grupo amino. Funcionam como chave falsa, se ligando ao ribossomo bacteriano, e causando a produção de proteínas defeituosas (Andrade, 2002).

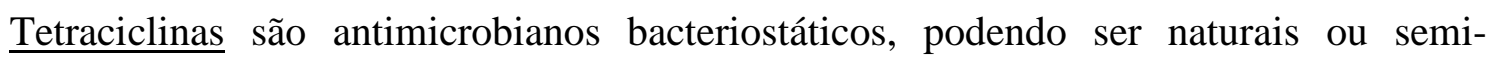
sintéticos. Fazem parte desse grupo a doxiciclina, oxitetraciclina, clortetraciclina, metaciclina e a minociclina (Spinosa et al., 2002). Apresentam amplo espectro, atuando em bactérias Gram-negativas aeróbias e anaeróbias, Clamídias, Riquétsias, Espiroquetas e Micoplasmas, inibindo sua síntese protéica (Andrade, 2002).

Quinolonas - São um grupo de antimicrobianos bactericidas de amplo espectro (Mitchell, 2006). Existem atualmente quatro gerações de quinolonas: primeira geração (ácido nalidíxico, ácido oxonílico), segunda geração que são as fluorquinonas (norfloxacino, ciprofloxacino, ofloxacino, pefloxacino, enrofloxacino, danofloxacino, orbifloxacino, marbofloxacino), terceira geração (levofloxacino, esparfloxacino) e de quarta geração (trovafloxacino, clinafloxacino, sitafloxacino) (Spinosa et al., 2002).

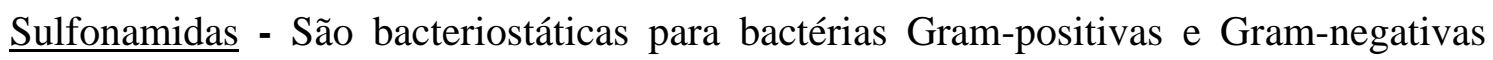
entéricas, clamídias, Nocardia sp. e protozoários. São derivados da sulfanilamida, que se caracterizam por conter moléculas de enxofre e grupamentos amina na molécula (Andrade 2002; Brooks et al., 2000).

Nitrofuranos - O componente estrutural dos nitrofuranos é um anel de furano associado a um grupo nitro. Pertencem a este grupo Furazolidona, Nitrofurantoína, Nitrofurazona, Nifurquinazol, Nifurtoinol e Nifuroxazida. Atuam sobre Gram-negativos, Gram-positivos, 
Trypanossoma, Giardia, Trichomonas e Candida. Os derivados do nitrofurano são substâncias bacteriostáticas que inibem a acetilcoenzima A do ciclo de Krebs, causando bloqueio no metabolismo bacteriano (Andrade, 2002).

\subsubsection{Resistência a antimicrobianos}

A utilização indiscriminada de agentes antimicrobianos passou a atuar como mecanismo seletivo, suprimindo os microrganismos susceptíveis e permitindo o crescimento de mutantes resistentes (Brooks et al., 2000) Seu uso frequente tem contribuído para a elevada incidência da resistência a antimicrobianos (Hyle et al., 2007).

A resistência antimicrobiana de linhagens da família Enterobacteriaceae aos maiores grupos de agentes antimicrobianos varia grandemente entre as linhagens estudadas, dependendo da procedência (origem clínica ou ambiental). A maioria destes organismos é inatamente resistente a agentes antimicrobianos mais antigos e tem a capacidade de rapidamente desenvolver resistência a novos antibióticos. Houve um aumento na incidência de casos hospitalares causados por bactérias desse gênero e cepas resistentes surgem principalmente nos hospitais (Sanders Jr et al., 1997). Por esse motivo, infecções causadas por linhagens da família Enterobacteriaceae resistentes a carbapenem são responsáveis por taxas de mortalidade de $47 \%$ a $70 \%$. Estes valores podem ser atribuídos à resistência múltipla e à perda de efetividade na terapia com antibióticos (Ben-David et al., 2010; Bratu et al., 2005; Borer et al., 2009).

Infecções nosocomiais estão geralmente relacionadas com linhagens de Klebsiella pneumoniae, causando infecções no trato urinário, sistema respiratório e no fluxo sanguíneo (Poirel et al., 2003; Struve, Krogfelt, 2004). Varon e Alangaden (2004) verificaram que, cepas desta espécie abrigam os plasmídios responsáveis pela resistência a $\beta$-lactâmicos especialmente cefalosporinas de amplo espectro e também carbapenêmicos.

A resistência a antimicrobianos pode ser de dois tipos: Natural: pela ausência da estrutura, ou da via metabólica alvo ou; Adquirida: através de mutações espontâneas e seleção ou por recombinação após transferência de genes. De um modo geral, os principais mecanismos de resistência podem ser descritos como:

-Impermeabilidade à droga: Muitas bactérias Gram-negativas são resistentes à penicilina $\mathrm{G}$ por serem impermeáveis à droga ou por apresentarem alterações em proteínas de ligação à penicilina. No caso das sulfonamidas, o microrganismo pode também apresentar menor permeabilidade à droga. 
-Inativação: muitas drogas são inativadas por enzimas codificadas pelos microrganismos. Por exemplo, a penicilinase ( $\beta$-lactamase) é uma enzima que cliva o anel $\beta$ lactâmico inativando a droga; ou por modificações, como por exemplo, a adição de grupamentos químicos ao antibiótico, promovendo sua fosforilação ou acetilação.

-Modificação de enzima ou estrutura alvo: Por exemplo, alterações na molécula do rRNA 23S (no caso de resistência à eritromicina e cloranfenicol), alteração da enzima, no caso de drogas que atuam no metabolismo, ou uso de vias metabólicas alternativas.

\subsubsection{Mecanismos de transferência de material genético entre bactérias}

Os Principais mecanismos de transferência de material genético incluem:

Conjugação - Processo de transferência de genes que requer contato célula a célula, mediado por um Pili sexual;

Transformação - Captação de DNA no meio, por células receptoras competentes.

Transdução - Transferência genética com auxílio de bacteriófagos;

Transposição - Transferência de genes dentro de uma mesma célula por intermédio de transposons. 
Quadro 1- Classe de antibióticos, mecanismos de ação, mecanismos de resistência e seus respectivos genes

\begin{tabular}{|c|c|c|c|c|}
\hline Classe & Antibiótico & Mecanismo de Ação & Mecanismos de resistência & $\begin{array}{l}\text { Genes de } \\
\text { resistência }\end{array}$ \\
\hline $\begin{array}{l}\text { Aminoglicosídeo } \\
\text { (Amplo Espectro) }\end{array}$ & Gentamicina & \multirow{2}{*}{$\begin{array}{l}\text { Liga-se à subunidade ribossomal } 30 \mathrm{~S} \\
\text { bacteriana, promovendo erros na } \\
\text { leitura do mRNA e interferindo com a } \\
\text { formação do complexo de iniciação } \\
(\text { Ding, He, 2010) }\end{array}$} & \multirow{2}{*}{$\begin{array}{l}\text { *Bactérias produzem enzimas que } \\
\text { inativam o antibiótico. Existem mais } \\
\text { de nove tipos não relacionados, que } \\
\text { acetilam, fosforilam ou adelinam os } \\
\text { aminoglicosídeos. }\end{array}$} & \multirow{2}{*}{$a a d A e a a d B$} \\
\hline $\begin{array}{l}\text { Aminoglicosídeo } \\
\text { (Espectro Estrito) }\end{array}$ & Estreptomicina & & & \\
\hline $\begin{array}{l}\beta \text {-Lactâmico } \\
\text { Cefalosporinas } \\
\left(1^{\mathrm{a}} \text { geração }\right)\end{array}$ & Cefalotina & \multirow{4}{*}{$\begin{array}{l}\text { Durante a síntese da parede bacteriana, } \\
\text { o anel } \beta \text {-lactâmico do antibiótico } \\
\text { inativa as enzimas envolvidas na } \\
\text { transpeptidação, as PBPs (Penicillin } \\
\text { Binding Protein), responsáveis pela } \\
\text { ligação entre as cadeias peptídicas do } \\
\text { peptideoglicano. Com isso, não há a } \\
\text { formação de ligações cruzadas, } \\
\text { desestruturando a parede celular, } \\
\text { causando uma perda na rigidez. } \\
\text { Acredita-se também que tais drogas } \\
\text { podem atuar promovendo a ativação de } \\
\text { enzimas autolíticas, resultando na } \\
\text { degradação da parede. }\end{array}$} & \multirow{4}{*}{$\begin{array}{l}\text { *Ocorre devido à produção de enzimas } \\
\beta \text {-Lactamases } \\
\text { *Alteração na permeabilidade da } \\
\text { membrana externa ocasionando } \\
\text { diminuição da expressão ou perda de } \\
\text { porinas. } \\
\text { *Mecanismos de efluxo. }\end{array}$} & \multirow[t]{4}{*}{$\begin{array}{l}\text { bla }_{\mathrm{SHV}}-\text { like } \\
\text { bla }_{\mathrm{TEM}}-\text { like } \\
\text { bla }_{\mathrm{CTX}-\mathrm{M}-\mathrm{like}} \\
\text { bla }_{\mathrm{KPC}}-2\end{array}$} \\
\hline \multirow{2}{*}{$\begin{array}{l}\beta \text {-Lactâmico } \\
\text { Cefalosporinas } \\
\left(3^{\mathrm{a}} \text { geração }\right)\end{array}$} & Cefotaxima & & & \\
\hline & Ceftiofur & & & \\
\hline Carbapêmicos & Ertapenem & & & \\
\hline Nitrofurano & Nitrofurantoína & $\begin{array}{l}\text { Causam inibição da acetilcoenzima A } \\
\text { do ciclo de Krebs, causando bloqueio } \\
\text { no metabolismo bacteriano (Andrade, } \\
\text { 2002). }\end{array}$ & *Mecanismos ainda não definidos & \\
\hline \multirow{3}{*}{ Quinolona } & Ácido Nalidíxico & \multirow{3}{*}{$\begin{array}{l}\text { Inibem a DNA girase, afetando a } \\
\text { replicação, transcrição e reparo do } \\
\text { DNA (Ding et al., 2010). }\end{array}$} & \multirow{3}{*}{$\begin{array}{l}\text { * mutações nos genes que codificam a } \\
\text { DNA girase e Topoisomerase IV e } \\
\text { levam à Quinolone-Resistant } \\
\text { Determining Region (QRDR) } \\
\text { * mudanças na permeabilidade da } \\
\text { membrana externa que diminuem a } \\
\text { penetração intracelular da droga } \\
\text { * mecanismos de efluxo. } \\
\end{array}$} & \multirow{3}{*}{$\begin{array}{l}\text { qnrA } \\
\text { qnrB } \\
\text { qnrS } \\
\text { gyrA } \\
\text { parC }\end{array}$} \\
\hline & Ciprofloxacina & & & \\
\hline & Enrofloxacina & & & \\
\hline Sulfa & Cotrimoxazol & $\begin{array}{l}\text { Inibidoras competitivas da enzima } \\
\text { bacteriana dihidroperoato sintetase } \\
\text { [são análogos do substrato, o ácido } \\
\text { para-aminobenzóico (PABA)] A } \\
\text { enzima catalisa uma reação envolvida } \\
\text { com a síntese de ácido fólico, } \\
\text { necessário para a síntese de } \\
\text { precursores de DNA e RNA nas } \\
\text { bactérias. }\end{array}$ & $\begin{array}{l}\text { *Modificação de estruturas alvo e/ou; } \\
\text { *redução na permeabilidade da } \\
\text { membrana }\end{array}$ & $\begin{array}{l}\text { sul1 } \mathrm{e} \\
\text { sul2 }\end{array}$ \\
\hline Tetraciclina & Tetraciclina & $\begin{array}{l}\text { Liga-se à subunidade ribossomal } 30 \mathrm{~S} \\
\text { (sítio A), impedindo a ligação do } \\
\text { aminoacil-tRNA, impossibilitando a } \\
\text { síntese protéica. }\end{array}$ & *mecanismo de efluxo & $\begin{array}{l}\text { tetA } \\
\text { tetB } \\
\text { tet } G\end{array}$ \\
\hline
\end{tabular}




\section{JUSTIFICATIVA}

Isolados bacterianos endofíticos ou rizosféricos diazotróficos de cana de açúcar foram obtidos, e os gêneros da família Enterobacteriaceae foram predominantes neste vegetal. Estas mesmas linhagens apresentaram um grande potencial para um possível bioinoculante mas, devido à relevância destes mesmos gêneros na clínica humana e veterinária é importante estudar nos microrganismos de ambas as procedências, determinadas características fisiológicas, de patogenicidade e resistência a antibióticos que permitam compreender as possíveis vias de disseminação e estabelecimentos de processos benéficos ou patogênicos para hospedeiros ambientais, animais e humanos. 


\section{OBJETIVOS}

\subsection{Objetivo geral}

Comparar cepas da família Enterobacteriaceae isoladas de rizosfera ou endofíticas de cana de açúcar, com de amostras clínicas (sangue, urina, secreção traqueal e amostras de água) quanto a: características fisiológicas, proximidade filogenética e resistência aos antimicrobianos.

\subsection{Objetivos específicos}

- Identificação por MALDI TOF-MS e sequenciamento dos genes 16S, rpoB e gapA;

- determinar a similaridade dos perfís de susceptibilidade aos antibióticos;

- avaliar a atividade hemolítica;

- verificar a presença do gene nifH;

- avaliar a capacidade de redução $\mathrm{N}_{2}$;

- avaliar a produção de substâncias que estimulam o crescimento vegetal;

- determinar a relação genética de todas as amostras. 


\section{MATERIAL E MÉTODOS}

\subsection{Material Biológico}

Foram utilizadas 39 linhagens bacterianas pertencentes à família Enterobacteriaceae, sendo 24 de origem ambiental e 15 de origem clínica. As bactérias de origem ambiental foram escolhidas dentre 74 isolados de cana-de-açúcar (endofíticos e rizosféricos) submetida a diferentes tipos de adubação (orgânica, inorgânica e sem adubação). Estas bactérias fazem parte da coleção do laboratório de Fisiologia de Microrganismos, Departamento de Microbiologia da Universidade de São Paulo. As linhagens de origem clínica (humana, veterinária e efluentes urbanos) foram cedidas pelo prof ${ }^{\circ}$ Nilton Erbet Lincopan Huenuman, docente do mesmo departamento. As escolhas das linhagens foram feitas com base nas diferenças fisiológicas já estudadas em trabalhos anteriores (Ferrara, 2010; Oliveira, 2009).

\subsection{Meios de cultura}

Todos os meios de cultura foram autoclavados a $121^{\circ} \mathrm{C}$ por 20 minutos a pressão de 1 atmosfera. Antes de sua utilização, os meios foram previamente incubados por 24 horas em estufa a $30^{\circ} \mathrm{C}$ para o teste de esterilidade.

\subsubsection{Meios caldo nutriente e ágar nutriente $-\mathrm{g} . .^{-1}$}

Estes meios foram utilizados para manutenção e preservação das diferentes bactérias.

Extrato de carne $3 \mathrm{~g}$

Peptona.

Água destilada q.s.p. $1000 \mathrm{ml}$

O meio Ágar Nutriente apresenta composição similar ao caldo nutriente, sendo apenas acrescido de 15 g. $1^{-1}$ de Ágar Bacteriológico.

\section{$\underline{4.2 .2 ~ M e i o ~ L u r i a ~-~ B e r t a n i ~(L B) ~}-$ g..$^{-1}$}

O meio LB foi utilizado para cultivar microrganismos que seriam submetidos à extração de DNA total ou Plasmidial. 


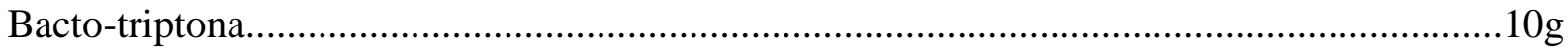

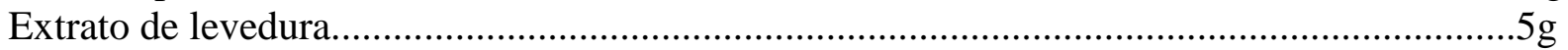

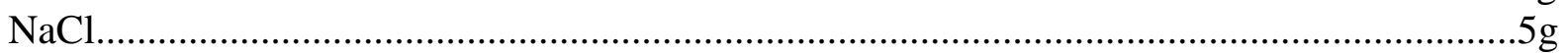

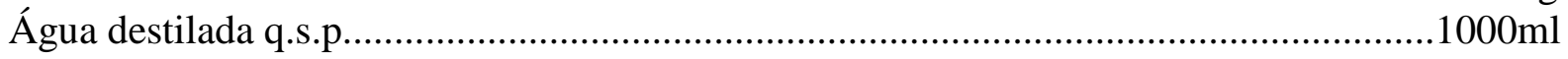

\subsubsection{Meio MP (Hankin et al., 1971)}

Para o ensaio de presença de pectinase foi utilizado o meio MP sólido, com o $\mathrm{pH}$ ajustado para 7,0 e para 5,0, com a seguinte composição:

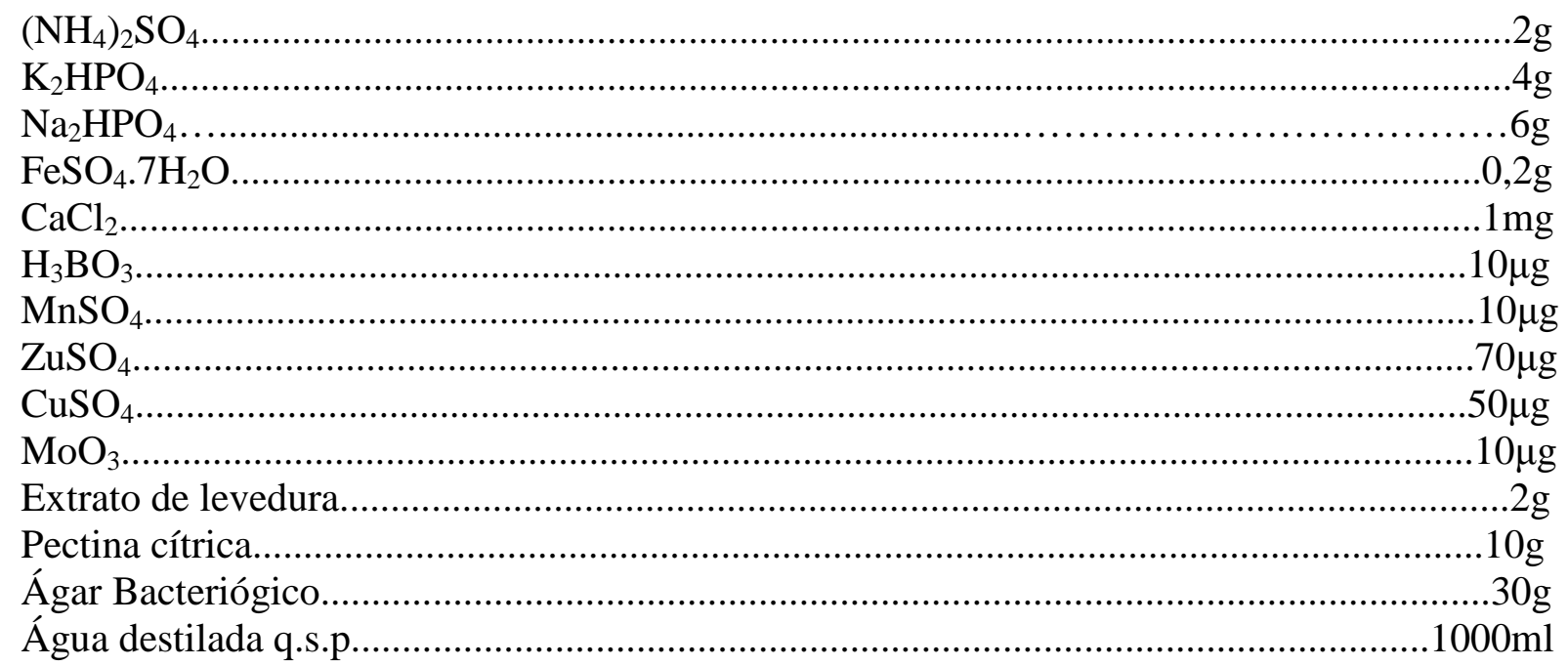

\subsubsection{Meio MS modificado (MMS) pH 5,8-g..$^{-1}$}

Este meio de cultura foi utilizado no ensaio de produção de Etileno, tendo como precursor 0,40g. $1^{-1}$ de metionina (Met) (Thuler et al. 2003).

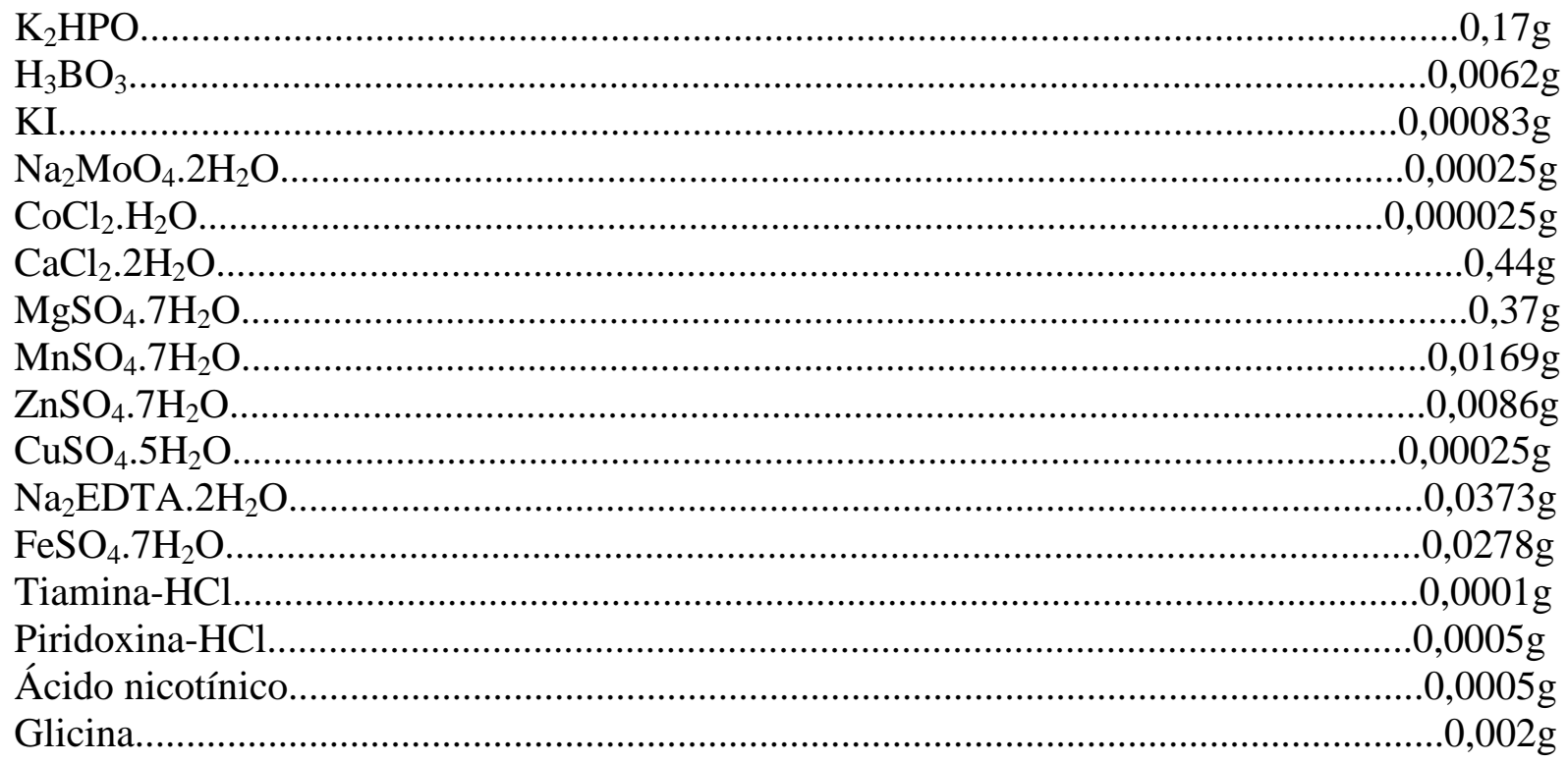


Mio-inositol. $.0,1 \mathrm{~g}$

Sacarose. $.20 \mathrm{~g}$

Água destilada q.s.p. $1000 \mathrm{ml}$

O meio semi-sólido foi acrescido de 1,8g. $1^{-1}$ de Ágar Bacteriológico.

4.2.5 Meios de cultura NFB, JNFB, LGD, LGI e LGIP - g.1 . $^{-1}$ (Döbereiner et al., 1995)

Os meios NFB, JNFB, LGD, LGI e LGIP (Quadro 2) isentos de fonte de nitrogênio combinado, foram utilizados para os testes de fixação de nitrogênio e para a contagem de UFC, respeitando o meio em que cada bactéria foi isolada ou apresentou melhor crescimento.

Quadro 2 - Meios de cultura (em g.L- ${ }^{1}$ ) para bactérias fixadoras de nitrogênio

\begin{tabular}{|c|c|c|c|c|c|}
\hline $\begin{array}{ll}\text { Componentes } & \text { Meios de Cultura } \\
\end{array}$ & NFB & JNFB & LGD & LGI & LGIP \\
\hline Glicose & - & - & 20 & - & - \\
\hline Sacarose & - & - & - & 5 & 100 \\
\hline Ácido Málico & 5 & 5 & - & - & - \\
\hline $\mathrm{K}_{2} \mathrm{HPO}_{4}$ & 0,5 & 0,6 & 0,05 & 0,2 & 0,2 \\
\hline $\mathrm{KH}_{2} \mathrm{PO}_{4}$ & - & 1,8 & 0,15 & 0,6 & 0,6 \\
\hline $\mathrm{CaCl}_{2}$ & - & - & 0,01 & - & - \\
\hline $\mathrm{CaCl}_{2} \cdot 2 \mathrm{H}_{2} \mathrm{O}$ & 0,02 & 0,02 & - & 0,02 & 0,02 \\
\hline $\mathrm{MgSO}_{4} .7 \mathrm{H}_{2} \mathrm{O}$ & 0,2 & 0,2 & 0,2 & 0,2 & 0,2 \\
\hline $\mathrm{Na}_{2} \mathrm{MoO}_{4} \cdot 2 \mathrm{H}_{2} \mathrm{O}$ & 0,002 & 0,002 & 0,002 & 0,002 & 0,002 \\
\hline $\mathrm{FeCl}_{3} \cdot 2 \mathrm{H}_{2} \mathrm{O}$ & - & - & 0,01 & - & 0,01 \\
\hline Azul de Bromotimol $(0,5 \%$ em $2 \mathrm{~N}$ de $\mathrm{KOH})$ & $2 \mathrm{ml}$ & $2 \mathrm{ml}$ & - & $5 \mathrm{ml}$ & $5 \mathrm{ml}$ \\
\hline $\mathrm{NaHCO}_{3}$ & - & - & 0,01 & - & - \\
\hline $\mathrm{NaCl}$ & 0,1 & 0,1 & - & - & - \\
\hline FeEDTA (sol. 1,64\%) & $4 \mathrm{ml}$ & $4 \mathrm{ml}$ & - & $4 \mathrm{ml}$ & $4 \mathrm{ml}$ \\
\hline $\mathrm{KOH}$ & 4,5 & 4,5 & - & - & - \\
\hline $\mathrm{CuSO}_{4} .5 \mathrm{H}_{2} \mathrm{O}$ & 0,00008 & 0,00008 & - & - & - \\
\hline $\mathrm{ZnSO}_{4} \cdot 7 \mathrm{H}_{2} \mathrm{O}$ & 0,0024 & 0,0024 & - & - & - \\
\hline $\mathrm{H}_{3} \mathrm{BO}_{3}$ & 0,0028 & 0,0028 & - & - & - \\
\hline $\mathrm{MnSO}_{4} \cdot 7 \mathrm{H}_{2} \mathrm{O}$ & 0,00235 & 0,00235 & - & - & - \\
\hline Biotina & 0,00001 & 0,00001 & - & 0,00001 & 0,00001 \\
\hline Piridoxol-HCl & 0,00002 & 0,00002 & - & 0,00002 & 0,00002 \\
\hline $\mathrm{pH}$ & $6,5-6,8$ & 5,8 & 7,0 & 6,0 & 6,0 \\
\hline
\end{tabular}

4.2.6 Meio ágar fosfato insolúvel - g. . $^{-1}$ (Verma et al., 2001)

Este meio de cultura foi utilizado para o ensaio de solubilização de fosfato inorgânico.

Glicose. $.5 \mathrm{~g}$

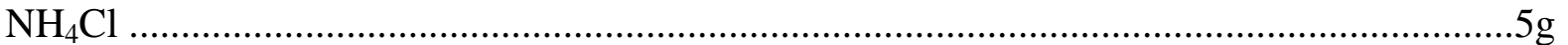

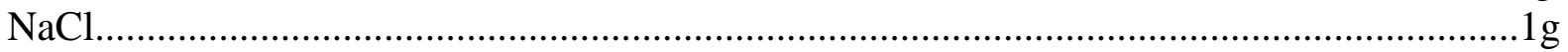

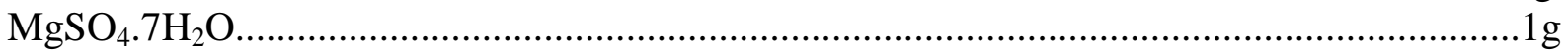

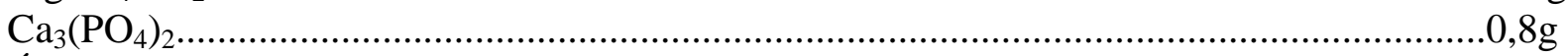

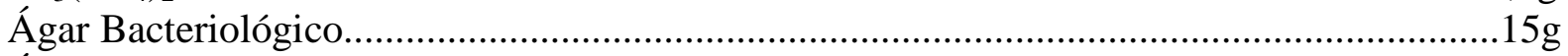

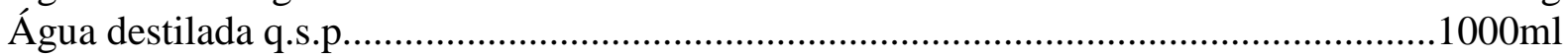


O meio Müeller Hinton é rico nutricionalmente e é recomendado pela OMS (Organização Mundial de Saúde) para a realização de provas de sensibilidade para o método de Kirby-Bauer. Este meio também foi utilizado para avaliar a concentração mínima inibitória (MIC) através da utilização de fitas de E-Test.

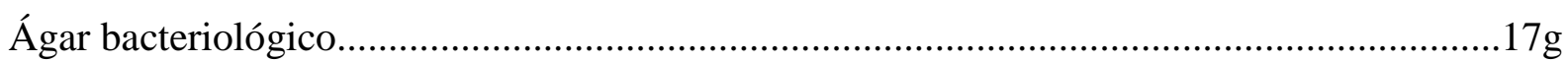

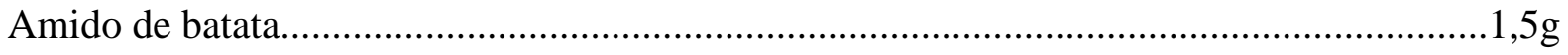

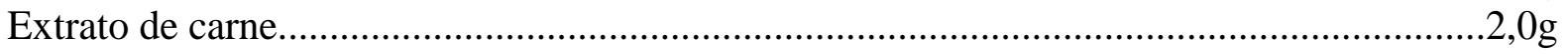

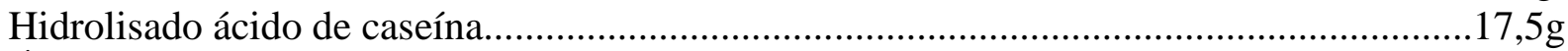

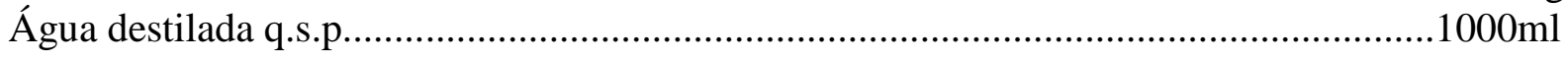

\subsection{Soluções e Tampões}

\section{$\underline{4.3 .1 \text { Solução de lugol g. } .^{-1}}$}

A solução de lugol foi utilizada para corar as placas submetidas ao ensaio de atividade pectinolítica.

KI. $30 \mathrm{~g}$

Cristais de iodo. $10 \mathrm{~g}$ Água destilada q.s.p. $1000 \mathrm{ml}$

\subsubsection{Solução de $\mathrm{NaCl} 1 \mathrm{M}$}

A solução de $\mathrm{NaCl} 1 \mathrm{M}$ foi utilizada para lavagem das placas coradas com solução de lugol.

$\mathrm{NaCL}$ $58,44 \mathrm{~g}$

Água destilada q.s.p. $1000 \mathrm{ml}$

\subsubsection{Solução de vermelho congo g. $1^{-1}$}

A solução de vermelho congo foi utilizada para corar as placas submetidas ao ensaio de atividade da enzima endoglucanase.

Vermelho Congo. $1 \mathrm{~g}$ 


\subsection{Identificação bacteriana}

As linhagens foram identificadas por mais de uma técnica. As amostras utilizadas neste trabalho já haviam sido submetidas a ensaios bioquímicos e moleculares, porém, pela incerteza dos resultados, houve necessidade da repetição e de serem realizados novos testes. A família Enterobacteriaceae foi escolhida, pois foi encontrada, simultaneamente, no ambiente e em infecções hospitalares. As novas técnicas escolhidas foram a espectrometria de massa por ionização e dessorção a laser assistida por matriz (MALDI TOF-MS), a amplificação e sequenciamento de genes housekeeping recomendados para enterobactérias $(16 S$, rpoB e gapA). Para as amostras que apresentaram um perfil de similaridade com Klebsiella sp. também foram amplificados mais cinco genes, recomendados por Diancourt et al. 2005 ( $m d h$, pgi, phoe, infB e tonB).

\subsubsection{MALDI TOF-MS}

Uma colônia bacteriana foi colocada na placa específica para o equipamento (96 MSP; Bruker Daltonics, EUA) e submetida a secagem em temperatura ambiente. Em seguida, foi coberta por 1,0 uL de solução de matriz (acetonitrila 50\%, água 47,5\% e ácido trifluoroacético $2,5 \%)$.

Os espectros obtidos foram analisados pelo programa MALDI Biotyper 2.0 (Bruker Daltonics, EUA) com as configurações padrão para identificação bacteriana. O algoritmo utilizado pelo Maldi Biotyper compara os espectros da amostra desconhecida com as amostras de referência contidas em um banco de dados. O procedimento de análise leva em consideração as massas e as intensidades relativas dos espectros desconhecidos (Lartigue et al., 2009).

\subsubsection{Amplificação e sequenciamento de genes housekeeping}

As bactérias foram também submetidas ao sequenciamento dos genes $16 S$ rRNA, gapA e rрoB.

Extração do DNA Genômico - Foram preparadas culturas de todas as linhagens em caldo nutriente e cultivadas "overnight" sob agitação. A extração do DNA foi feita de acordo com o protocolo de "Wizard Genomic DNA Purification Kit", catálogo número \#A1120 (Promega). Cada material foi submetido a eletroforese em gel de agarose (1,0\%) (Invitrogen) 
seguida de imersão em solução de brometo de etídio por 15 min. As concentrações dos DNAs foram medidas no equipamento NanoDrop 1000 Spectrometer (Thermo Scientific) e diluídas em água deionizada "DNAse Free” para concentração final de $100 \eta g . \mu 1^{-1}$.

Amplificação dos fragmentos - Para a amplificação dos genes $16 \mathrm{~S}$ rRNA, gapA e rpoB foi utilizado o método de Reação em Cadeia da Polimerase (PCR). Para cada reação foram utilizados $25 \mu 1$ de Master Mix ${ }^{\circledR}$ (Promega), $20 \mu 1$ de água deionizada "DNAse Free”, 1 $\mu l$ de DNA bacteriano e $2 \mu 1$ de cada primer ("forward" e "reverse") específico para os genes estudados (quadro 3). A amplificação dos fragmentos foi realizada através de um termociclador Eppendorff (Mastercycle Personal). Os protocolos de temperatura para a amplificação dos genes $16 \mathrm{~S}$ rRNA e "housekeeping" foram os seguintes:

$16 S$ rRNA $-95^{\circ} \mathrm{C}$ por $2 \mathrm{~m}$ seguido por 40 ciclos de $95^{\circ} \mathrm{C}$ por $1 \mathrm{~m}$ para a desnaturação, $56{ }^{\circ} \mathrm{C}$ por $1 \mathrm{~m}$ para o anelamento e $72{ }^{\circ} \mathrm{C}$ por $1 \mathrm{~m}$ para a extensão do DNA.

gapA e $r p o B-92^{\circ} \mathrm{C}$ por $5 \mathrm{~m}$ seguido de 40 ciclos de $92^{\circ} \mathrm{C}$ por $2 \mathrm{~m}$ para a desnaturação, $50{ }^{\circ} \mathrm{C}$ por $2 \mathrm{~m}$ e $15 \mathrm{~s}$ para o anelamento e $72^{\circ} \mathrm{C}$ por $1 \mathrm{~m}$ e $15 \mathrm{~s}$ para a extensão do DNA.

Para todos os genes, após o término dos ciclos, foi realizada uma etapa de $10 \mathrm{~m}$ a $72{ }^{\circ} \mathrm{C}$ para a estabilização do DNA.

Purificação dos produtos de PCR_- Os produtos amplificados foram purificados com “GFXTM PCR DNA and Gel Band Purification Kit”, catálogo n 27-9602-01 (GE Healthcare), seguindo instruções do fabricante.

Reação de Sequenciamento - Os produtos purificados foram enviados para sequenciamento realizado no Centro de pesquisas sobre o Genoma Humano/USP. As reações de sequenciamento foram realizadas seguindo o protocolo do kit "DYEnamicTM ET dye terminator kit” (MegaBACETM), catálogo nUS81090 Amersham Biosciences/GE Healthcare com 5 pmoles de "primer" e $4 \mu$ de DYE ET. As concentrações de produtos amplificados utilizados nas reações de sequenciamento variaram de acordo com o tamanho do fragmento em análise. As temperaturas foram de $95^{\circ} \mathrm{C}$ por $20 \mathrm{~s} ; 50-55^{\circ} \mathrm{C}$ por $15 \mathrm{~s} \mathrm{e} 60{ }^{\circ} \mathrm{C}$ por $1 \mathrm{~m}$. Os ciclos foram repetidos por 30 ou 45 vezes.

Análises Filogenéticas - Após a reação de sequenciamento, os dados brutos foram capturados e a análise de qualidade e obtenção das sequências "contig" ou "consenso" foram realizadas utilizando o programa "Chromas Pro". Após obtenção das sequências consenso, as linhagens foram exportadas em formato FASTA para inferência filogenética. O alinhamento das sequências dos genes $16 \mathrm{~S}$ rRNA, gapA e rpoB, a geração das matrízes de similaridade e as construções das árvores filogenéticas dos isolados foram realizadas através do programa MEGA "Molecular Evolutionary Genetics Analysis, v. 6.0.5" 
Quadro 3 - Sequência dos primers utilizados para amplificação dos genes 16S rRNA e housekeeping

\begin{tabular}{|c|c|c|c|c|c|}
\hline "Primer" & Sequencia $\left(5^{\prime}-3^{\prime}\right)$ & Gene alvo & Tamanho & Utilização & Referência \\
\hline $27 \mathrm{f}$ & AGAGTTTGATCCTGGCTCAG & \multirow{4}{*}{$16 \mathrm{~S}$ rRNA } & \multirow{4}{*}{$\sim 1.500 \mathrm{pb}$} & $\begin{array}{l}\text { Amplificação e } \\
\text { sequenciamento }\end{array}$ & $\begin{array}{l}\text { Weisburg et al., } \\
1991\end{array}$ \\
\hline $536 f$ & CAGCMGCCGCGGTAATWC & & & Sequenciamento & $\begin{array}{l}\text { Holben et al., } \\
2004\end{array}$ \\
\hline $782 \mathrm{r}$ & ACCAGGGTATCTAATCCTGT & & & Sequenciamento & $\begin{array}{l}\text { Chimetto et al., } \\
2008\end{array}$ \\
\hline $1492 \mathrm{r}$ & GGTTACCTTGTTACGACTT & & & $\begin{array}{l}\text { Amplificação e } \\
\text { sequenciamento }\end{array}$ & $\begin{array}{c}\text { Weisburg et al., } \\
1991\end{array}$ \\
\hline rpoBf & GGCGAAATGGCWGAGAACCA & \multirow{2}{*}{$r p o B$} & \multirow{2}{*}{$501 \mathrm{pb}$} & $\begin{array}{l}\text { Amplificação e } \\
\text { sequenciamento }\end{array}$ & $\begin{array}{c}\text { Diancourt et al., } \\
2005\end{array}$ \\
\hline rpoBr & GAGTCTTCGAAGTTGTAACC & & & $\begin{array}{l}\text { Amplificação e } \\
\text { sequenciamento }\end{array}$ & $\begin{array}{l}\text { Diancourt et al., } \\
2005\end{array}$ \\
\hline gapAf & TGAAATATGACTCCACTCACGG & \multirow{2}{*}{ gapA } & \multirow{2}{*}{$450 \mathrm{pb}$} & $\begin{array}{l}\text { Amplificação e } \\
\text { sequenciamento }\end{array}$ & $\begin{array}{c}\text { Diancourt et al., } \\
2005\end{array}$ \\
\hline gapAr & CTTCAGAAGCGGCTTTGATGGCTT & & & $\begin{array}{l}\text { Amplificação e } \\
\text { sequenciamento }\end{array}$ & $\begin{array}{c}\text { Diancourt et al., } \\
2005\end{array}$ \\
\hline
\end{tabular}

\subsubsection{Multilocus sequence typing 'MLST' das amostras de Klebsiella sp.}

Para análise das amostras que apresentaram similaridade com perfis de Klebsiella sp. também foram amplificados mais cinco genes específicos este gênero (Diancourt et al., 2005). As sequências nucleotídicas obtidas permitiram definir os alelos de cada locus e, de acordo com a combinação de alelos de cada isolado, identificar os Sequence Types (STs) na base de dados do Instituto Pasteur (www.pasteur.fr/mlst).

Amplificação dos fragmentos - Para a amplificação dos genes $m d h$, pgi, phoE, infB $e$ tonB foi utilizado o método de Reação em Cadeia da Polimerase (PCR). Para cada reação foram utilizados $25 \mu 1$ de Master Mix (Promega), $20 \mu 1$ de água deionizada "DNAse Free", $1 \mu 1$ de DNA bacteriano e $2 \mu 1$ de cada primer ("forward" e "reverse") específico para os genes estudados (quadro 4). A amplificação dos fragmentos foi realizada através de um termociclador Eppendorff (Mastercycle Personal). Os protocolos de temperatura para a amplificação destes genes foram os seguintes:

$M d h$, pgi, phoE, infB $-92{ }^{\circ} \mathrm{C}$ por $2 \mathrm{~m}$ seguido por 40 ciclos de $95{ }^{\circ} \mathrm{C}$ por $2 \mathrm{~m}$ para a desnaturação, $50{ }^{\circ} \mathrm{C}$ por $2 \mathrm{~m}$ e $15 \mathrm{~s}$ para o anelamento e $72^{\circ} \mathrm{C}$ por $1 \mathrm{~m}$ e $15 \mathrm{~s}$ para a extensão do DNA. 
tonB $-92^{\circ} \mathrm{C}$ por $5 \mathrm{~m}$ seguido de 40 ciclos de $92{ }^{\circ} \mathrm{C}$ por $2 \mathrm{~m}$ para a desnaturação, $45^{\circ} \mathrm{C}$ por $2 \mathrm{~m}$ e $15 \mathrm{~s}$ para o anelamento e $72^{\circ} \mathrm{C}$ por $1 \mathrm{~m}$ e $15 \mathrm{~s}$ para a extensão do DNA.

Para todos os genes, após o término dos ciclos, foi realizada uma etapa de $10 \mathrm{~m}$ a $72{ }^{\circ} \mathrm{C}$ para a estabilização do DNA.

Quadro 4 - Sequência dos “primers” utilizados para MLST em Klebsiella pneumoniae.

\begin{tabular}{|c|c|c|c|c|c|}
\hline "Primer" & Sequencia $\left(5^{\prime}-3^{\prime}\right)$ & Gene alvo & Tamanho & Utilização & Referência \\
\hline mdh:F:130 & $\begin{array}{l}\text { CCCAACTCGCTTCAGGTTCAG } \\
\text { CCGTTTTTCCCCAGCAGCAG }\end{array}$ & $m d h$ & $477 \mathrm{pb}$ & $\begin{array}{l}\text { Amplificação e } \\
\text { sequenciamento } \\
\text { Amplificação e } \\
\text { sequenciamento }\end{array}$ & $\begin{array}{l}\text { Diancourt et al., } \\
2005 \\
\text { Diancourt et al., } \\
2005\end{array}$ \\
\hline pgi:F:1R & $\begin{array}{l}\text { GAGAAAAACCTGCCTGTACTGCTGGC } \\
\text { CGCGCCACGCTTTATAGCGGTTAAT }\end{array}$ & pgi & $432 \mathrm{pb}$ & $\begin{array}{l}\text { Amplificação e } \\
\text { sequenciamento } \\
\text { Amplificação e } \\
\text { sequenciamento }\end{array}$ & $\begin{array}{l}\text { Diancourt et al. } \\
2005 \\
\text { Diancourt et al. } \\
2005\end{array}$ \\
\hline phoE:F:604.1 & ACCTACCGCAACACCGACTTCTTCGG & phoE & $420 \mathrm{pb}$ & $\begin{array}{l}\text { Amplificação e } \\
\text { sequenciamento } \\
\text { Amplificação e } \\
\text { sequenciamento }\end{array}$ & $\begin{array}{l}\text { Diancourt et al. } \\
2005 \\
\text { Diancourt et al., } \\
2005\end{array}$ \\
\hline infB: $1 \mathrm{~F}$ & CTCGCTGCTGGACTATATTCG & $\inf B$ & $318 \mathrm{pb}$ & $\begin{array}{l}\text { Amplificação e } \\
\text { sequenciamento } \\
\text { Amplificação e } \\
\text { sequenciamento }\end{array}$ & $\begin{array}{l}\text { Diancourt et al., } \\
2005 \\
\text { Diancourt et al., } \\
2005\end{array}$ \\
\hline tonB: $1 \mathrm{~F}$ & CTTTATACCTCGGTACATCAGGTT & $\operatorname{ton} B$ & $414 \mathrm{pb}$ & $\begin{array}{l}\text { Amplificação e } \\
\text { sequenciamento } \\
\text { Amplificação e } \\
\text { sequenciamento }\end{array}$ & $\begin{array}{l}\text { Diancourt et al. } \\
2005 \\
\text { Diancourt et al. } \\
2005\end{array}$ \\
\hline
\end{tabular}

Conforme descrito no item anterior, estes produtos de PCR também foram purificados, sequenciados e analisados.

\subsection{Avaliação da clonalidade por ERIC-PCR}

Para tipagem genotípica, as cepas foram submetidas ao método de ERIC-PCR que consiste na amplificação de seqüências do DNA através da técnica de PCR utilizando o primer ERIC-2 (5' - AAGTAAGTGACTGGGGTGAGCG - 3') (Versalovic et al., 1991). A reação ocorreu nas seguintes condições: etapa de desnaturação inicial a $94{ }^{\circ} \mathrm{C}$ por $10 \mathrm{~m}$; etapa de amplificação com 30 ciclos de desnaturação a $94{ }^{\circ} \mathrm{C}$ por $1 \mathrm{~m}$, hibridação a $52{ }^{\circ} \mathrm{C}$ por $1 \mathrm{~m}$, extensão a $72{ }^{\circ} \mathrm{C}$ por $8 \mathrm{~m}$; extensão final a $72{ }^{\circ} \mathrm{C}$ por $16 \mathrm{~m}$. Os segmentos separados por 
eletroforese em gel de agarose $2 \%$, corados com brometo de etídio foram visualizados em transluminador UV. A avaliação da clonalidade foi realizada através do programa Bionumerics (Applied Mathematics, Kortrijh, Belgium) a partir do perfil de amplificação obtido, utilizando o coeficiente de Dice numa tolerância de $2 \%$.

\subsection{Ensaio de redução de Acetileno (ARA)}

A atividade da enzima nitrogenase foi analisada pelo método da redução de acetileno (ARA) (Pariona-Llanos et al., 2010). Após crescimento por $72 \mathrm{~h}$ a $30{ }^{\circ} \mathrm{C}$, as diferentes culturas foram incubadas com acetileno ( $10 \%$ do volume gasoso) sem agitação, a $30{ }^{\circ} \mathrm{C}$ por mais 72 h. Foram usadas triplicatas de cada amostra. A produção de etileno foi avaliada quantitativamente por cromatografia gasosa e as concentrações das amostras foram calculadas considerando-se os valores da curva padrão de etileno e aplicando-se a equação geral dos gases: $\mathrm{n}=\mathrm{PV} / \mathrm{RT}$.

Para quantificações específicas de ARA, medidas por fmol.UFC. $\mathrm{h}^{-1}$, foram feitas determinações do número de bactérias viáveis das culturas. Para tanto, foram realizadas contagens de Unidades Formadoras de Colônias (UFC) utilizando-se o método da gota (Barbosa et al., 1995).

\subsection{Detecção do gene nifH}

As bactérias foram submetidas à técnica de PCR para se verificar a presença ou não de genes nifH. As reações de amplificação foram realizadas separadamente, utilizando-se os iniciadores [PPf e PPr] e [Pol-f e Pol-r] (quadro 5).

Quadro 5 - Iniciadores para amplificação do gene nifH

\begin{tabular}{lcccc}
\hline "Primer" & Sequencia $\left(5^{\prime}-3\right.$ ') & Gene alvo & Tamanho & Referência \\
\hline pol-F & TGCGAYCCSAARGCBGACTC & Amplificação parcial & \multirow{2}{*}{ i60 pb } & Poly et al., 2001 \\
pol-R & ATSGCCATCATYTCRCCGGA & do gene nifH & & Poly et al., 2001 \\
\hline pp-F & GCAAGTCCACCACCTCC & Amplificação total do & \multirow{2}{*}{ 705 pb } & Liba et al., 2006 \\
pp-R & TCGCGTGGACCTTGTTG & gene nifH & & Liba et al., 2006 \\
\hline
\end{tabular}

Os protocolos de temperatura para a amplificação dos genes nifH foram os seguintes:

Para o iniciador Pol $-95{ }^{\circ} \mathrm{C}$ por $2 \mathrm{~m}$, seguido por 30 ciclos de $94{ }^{\circ} \mathrm{C}$ por $1 \mathrm{~m}$ para a desnaturação, $55^{\circ} \mathrm{C}$ por $1 \mathrm{~m}$ para anelamento e $72{ }^{\circ} \mathrm{C}$ por $2 \mathrm{~m}$ para extensão do DNA, e $5 \mathrm{~m}$ de extensão a $72{ }^{\circ} \mathrm{C}$ no último ciclo. 
Para o iniciador PP $-94{ }^{\circ} \mathrm{C}$ por $2 \mathrm{~m}$, seguido por 30 ciclos de $94{ }^{\circ} \mathrm{C}$ por $1 \mathrm{~m}$ para a desnaturação, $55^{\circ} \mathrm{C}$ por $1 \mathrm{~m}$ para o anelamento e $72{ }^{\circ} \mathrm{C}$ por $3 \mathrm{~m}$ para extensão do DNA e $10 \mathrm{~m}$ de extensão a $72{ }^{\circ} \mathrm{C}$ no último ciclo.

\subsection{Produção de Etileno}

As cepas foram inoculadas em frascos tipo penicilina de $60 \mathrm{ml}$ tampados com rolhas de borracha e lacre de metal contendo $24 \mathrm{ml}$ de meio MMS acrescido de metionina, em seguida, foram incubadas a $30^{\circ} \mathrm{C}$, por 144 e $220 \mathrm{~h}$. A fim de medir a produção de etileno, $1 \mathrm{ml}$ da fase aérea foi retirado do frasco e analisado por cromatografia gasosa (Thuler et al., 2003). As análises foram feitas em triplicata e as concentrações das amostras foram calculadas utilizando-se as áreas dos padrões com concentrações conhecidas.

\subsection{Teste de sensibilidade (Difusão em Disco e Concentração Mínima Inibitória)}

Os isolados foram submetidos à determinação do perfil qualitativo de resistência a antibióticos por meio do método de difusão em disco (CLSI, 2005). Os antibióticos selecionados para realização dos testes foram: Aminoglicosídeos (Gentamicina, Estreptomicina), $\beta$-lactâmicos (Cefalotina, Cefotaxima, Ceftiofur, Ertapenem), Quinolonas (Ácido Nalidíxico, Enrofloxacina, Ciprofloxacina), Sulfa (Cotrinoxazol), Tetraciclina (Tetraciclina) e Nitrofurano (Nitrofurantoína).

O teste de disco difusão foi realizado de acordo com as orientações do CLSI (Clinical and Laboratory Standards Institute, 2009). De cada isolado foi preparada uma suspensão bacteriana com turvação ajustada ao padrão 0,5 de McFarland por comparação visual. Cada suspensão foi semeada, maneira uniforme, sobre a superfície de uma placa de Petri contendo o meio Agar Müeller-Hinton. Após este procedimento, foram adicionados os discos com os antibióticos. As placas foram incubadas, durante $24 \mathrm{~h}$, a temperatura de $30{ }^{\circ} \mathrm{C}$. O tamanho do halo foi medido em milímetros $(\mathrm{mm})$ e categorizado como: sensível (S), intermediário (I) ou resistente (R), conforme padronizado pelo CLSI. Foi utilizado como controle, amostra de referência Escherichia coli (ATCC 25922).

As bactérias que apresentaram um perfil considerado resistente ou intermediário aos antibióticos testados foram submetidas à determinação da Concentração Inibitória Mínima (CIM), pelo método de diluição em ágar e mediante o uso de fitas E-Test (CLSI, 2005). O sistema do E-test consiste em uma fita plástica inerte e não porosa de $50 \mathrm{~mm}$ de comprimento 
e $5 \mathrm{~mm}$ de largura, que contém uma escala numérica que indica o gradiente de concentração de antibiótico. A fita do E-test pode detectar a concentração inibitória mínima (CIM) que varia entre 0,016 a $256 \mu \mathrm{g} / \mathrm{ml}$ dependendo do antimicrobiano utilizado (Bölmstrom, 1993).

\subsection{Transformação das bactérias e teste de estabilidade dos plasmídios}

Após o ensaio de sensibilidade a antibióticos, foram selecionadas duas linhagens ambientais sensíveis a todos antibióticos e duas linhagens clínicas resistentes à maioria dos antibióticos. O DNA plasmidial das linhagens clínicas foi extraído através do KIT MiniPrep para plasmídeo \#APMNP50, Axygen e as linhagens ambientais sensíveis foram submetidas a eletrocompetência.

Para tornar as linhagens ambientais competentes à recepção dos plasmídeos, $25 \mathrm{ml}$ de culturas em meio LB líquido, crescidas overnight, a $37{ }^{\circ} \mathrm{C}$ sob agitação, foram diluídas para uma densidade óptica (DO) de 0,1 em um volume de $500 \mathrm{ml}$ de meio LB. Foram incubadas até que a DO atinjisse entre 0,4 e 0,6. A cultura foi mantida em gelo por $15 \mathrm{~m}$, depois centrifugada a $4.800 \mathrm{rpm}$ durante $25 \mathrm{~m}$ a $4{ }^{\circ} \mathrm{C}$. As células foram suspensas em $5 \mathrm{ml}$ de água deionizada esterilizada e gelada. Foram adicionados $40 \mathrm{ml}$ de glicerol a $10 \%$ gelada, seguido de centrifugação por $10 \mathrm{~m}$ a $9.000 \mathrm{~g}$. O sedimento foi ressuspendido em $500 \mu \mathrm{l}$ de glicerol a $10 \%$ gelado. As alíquotas foram mantidas a $20^{\circ} \mathrm{C}$.

Para a transformação bacteriana, $40 \mu \mathrm{l}$ das células competentes foram depositadas em uma cubeta de eletroporação, previamente resfriada e acrescidas de $1 \mu 1$ de solução plasmidial logo acima das células. A eletroporação foi processada no equipamento Gene Pulser (Bio$\mathrm{Rad}$ ) com voltagem de $2,5 \mathrm{kV}$, corrente de $25 \mathrm{~mA}$, capacitância de $25 \mu \mathrm{F}$ e resistência de $200 \Omega$. Após o pulso, $1 \mathrm{ml}$ de meio LB líquido foi adicionado à suspensão e então mantido sob agitação $(150 \mathrm{rpm})$ por $1 \mathrm{~h} \mathrm{a} 37^{\circ} \mathrm{C}$. As bactérias transformadas foram submetidas ao teste de sensibilidade a antibióticos.

\subsection{Solubilização de Fosfato}

Os testes de solubilização de fosfato foram realizados pela aplicação de uma gota de cultura de cada isolado sobre o meio contendo fosfato insolúvel. A incubação foi a $30^{\circ} \mathrm{C}$ por $48 \mathrm{~h}$. A formação de um halo transparente ao redor do crescimento bacteriano foi indicadora da solubilização de $\mathrm{Ca}_{3}\left(\mathrm{PO}_{4}\right)_{2}$. (Verma et al., 2001). 


\subsection{Atividade da endoglicanase e pectinase}

As atividades de endoglicanase e pectinase foram determinadas pela aplicação de uma gota de cultura de cada isolado a um meio sólido equivalente para cada ensaio, sendo MP para atividade pectinolítica e CMC para atividade da endoglucanase. A incubação foi a $30{ }^{\circ} \mathrm{C}$ por 96 h. Para detectar o halo formado por ação da pectinase ou pela carboximetilcelulase, as culturas foram cobertas com solução de Lugol ou de Vermelho Congo, respectivamente (Hankin et al., 1971; Teather, Wood, 1982). O halo incolor ao redor do crescimento bacteriano foi tomado como indicação de atividade enzimática.

\subsection{Atividade hemolítica}

A atividade hemolítica foi avaliada pela presença de um halo transparente ao redor das colônias bacterianas após incubação overnight a $37{ }^{\circ} \mathrm{C}$ no meio ágar sangue (Difco) com eritrócitos de carneiro 5\% (Beutin, 1991).

\subsection{Produção de AIA (ácido indol-3-acético)}

Foram cultivadas triplicatas de cada amostra bacteriana em meio MS sem nitrogênio combinado acrescido de $0,5 \mathrm{~g} . \mathrm{l}^{-1}$ de triptofano por 7 dias. Após o crescimento, foram filtradas em filtros Sartorius $0,2 \mu \mathrm{m}$. Para determinar o rendimento da amostra foram adicionados $100 \mu \mathrm{l}$ de $\left[\mathrm{H}^{3}\right]$ AIA em $5 \mathrm{ml}$ do sobrenadante como padrão. As amostras foram particionadas com éter etílico, a fase orgânica foi seca em "speed vac" e suspensa em $300 \mu$ l de metanol $100 \%$. A produção de AIA foi adaptada para dosagem em culturas de microrganismos (Kojima, 1996). A quantificação de AIA foi realizada em HPLC de fase reversa, com coluna C18 (Shimadzu Shim-pack CLC ODS) e detector de fluorescência. Quarenta microlitros da amostra foram injetados na coluna. As perdas foram avaliadas por cintilação, por determinação da radioatividade em Cintilador Beckman - LS6500.

\subsection{Análise dos resultados}

A análise estatística foi realizada após o término de cada experimento, os dados foram analisados por ANOVA $(P<0.05)$. 


\section{RESULTADOS}

\subsection{Identificação dos isolados}

\section{$\underline{\text { 5.1.1 Identificação dos isolados por MALDI TOF-MS }}$}

A precisão dos resultados obtidos através desta técnica é medida através de um valor de "score" fornecido pelo software. Os valores de "score" obtidos (variando entre 1.600 e 3.000) fornecem um grau de confiança na identificação de gênero ou espécie. Os resultados obtidos confirmaram a identificação no nível de gênero comparada com os dados do sequenciamento de genes housekeeping em todas amostras de origem clínica. Entretanto, para as amostras de origem ambiental houve diferenças na identificação dos gêneros, 75\% das amostras foram identificadas corretamente. As amostras ICB117 e ICB118 foram identificadas pelo MALDI TOF-MS como pertencentes ao gênero Klebsiella e na identificação por sequenciamento e análise filogenética como Enterobacter sp.; o mesmo pode ser obervado nas amostras: ICB565 (MALDI TOF-MS = Enterobacter sp. - Análise Filogenética = Kosakonia sp.), ICB567 (MALDI TOF-MS = Klebsiella sp. - Análise Filogenética = Kosakonia sp. $) \mathrm{e}$ ICBR199 (MALDI TOF-MS = Enterobacter sp. - Análise Filogenética = Klebsiella sp.). Os resultados individuais obtidos neste experimento podem ser encontrados no quadro 7.

$\underline{\text { 5.1.2 Amplificação dos genes 16S rRNA, rpoB e gapA e construção das árvores filogenéticas }}$

Os genes $16 \mathrm{~S}$ RNA ribosomal, rрoB (subunidade beta da enzima RNA polimerase) e gapA (gliceraldeído-3-fosfato desidrogenase) dos 39 isolados foram amplificados pela técnica de PCR (reação em cadeia da polimerase). Foram obtidos amplicons destes genes com aproximadamente $1500 \mathrm{pb}, 600 \mathrm{pb}$ e $500 \mathrm{pb}$ respectivamente. As sequências dos isolados editadas pelo programa "Chromas Pro" e de linhagens tipo de algumas espécies obtidas através do NCBI/BLAST foram então exportadas para o programa MEGA "Molecular Evolutionary Genetics Analysis, v. 6.0.5" para a construção das árvores filogenéticas.

Foi construída uma árvore filogenética para o gene $16 \mathrm{~S}$ rRNA (figura 1), uma para o gene $r p o B$ (figura 2) e uma concatenada dos genes $16 S$ rRNA e rpoB (figura 3).

Pode-se verificar, a partir da análise da árvore filogenética baseada na amplificação e sequenciamento do gene $16 \mathrm{~S}$ rRNA, seis grupos distintos de enterobactérias. O primeiro formado pelas linhagens de Klebsiella sp. - C23, C26, C183, C42, C4900, C381150, 
KPC732, KPC-RJ, ICB365, ICB477, ICB369, ICB375, C44K, ICB572, ICBR174, ICBR183 e ICBR199; o segundo é formado pelas linhagens de Enterobacter sp. CEA4, CEA39, ICB484, ICBR63, ICBR188, ICB481, C301903, CEC1 e MARCO; o terceiro é formado pelo isolado ICBR210 que se mostrou próximo às linhagens de Enterobacter, mas não agrupou com nenhuma linhagem tipo utilizada; o quarto é formado pelas linhagens que se aproximaram do isolado Enterobacter sacchari ICB101, ICB105, ICB115, ICB117 e ICB118; o quinto grupo é formado pelas linhagens de Kosakonia sp. ICB561, ICB565, ICB573, ICBR79, ICB22 e ICB567; o sexto é formado pela linhagem de Pluralibacter gergoviae CEG2. Os isolados de origem ambiental mostraram-se distintos filogeneticamente dos de origem clínica, apenas o isolado $\mathrm{C} 44 \mathrm{~K}$ (origem clínica veterinária) mostrou-se mais próximo das linhagens ambientais.

Também foi amplificado e sequenciado o gene housekeeping rpoB e a árvore filogenética construída a partir destes resultados pode ser encontrada na figura 2. O resultado da análise filogenética deste gene foi similar à análise do gene $16 \mathrm{~S}$ com excessão dos isolados: C26, ICBR188 e ICB115 que estavam agrupados em outros gêneros. O isolado C26 possui o gene $16 \mathrm{~S}$ similar ao grupo Klebsiella e o gene $r p o B$ não se aproximou de nenhum grupo ou linhagem tipo utilizadas neste trabalho. O isolado ICBR188 possui o $16 \mathrm{~S}$ similar ao grupo Enterobacter e o gene rpoB próximo ao grupo Kosakonia. O isolado ICB115 possui o $16 S$ próximo ao grupo Enterobacter sacchari e o rpoB próximo ao grupo Klebsiella.

A amplificação do gene gapA não está mostrada neste trabalho pois não haviam sequências das linhagens tipo disponíveis. Porém estas sequências serão depositadas no GenBank a partir da identificação obtida com os outros dois genes utilizados.

A partir dos resultados obtidos no sequenciamento do gene $16 S$ e $r p o B$ foi construída uma árvore filogenética concatenada destes dois genes (figura 3). 
Figura 1 - Árvore filogenética inferida a partir do alinhamento das sequências do gene $16 \mathrm{~S}$ rRA

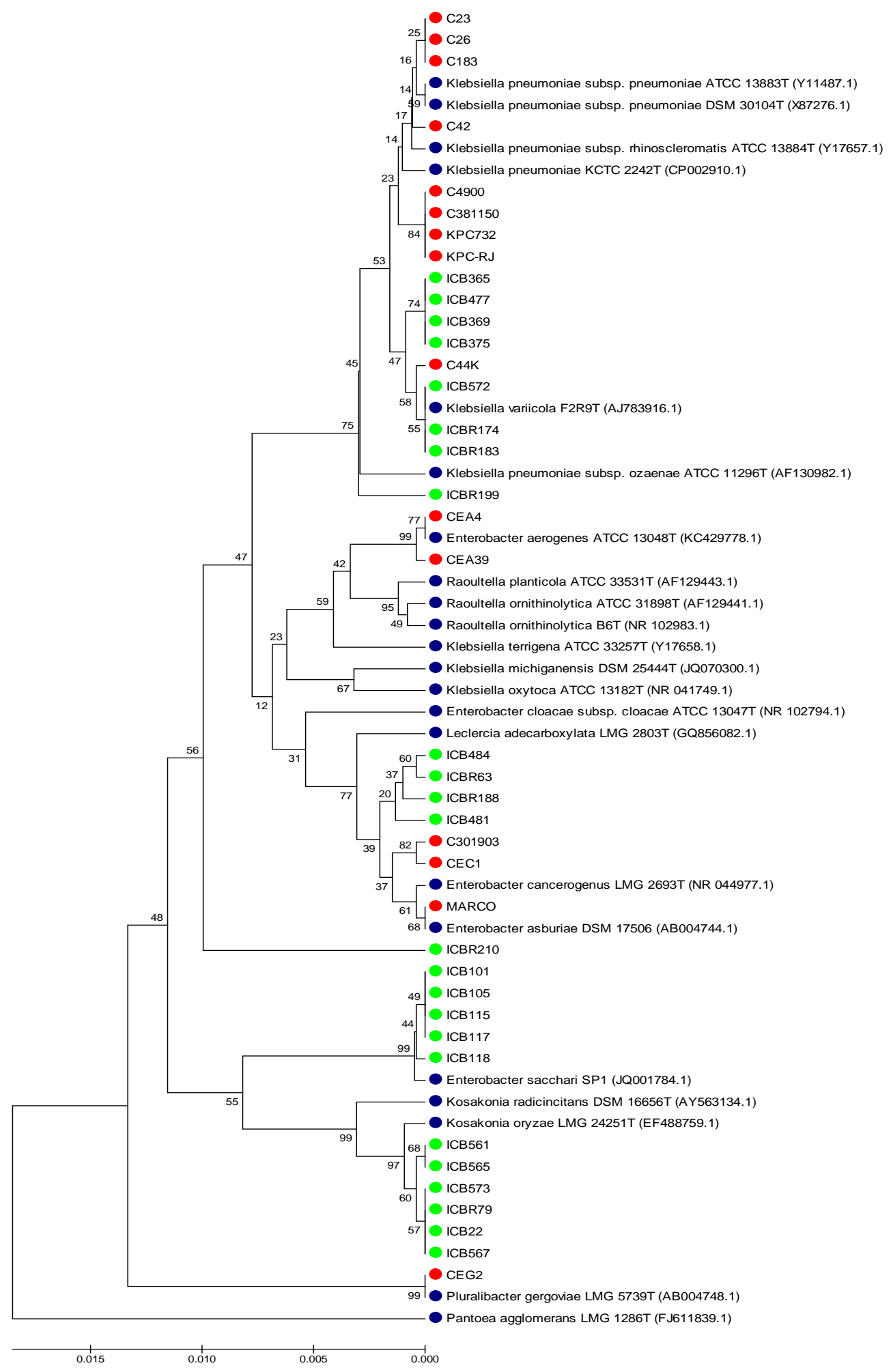

Árvore filogenética baseada na sequência parcial do gene 16S rRNA. Foram utilizadas 39 linhagens bacterianas, sendo algumas isoladas de cana-de-açúcar $(\bullet)$ ou isolados clínicos $(\bullet)$ também foram utilizadas sequencias de linhagens tipo de algumas espécies de enterobactérias com os respectivos números de acesso ao GenBank $(\bullet)$. A história evolutiva foi inferida através do método UPGMA (Sneath et al., 1973). Próximo aos ramos é mostrada a porcentagem do teste de filogenia por bootstrap (1.000 repetições) (Felsenstein, 1985). As distâncias evolutivas foram calculadas através do método da máxima verossimilhança (Tamura et al., 2004). As análises foram realizadas através do programa MEGA "Molecular Evolutionary Genetics Analysis, v. 6.0.5" (Tamura et al., 2013). 
Figura 2 - Árvore filogenética inferida a partir do alinhamento das sequências do gene rpoB

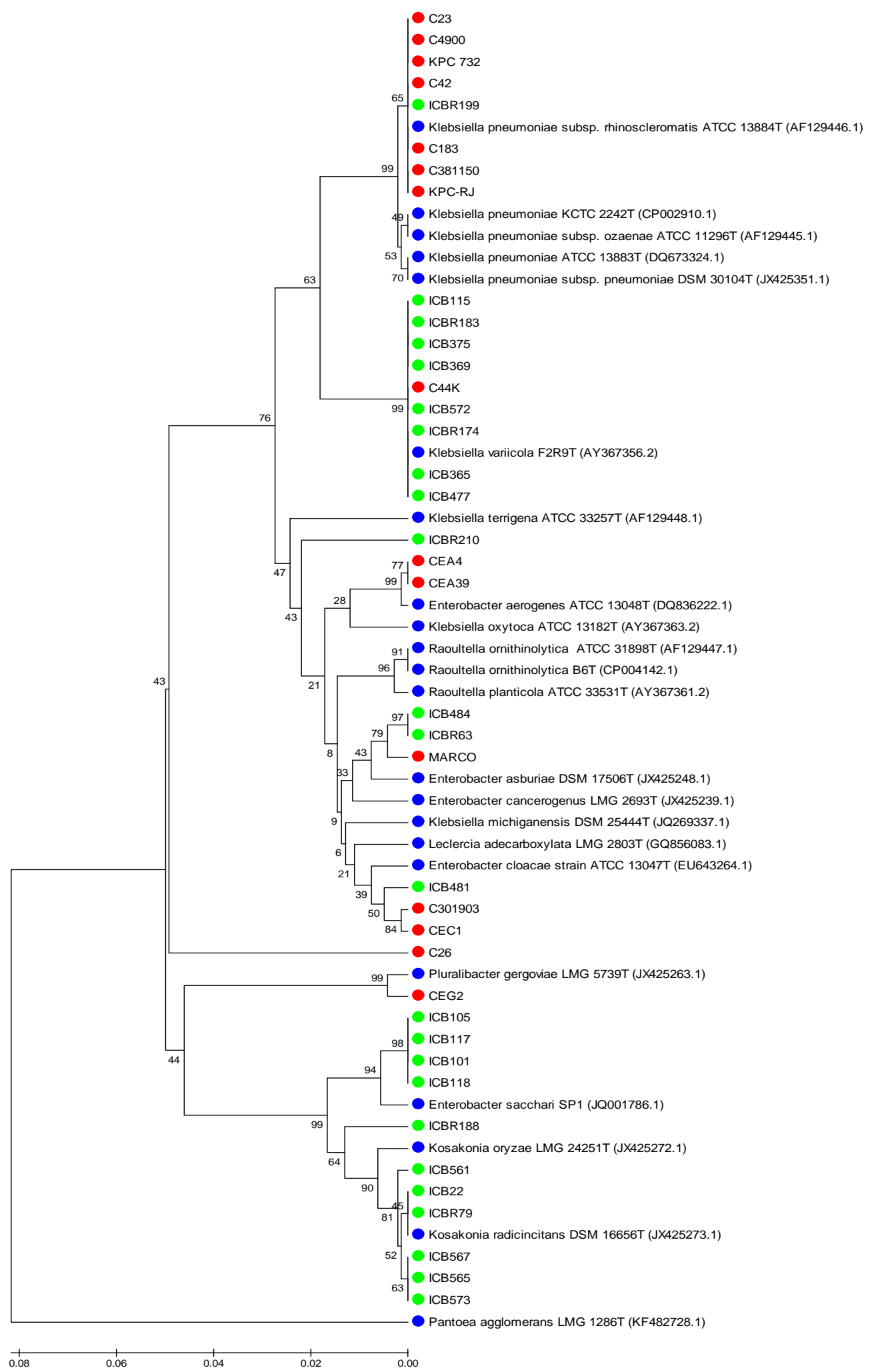

Árvore filogenética baseada na sequência do gene $r p o B$ (subunidade $\beta$ da RNA polimerase bacteriana). Foram utilizadas 39 linhagens bacterianas, sendo algumas isoladas de cana-de-açúcar $(\bullet)$ ou isolados clínicos $(\bullet)$ também foram utilizadas sequencias de linhagens tipo de algumas espécies de enterobactérias com os respectivos números de acesso ao GenBank $(\bullet)$. A história evolutiva foi inferida através do método UPGMA (Sneath et al., 1973). Próximo aos ramos é mostrada a porcentagem do teste de filogenia por bootstrap (1.000 repetições) (Felsenstein, 1985). As distâncias evolutivas foram calculadas através do método da máxima verossimilhança (Tamura et al., 2004). As análises foram realizadas através do programa MEGA “Molecular Evolutionary Genetics Analysis, v. 6.0.5” (Tamura et al., 2013). 
Figura 3 - Árvore filogenética inferida a partir do alinhamento das sequências concatenadas dos genes $16 S$ e $r p o B$

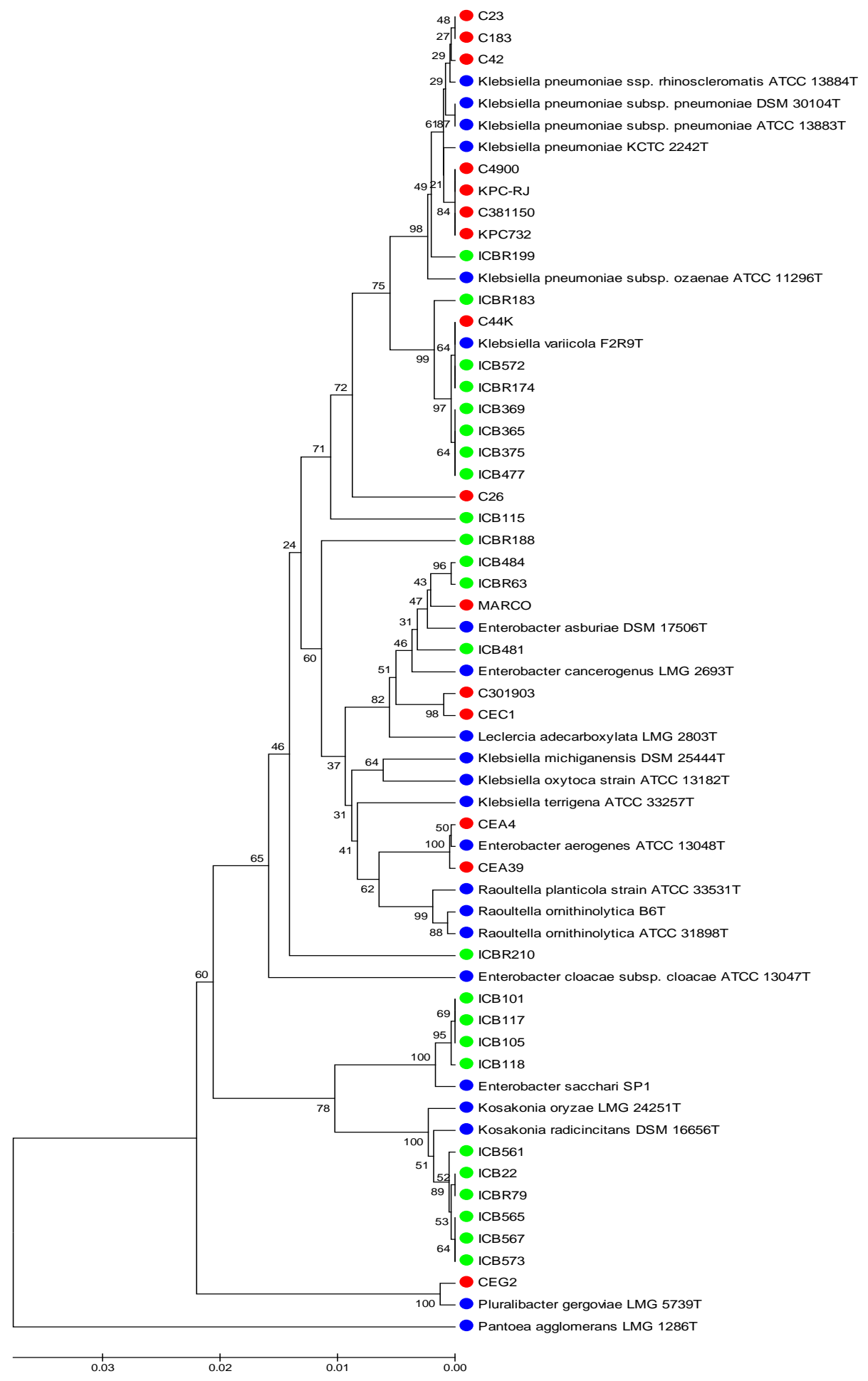

Árvore filogenética baseada nas sequências concatenadas dos genes $16 \mathrm{~S}$ rRNA e rpoB. Foram utilizadas 39 linhagens bacterianas, sendo algumas isoladas de cana-de-açúcar $(\bullet)$ ou isolados clínicos $(\bullet)$ também foram utilizadas sequencias de linhagens tipo de algumas espécies de enterobactérias com os respectivos números de acesso ao GenBank $(\bullet)$. A história evolutiva foi inferida através do método UPGMA (Sneath et al., 1973). Próximo aos ramos é mostrada a porcentagem do teste de filogenia por bootstrap (1.000 repetições) (Felsenstein, 1985). As distâncias evolutivas foram calculadas através do método da máxima verossimilhança (Tamura et al., 2004). As análises foram realizadas através do programa MEGA "Molecular Evolutionary Genetics Analysis, v. 6.0.5" (Tamura et al., 2013). 
Como resultado, obteve-se a identificação dos isolados em quatro gêneros, Klebsiella, Enterobacter, Kosakonia e Pluralibacter. A identificação de cada isolado, comparada com o resultado obtido no MALDI TOF-MS podem ser encontradas no quadro 7.

Pode-se confirmar, a partir da análise da árvore filogenética concatenada, a formação de seis grupos distintos de enterobactérias. O primeiro é formado pelas linhagens de Klebsiella sp. - C23, C26, C183, C42, C4900, C381150, KPC732, KPC-RJ, ICB115, ICB365, ICB477, ICB369, ICB375, C44K, ICB572, ICBR174, ICBR183 e ICBR199; o segundo, pelas linhagens de Enterobacter sp. CEA4, CEA39, ICB484, ICBR63, ICBR188, ICB481, C301903, CEC1 e MARCO; o terceiro, formado pelo isolado ICBR210 que se mostrou próximo às linhagens de Enterobacter, mas não agrupou com nenhuma linhagem tipo utilizada; o quarto é formado pelas linhagens que se aproximaram do isolado Enterobacter sacchari ICB101, ICB105, ICB117 e ICB118; o quinto grupo é formado pelas linhagens de Kosakonia sp. ICB561, ICB565, ICB573, ICBR79, ICB22 e ICB567 e o sexto, pela linhagem de Pluralibacter gergoviae CEG2. Os isolados de origem ambiental ou clínica mostraram-se distintos filogeneticamente em todos os grupos, apenas o isolado C44K (origem clínica veterinária) mostrou-se mais próximo das linhagens ambientais.

\subsubsection{MLST (Multilocus sequence typing) das amostras identificadas como Klebsiella sp.}

Após a análise da árvore filogenética concatenada, as linhagens que se aproximaram do grupo Klebsiella sp. tiveram mais cinco genes housekeeping amplificados: infB (fator de iniciação da tradução), $m d h$ (malato desidrogenase), pgi (fosfoglicose isomerase), phoE (fosfoporina E) e tonB (transdutor energético periplasmático) para identificação em nível de espécie. Esta técnica consiste na amplificação de fragmentos internos de sete genes housekeeping característicos para o gênero Klebsiella, onde as alterações nucleotídicas fornecem um perfil alélico para cada isolado. Os perfis são comparados com uma base de dados que permite, então, identificar os diferentes "sequence types" (ST) por homologia com os perfis já descritos na base de dados do Instituto Pasteur (http://www.pasteur.fr/recherche/genopole/PF8/mlst/Kpneumoniae.html). E como resultado, obteve-se os seguintes perfis alélicos mostrados no quadro 6. 
Quadro 6: Perfil alélico obtido para os isolados de Klebsiella sp.

\begin{tabular}{|c|c|c|c|c|c|c|c|c|c|}
\hline Cepa & Origem & gapA & infB & $m d h$ & $p g i$ & phoE & rpoB & tonB & ST \\
\hline C23 & Clínica & 4 & 1 & 2 & $\sim 52$ & 1 & 1 & 7 & $\mathrm{NE}$ \\
\hline C26 & Clínica & 4 & 1 & 2 & $\sim 52$ & 1 & $\mathrm{NE}$ & 7 & $\mathrm{NE}$ \\
\hline $\mathrm{C} 42$ & Clínica & 4 & 1 & 2 & 52 & 1 & 1 & 7 & 307 \\
\hline C183 & Clínica & 4 & 1 & 2 & $\sim 52$ & 1 & 1 & 7 & $\mathrm{NE}$ \\
\hline C4900 & Clínica & 3 & 3 & 1 & 80 & 1 & 1 & 31 & IN \\
\hline C381150 & Clínica & 3 & 3 & 1 & 1 & 1 & 1 & 31 & 437 \\
\hline KPC-RJ & Clínica & 3 & 3 & 1 & 80 & 1 & 1 & 31 & IN \\
\hline KPC-732 & Clínica & 3 & $\mathrm{NE}$ & 1 & $\sim 1$ & $\mathrm{NE}$ & 1 & $\mathrm{NE}$ & $\mathrm{NE}$ \\
\hline C44K & Clínica & 16 & 62 & 21 & $\sim 27$ & 55 & $\sim 22$ & 31 & $\mathrm{NE}$ \\
\hline ICB115 & Ambiental & 16 & 24 & 45 & 40 & 53 & $\sim 22$ & 7 & $\mathrm{NE}$ \\
\hline ICB365 & Ambiental & 16 & 24 & 45 & 40 & 53 & $\sim 22$ & $\mathrm{NE}$ & $\mathrm{NE}$ \\
\hline ICB369 & Ambiental & 16 & 24 & 45 & 40 & 53 & $\sim 22$ & 7 & $\mathrm{NE}$ \\
\hline ICB375 & Ambiental & 16 & 24 & 45 & 40 & 53 & $\sim 22$ & 67 & $\mathrm{NE}$ \\
\hline ICB477 & Ambiental & 16 & 24 & 45 & 40 & 53 & $\sim 22$ & $\mathrm{NE}$ & $\mathrm{NE}$ \\
\hline ICB572 & Ambiental & 16 & 24 & 21 & 27 & 54 & $\sim 22$ & 4 & $\mathrm{NE}$ \\
\hline ICBR174 & Ambiental & $\sim 16$ & 24 & $\sim 21$ & $\mathrm{NE}$ & 54 & $\sim 22$ & $\mathrm{NE}$ & $\mathrm{NE}$ \\
\hline ICBR183 & Ambiental & 16 & 24 & $\mathrm{NE}$ & 41 & $\sim 42$ & $\mathrm{NE}$ & $\mathrm{NE}$ & $\mathrm{NE}$ \\
\hline ICBR199 & Ambiental & 3 & 3 & $\mathrm{NE}$ & 1 & 1 & 1 & 31 & $\mathrm{NE}$ \\
\hline
\end{tabular}

: Perfil aproximado; NE: ST ou alelo não encontrado na base de dados; IN: Perfil inexistente.

Após a combinação dos sete alelos, foram identificadas quatro "sequence typing". Para os isolados C42 e C381150, os perfis encontrados já existiam na base de dados, enquanto para os isolados C4900 e KPC-RJ as ST's identificadas não foram descritas previamente na base de dados utilizada, sendo a mais próxima a ST437, cujas sequências nucleotídicas dos genes estudados diferem do isolado C381150 apenas no gene $p g i$.

Pode-se observar também que há similaridade entre o perfil da cepa ICBR199, isolada da rizosfera de cana-de-açúcar, com os perfis de amostras clínicas, diferindo apenas no gene $m d h$.

A cepa de origem clínica veterinária $\mathrm{C} 44 \mathrm{~K}$, possui o perfil mais diferenciado, sendo mais próxima da amostra de origem ambiental ICB572, apresentando o mesmo perfil alélico nos genes: gapA, $m d h$, pgi (aproxim.) e rpoB. A partir destes resultados, o quadro 7 mostra a comparação entre as duas técnicas de identificação utilizadas neste trabalho. 
Quadro 7 -- Comparação entre resultados obtidos pelos métodos MALDI TOF-MS e análise filogenética

\begin{tabular}{|c|c|c|c|c|}
\hline Linh & Origem & Score & MALDI TOF- & Análise filogenética \\
\hline ICB 22 & Ambiental & 2.170 & Kosakonia radicincitans & Kosakonia radicincitans \\
\hline ICB 101 & Ambiental & 1.899 & Enterobacter cowanii & Enterobacter sacchari \\
\hline ICB 105 & Ambiental & 1.789 & Enterobacter cowanii & Enterobacter sacchari \\
\hline ICB 115 & Ambiental & 2.231 & Klebsiella pneumoniae & Klebsiella sp. \\
\hline ICB 117 & Ambiental & 2.087 & Klebsiella pneumoniae & Enterobacter sacchari \\
\hline ICB 118 & Ambiental & 2.124 & Klebsiella pneumoniae & Enterobacter sacchari \\
\hline ICB 365 & Ambiental & 1.778 & Klebsiella pneumoniae & Klebsiella $s p$ \\
\hline ICB 369 & Ambiental & 2.201 & Klebsiella pneumoniae & Klebsiella sp. \\
\hline ICB 375 & Ambiental & 2.079 & Klebsiella pneumoniae & Klebsiella sp. \\
\hline ICB 477 & Ambiental & 1.855 & Klebsiella pneumoniae & Klebsiella sp. \\
\hline ICB 481 & Ambiental & 1.768 & Enterobacter cloacae & Enterobacter sp. \\
\hline ICB 484 & Ambiental & 1.756 & Enterobacter cloacae & Enterobacter $s p$ \\
\hline ICB 561 & Ambiental & 1.868 & Kosakonia radicincitans & Kosakonia radicincitans \\
\hline ICB 565 & Ambiental & 2.206 & Enterobacter asburiae & Kosakonia radicincitans \\
\hline ICB 567 & Ambiental & 1.865 & Klebsiella pneumoniae & Kosakonia radicincitans \\
\hline ICB 572 & Ambiental & 2.030 & Klebsiella variicola & Klebsiella variicola \\
\hline ICB 573 & Ambiental & 2.209 & Klebsiella pneumoniae & Kosakonia radicincitans \\
\hline ICBR 63 & Ambiental & 2.189 & Enterobacter asburiae & Enterobacter $s p$ \\
\hline ICBR 79 & Ambiental & 2.369 & Kosakonia radicincitans & Kosakonia radicincitans \\
\hline ICBR 174 & Ambiental & 2.061 & Klebsiella pneumoniae & Klebsiella variicola \\
\hline ICBR 183 & Ambiental & 2.098 & Klebsiella pneumoniae & Klebsiella variicola \\
\hline ICBR 188 & Ambiental & 2.075 & Enterobacter asburiae & Enterobacter sp. \\
\hline ICBR 199 & Ambiental & 2.263 & Enterobacter asburiae & Klebsiella sp. \\
\hline ICBR 210 & Ambiental & 1.808 & Enterobacter cloacae & Enterobacter sp. \\
\hline $\mathrm{C} 23$ & Clínica & 2.337 & Klebsiella pneumoniae & Klebsiella pneumoniae \\
\hline $\mathrm{C} 26$ & Clínica & 2.119 & Klebsiella pneumoniae & Klebsiella pneumoniee \\
\hline C183 & Clínica & 2.121 & Klebsiella pneumoniae & Klebsiella pneumoniae \\
\hline C42 & Clínica & 2.227 & Klebsiella pneumoniae & Klebsiella pneumoniae \\
\hline C4900 & Clínica & 2.497 & Klebsiella pneumoniae & Klebsiella pneumoniae \\
\hline KPC732 & Clínica & 2.360 & Klebsiella pneumoniae & Klebsiella pneumoniae \\
\hline MARCO & Clínica & 2.146 & Enterobacter asburiae & Enterobacter sp. \\
\hline KPC-RJ & Clínica & 2.172 & Klebsiella pneumoniae & Klebsiella pneumoniae \\
\hline C301903 & Clínica & 2.257 & Enterobacter cloacae & Enterobacter $s p$ \\
\hline CEG2 & Clínica & 2.015 & Pluralibacter gergoviae & Pluralibacter gergoviae \\
\hline CEA39 & Clínica & 2.306 & Enterobacter aerogenes & Enterobacter aerogenes \\
\hline CEA4 & Clínica & 2.343 & Enterobacter aerogenes & Enterobacter aerogenes \\
\hline CEC1 & Clínica & 2.080 & Enterobacter cancerogenus & Enterobacter sp. \\
\hline C381150 & Clínica & 2.380 & Klebsiella pneumoniae & Klebsiella pneumoniae \\
\hline $\mathrm{C} 44 \mathrm{~K}$ & Clínica & 1.856 & Klebsiella variicola & Klebsiella variicola \\
\hline
\end{tabular}

Legenda de score para MALDI TOF-MS

2.000 - 3.000: Altamente provável a identificação de gênero e espécie

1.800 - 1.999: Seguro para a identificação do gênero e provável espécie

1.600 - 1.799: Provável identificação de gênero 


\subsection{ERIC-PCR}

O tamanho das bandas geradas após a eletroforese dos produtos de ERIC-PCR foi determinado por comparação direta com um marcador de massa molecular de 1 kb (Axygen, Catálogo \#M-DNA-1kb / Lot\#MD02100601). O gel foi analisado por inspeção visual, considerando todas as bandas visíveis independente do formato e da intensidade. O perfil de bandas visíveis, foi convertido para uma matriz binária e foram atribuídos os seguintes valores: ausência $=0$ e presença $=1$. $O$ grau de similaridade foi determinado pelo coeficiente de Dice com tolerância de $2 \%$ e os respectivos dendrogramas foram gerados por UPGMA através do programa Biomerics versão 7 (Applied Maths).

Figura 4 - ERIC-PCR - Dendrograma demonstrando grau de similaridade entre amostras de Klebsiella sp.

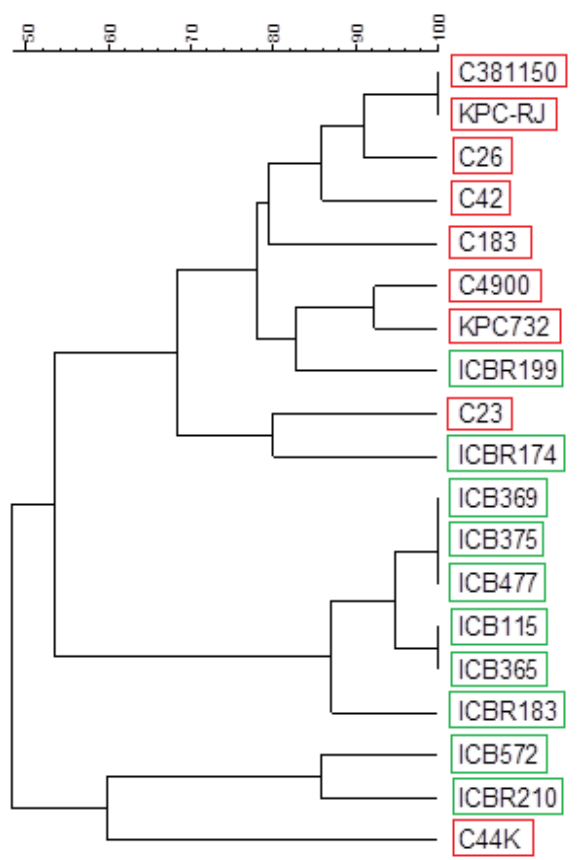

Calculado pelo método UPGMA e coeficiente de Dice com tolerância de $2 \%$.

[] Amostras clínicas e [] Amostras ambientais
Figura 5 - ERIC-PCR - Dendrograma demonstrando grau de similaridade entre amostras de Enterobacter sp.; Pluralibacter gergoviae e Kosakonia sp.

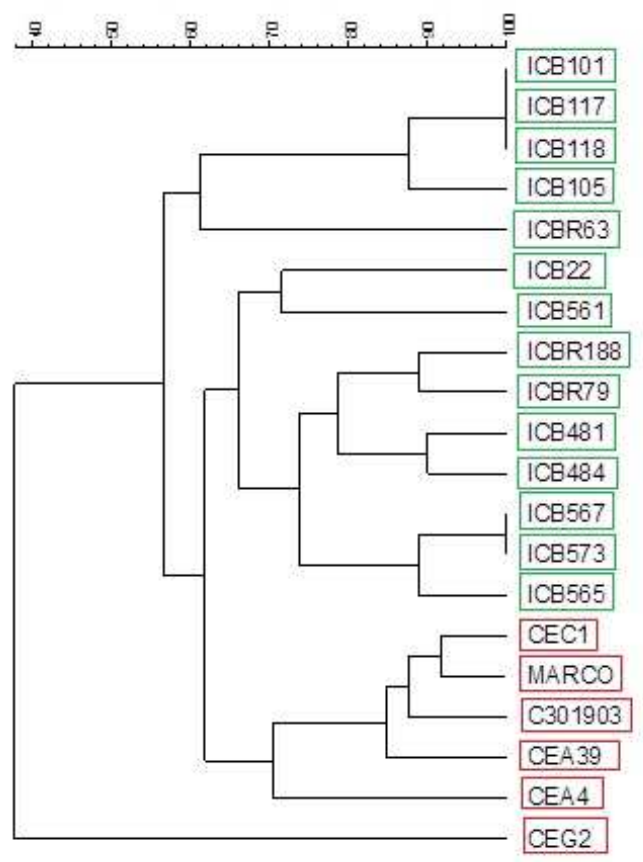

Calculado pelo método UPGMA e coeficiente de Dice com tolerância de $2 \%$.

[] Amostras clínicas e [] Amostras ambientais

Após a construção das árvores filogenéticas pode-se observar na figura 4, entre as amostras de Klebsiella sp., a formação de quatro grandes grupos. O primeiro é formado pelas sete amostras clínicas e uma amostra ambiental, C381150, KPC-RJ, C26, C42, C183, C4900, KPC732, ICBR199. O segundo grupo é formado por uma amostra clínica (C23) e uma ambiental (ICBR174). O terceiro é formado somente por amostras ambientais: ICB369, ICB375, ICB477, ICB115, ICB365 e ICBR183. E o último grupo é formado por duas amostras ambientais: ICB572 e ICBR210 e por uma amostra clínica: C44K. 
A árvore filogenética da figura 5 é formada por amostras identificadas como: Enterobacter sp.; Kosakonia sp. e Pluralibacter. E pode-se observar que as amostras de origem clínica se agrupam entre si, ficando distante das amostras de origem ambiental.

\subsection{Ensaio de redução de Acetileno}

A atividade da enzima nitrogenase foi analisada pelo método de redução de acetileno (ARA) (Pariona-Llanos, et al., 2010) e contagem de células viáveis por UFC (Unidades formadoras de colônias). Os valores de área obtidos através de cromatografia gasosa, UFC e curva padrão de etileno foram colocados em equação capaz de calcular a Atividade Específica da Enzima Nitrogenase. Os valores obtidos podem ser encontrados na figura 6.

Através deste experimento, pode-se observar que a nitrogenase estava ativa nas bactérias de origem ambiental, porém, também foi detectada em alguns isolados clínicos. Das 24 cepas ambientais testadas, 21 (87,5\%) apresentam atividade da enzima nitrogenase, enquanto, das 15 linhagens clínicas estudadas 3 (20\%) demonstraram atividade desta enzima. Todas as linhagens clínicas que possíam a capacidade de reduzir acetileno a etileno pertenciam ao gênero Klebsiella. Sendo a cepa C44K (clínica - origem veterinária) com maior valor encontrado entre elas. A linhagem ambiental que apresentou o maior valor (ICB484) pertence ao gênero Enterobacter.

A análise estatística (Figura 7) comprova que a atividade específica da Nitrogenase é maior nos isolados ambientais. 
Figura 6 - Ensaio de Redução de Acetileno

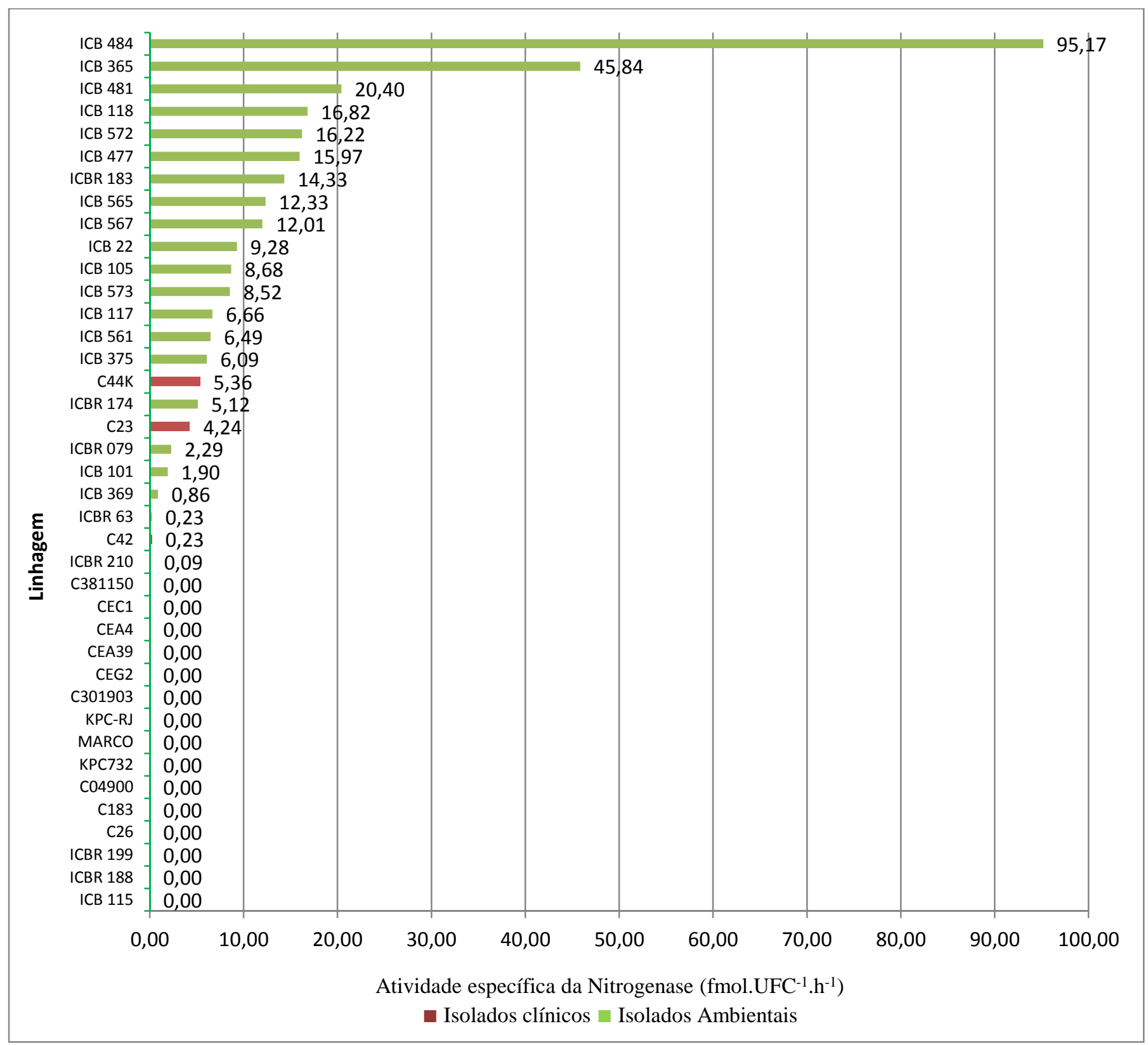

Figura 7 - Análise Estatística - Ensaio de redução de acetileno

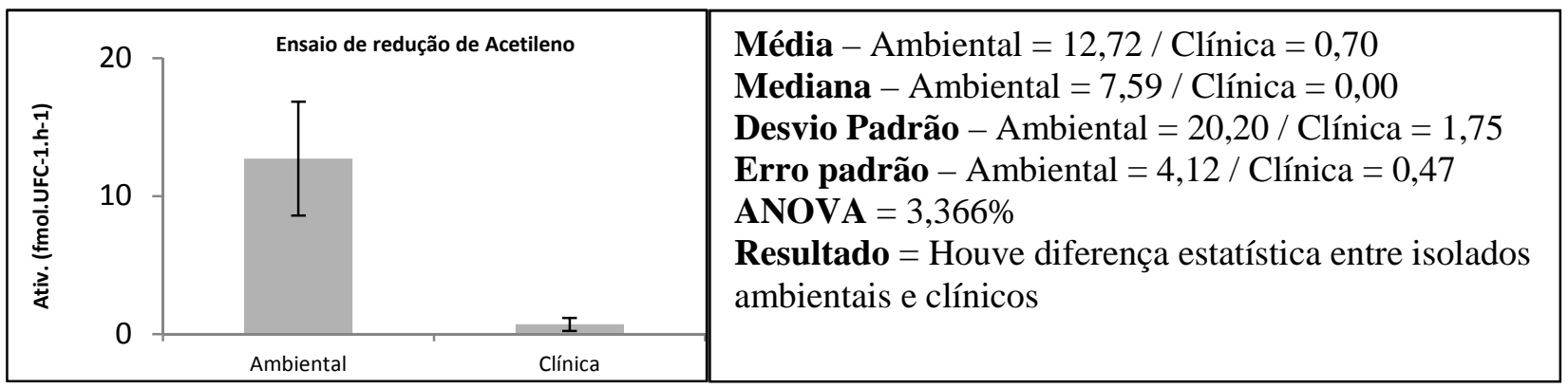




\subsection{Detecção do gene nifH}

Todas as linhagens foram submetidas a técnica de PCR com o iniciador Pol-r / Pol-f para verificar a presença do gene nifH. Das 24 amostras ambientais, 22 revelaram a presença do gene nifH. E das 15 amostras clínicas analisadas, 5 possuíam o gene nifH. As linhagens que apresentaram resultado negativo foram submetidas à técnica de PCR com os iniciadores PP-r / PP-f. Igualmente com estes iniciadores, as 2 amostras ambientais, não amplificaram o gene nifH e, das 10 amostras clínicas, uma amplificou (CEC1). Os resultados podem ser encontrados no quadro 8.

Quadro 8 - Detecção do gene nifH

\begin{tabular}{|c|c|c|c|c|}
\hline Linhag & Gênero & Origem & Pol-r e & PP-r e PP- \\
\hline ICB 22 & Kosakonia radicincitans & Ambiental & + & \\
\hline ICB 101 & Enterobacter sacchari & Ambiental & + & \\
\hline ICB 105 & Enterobacter sacchari & Ambiental & + & \\
\hline ICB 115 & Klebsiella $s p$ & Ambiental & + & \\
\hline ICB 117 & Enterobacter sacchari & Ambiental & + & \\
\hline ICB 118 & Enterobacter sacchari & Ambiental & + & \\
\hline ICB 365 & Klebsiella sp. & Ambiental & + & \\
\hline ICB 369 & Klebsiella sp. & Ambiental & + & \\
\hline ICB 375 & Klebsiella sp. & Ambiental & + & \\
\hline ICB 477 & Klebsiella sp. & Ambiental & + & \\
\hline ICB 481 & Enterobacter sp. & Ambiental & - & - \\
\hline ICB 484 & Enterobacter sp. & Ambiental & - & - \\
\hline ICB 561 & Kosakonia radicincitans & Ambiental & + & \\
\hline ICB 565 & Kosakonia radicincitans & Ambiental & + & \\
\hline ICB 567 & Kosakonia radicincitans & Ambiental & + & \\
\hline ICB 572 & Klebsiella variicola & Ambiental & + & \\
\hline ICB 573 & Kosakonia radicincitans & Ambiental & + & \\
\hline ICBR 63 & Enterobacter sp. & Ambiental & + & \\
\hline ICBR 79 & Kosakonia radicincitans & Ambiental & + & \\
\hline ICBR 174 & Klebsiella variicola & Ambiental & + & \\
\hline ICBR 183 & Klebsiella variicola & Ambiental & + & \\
\hline ICBR 188 & Enterobacter sp. & Ambiental & + & \\
\hline ICBR 199 & Klebsiella sp. & Ambiental & + & \\
\hline ICBR 210 & Enterobacter sp. & Ambiental & + & \\
\hline $\mathrm{C} 23$ & Klebsiella pneumoniae & Clínica & + & \\
\hline $\mathrm{C} 26$ & Klebsiella pneumoniee & Clínica & - & - \\
\hline C183 & Klebsiella pneumoniae & Clínica & - & - \\
\hline C42 & Klebsiella pneumoniae & Clínica & + & \\
\hline C4900 & Klebsiella pneumoniae & Clínica & - & - \\
\hline KPC732 & Klebsiella pneumoniae & Clínica & - & - \\
\hline MARCO & Enterobacter sp. & Clínica & + & \\
\hline KPC-RJ & Klebsiella pneumoniae & Clínica & + & \\
\hline C301903 & Enterobacter $s p$ & Clínica & - & - \\
\hline CEG2 & Pluralibacter gergoviae & Clínica & - & - \\
\hline CEA39 & Enterobacter aerogenes & Clínica & - & - \\
\hline CEA4 & Enterobacter aerogenes & Clínica & - & - \\
\hline CEC1 & Enterobacter sp. & Clínica & - & + \\
\hline C381150 & Klebsiella pneumoniae & Clínica & - & - \\
\hline $\mathrm{C} 44 \mathrm{~K}$ & Klebsiella variicola & Clínica & + & \\
\hline
\end{tabular}




\subsection{Produção de Etileno}

A produção de etileno foi detectada em cerca de $93 \%$ de todas as amostras. A maioria apresentou aumento da quantidade do fitormônio entre 144 e $220 \mathrm{~h}$. A figura 8 mostra que as maiores quantidades de etileno foram liberadas pelas amostras ambientais. A análise estatística não revelou diferenças significativas entre amostras ambientais e clínicas na produção de etileno (figura 9). A linhagem ambiental que produziu mais etileno (ICB101) pertence ao gênero Kosakonia, enquanto a linhagem clínica que mais produziu foi KPC732, que pertence ao gênero Klebsiella.

Figura 8 - Produção de etileno

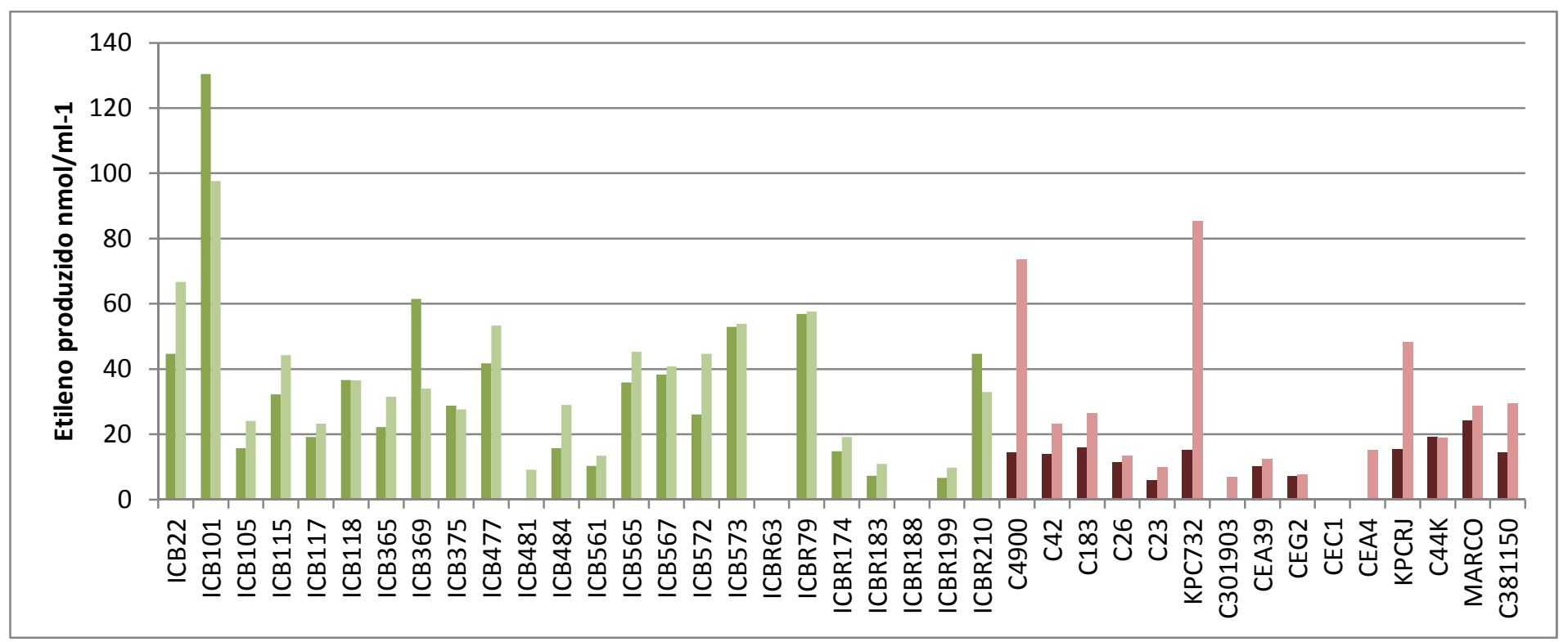

— Ambiental 144h; Ambiental 200h; - Clínica 144h; —Clínica 200h

Figura 9 - Análise Estatística - Produção de Etileno

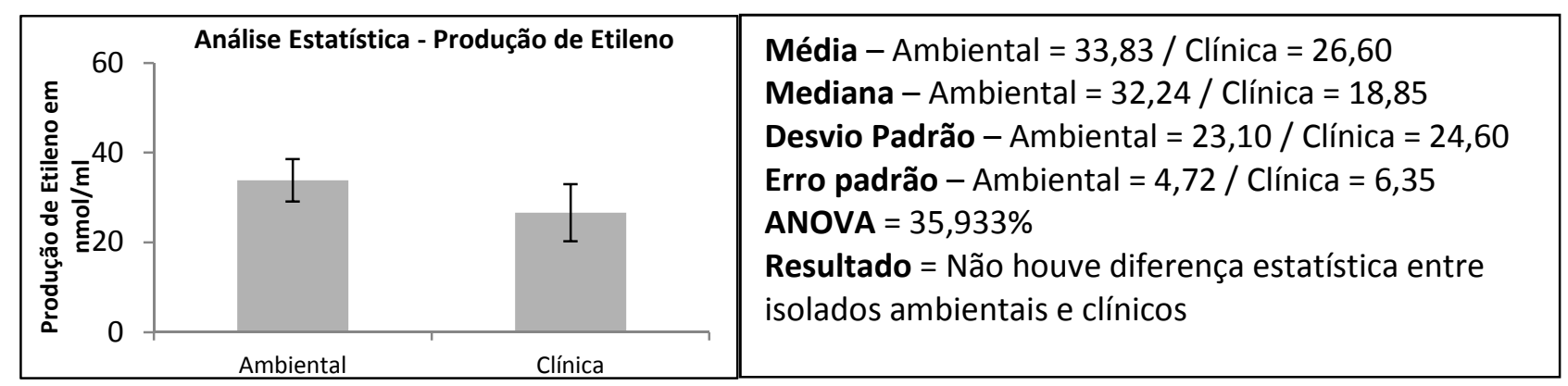




\subsection{Sensibilidade a antibióticos por difusão em disco e Concentração Inibitória Mínima}

Após incubação das amostras com os respectivos discos com os antibióticos testados, pode-se verificar a formação de halos de inibição (figuras 10 e 11). Os halos foram medidos e, de acordo com os dados de uma tabela padrão, para os antibióticos testados, a cepa foi considerada sensível (S), intermediária (I) ou resistente (R). Os valores de referência podem ser encontrados no quadro 9. Os dados da determinação do perfil qualitativo de resistência a antibióticos, por meio do método de difusão em disco, mostram a proporção de linhagens ambientais ou clínicas que apresentaram resistência aos antibióticos (figura 12). Os resultados individuais para cada antibiótico podem ser encontrados nos quadros 10 a 13.

Figura 10 - Teste de difusão em disco Amostra de origem ambiental ICB369

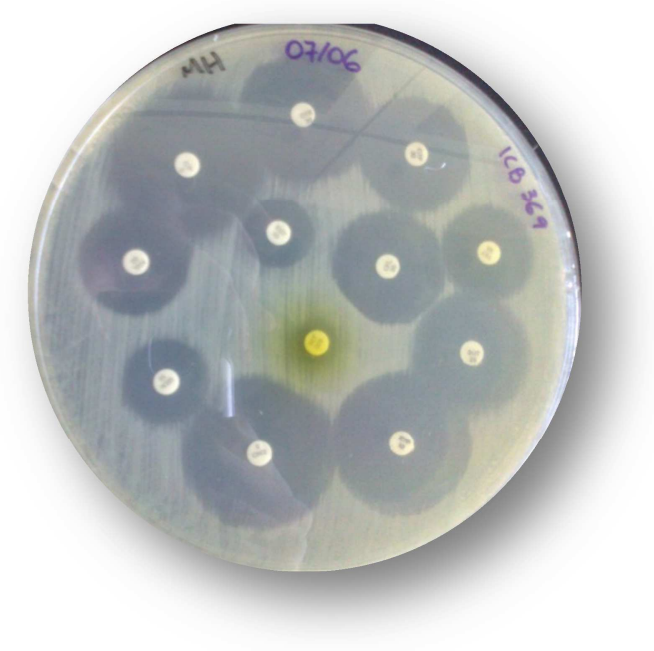

Figura 11 - Teste de difusão em disco Amostra de origem clínica C183

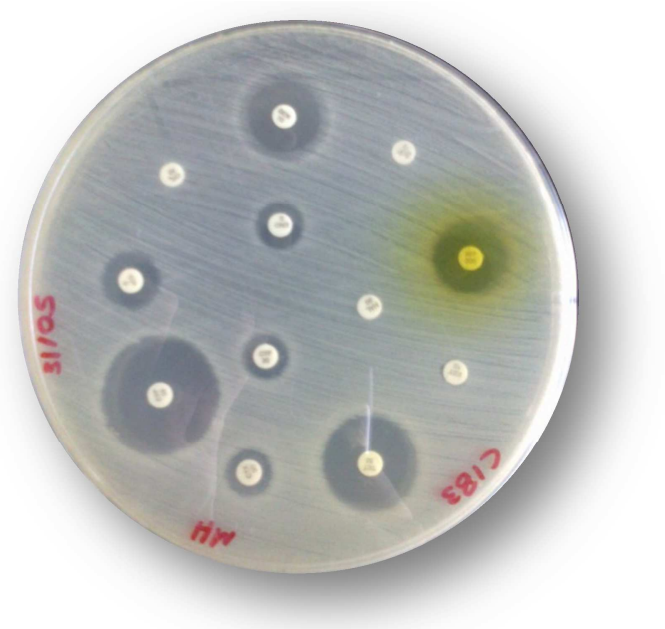

As amostras ambientais mostraram-se mais sensíveis em onze, dos doze antibióticos testados. Apenas quando expostas ao antibiótico Nitrofurantoína, foram equivalentes (figura 14). Oitenta e sete por cento das amostras clínicas foram resistentes aos antibióticos: Cefalotina, Cefotaxima e Ácido Nalidíxico; o isolado clínico CEG2 é resistente a todos os antibióticos testados. Os isolados ambientais: ICB115, ICB117, ICB365, ICB375 e ICB477 foram sensíveis a todos antibióticos.

Todas as amostras ambientais se mostraram sensíveis aos antibióticos: Gentamicina, Estreptomicina, Cefotaxima, Enrofloxacina, Cotrimoxazol, Ciprofloxacina e Ceftiofur. 
Figura 10 - Proporção de amostras resistentes de isolados ambientais e clínicos quando expostos a diferentes antibióticos

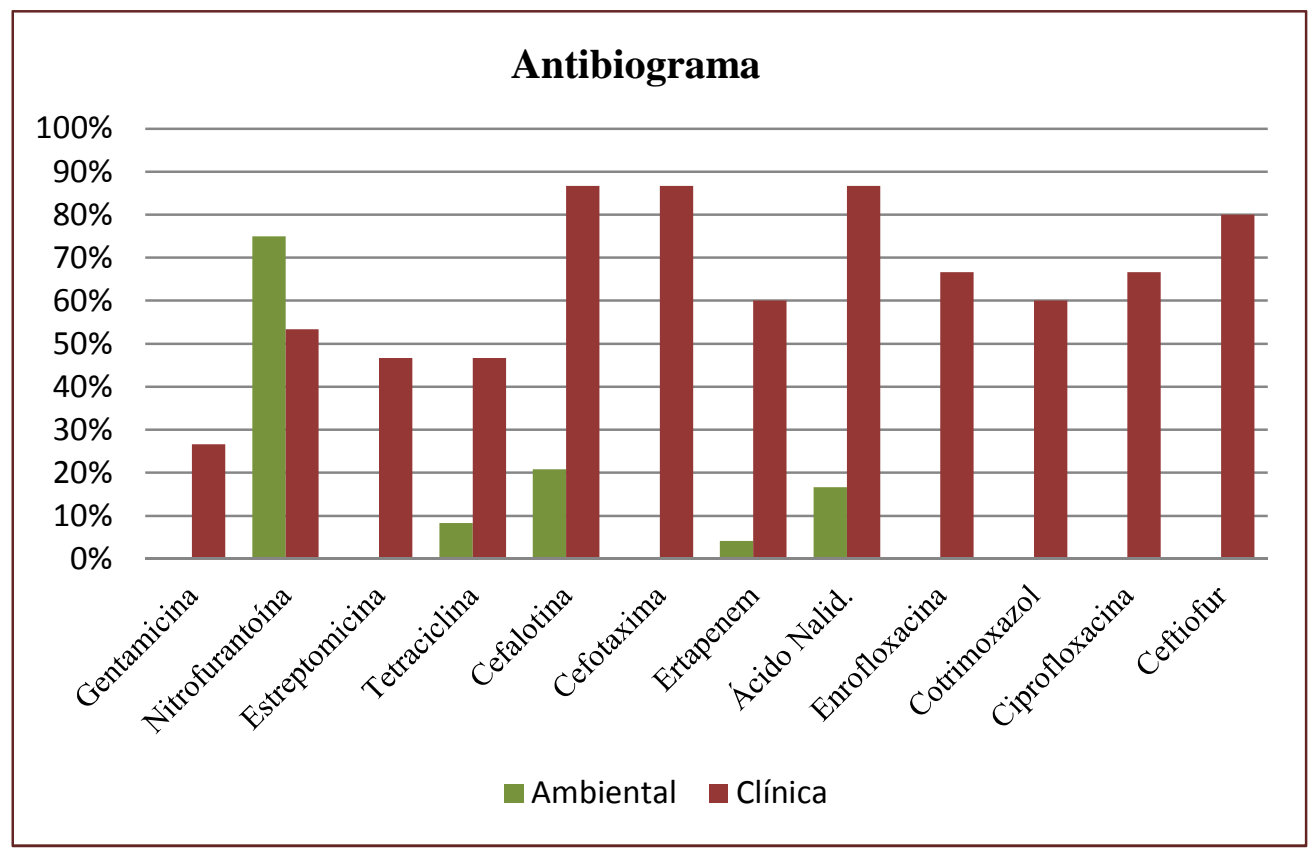

Figura 11 - Análise estatística dos resultados de resistência a diferentes antibióticos

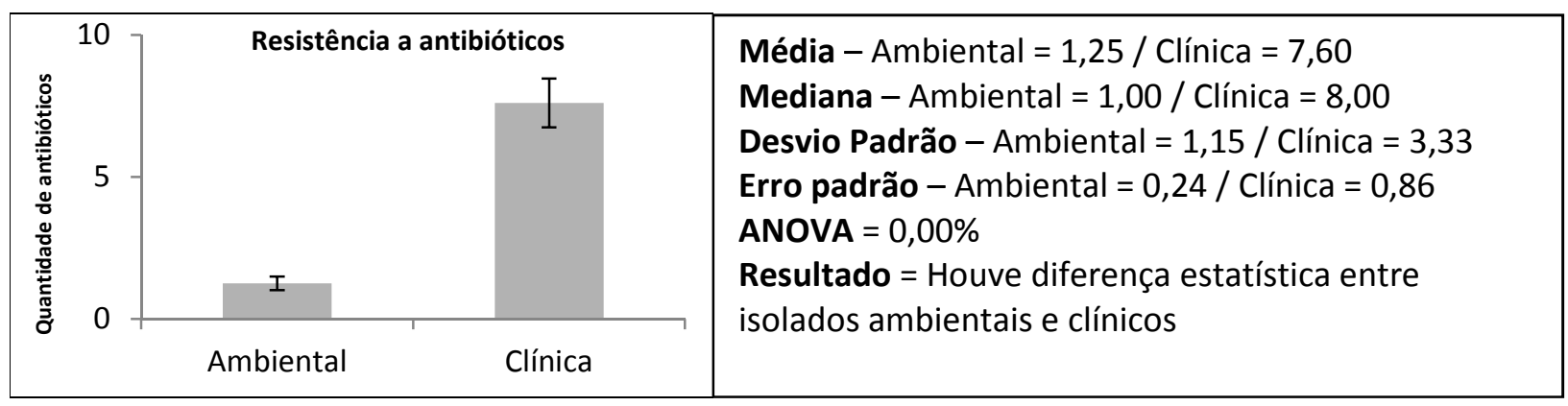

Figura 12 - Análise estatística. CIM - Nitrofurantoína

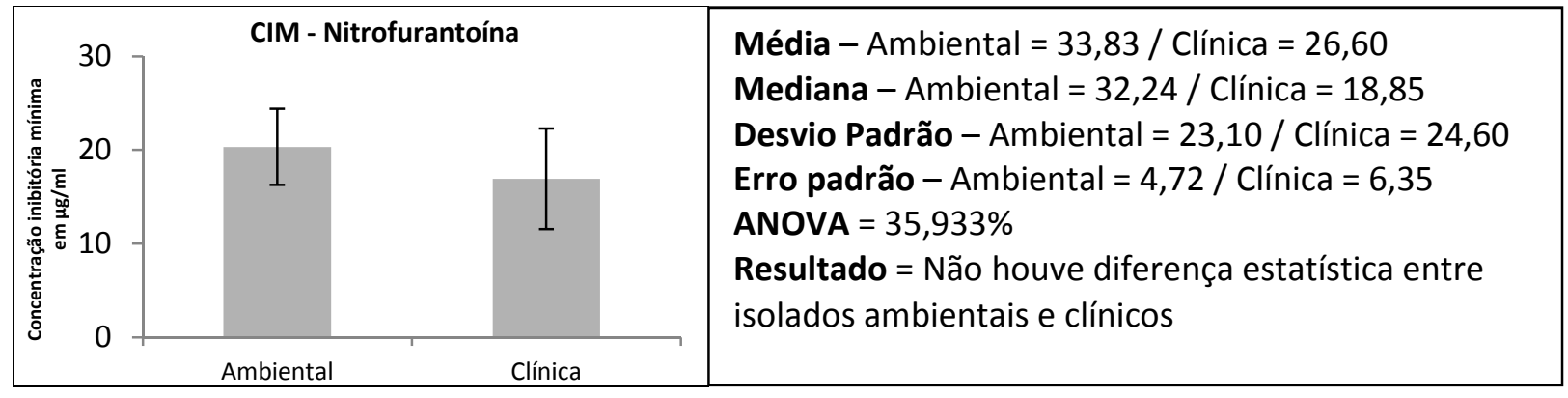

As amostras que apresentaram um halo de inibição considerado intermediário (I) ou resistente (R), de acordo com as orientações do CLSI, então, foram submetidas à avaliação da concentração mínima inibitória (CIM) através da utilização de fitas E-TEST. (Bölmstrom, 1993). As concentrações inibitórias mínimas para as amostras de origem clínica foram maiores que as amostras ambientais. Somente para o antibiótico Nitrofurantoína a CIM foi 
similar às amostras clínicas. Os resultados individuais do teste de difusão em disco e concentração inibitória mínima obtidos para cada antibiótico podem ser encontrados nos quadros 10 a 13.

Quadro 9 - Valores de referência para o teste de difusão em disco.

\begin{tabular}{|c|c|c|c|}
\hline Antibiótico & Sensível (S) & Intermediário (I) & $\underline{\text { Resistente (R) }}$ \\
\hline Gentamicina & $\leq 12 \mathrm{~mm}$ & $13-14 \mathrm{~mm}$ & $\geq 15 \mathrm{~mm}$ \\
\hline Nitrofurantoína & $\leq 14 \mathrm{~mm}$ & $15-16 \mathrm{~mm}$ & $\geq 17 \mathrm{~mm}$ \\
\hline Estreptomicina & $\leq 11 \mathrm{~mm}$ & $12-14 \mathrm{~mm}$ & $\geq 15 \mathrm{~mm}$ \\
\hline Tetraciclina & $\leq 14 \mathrm{~mm}$ & $15-18 \mathrm{~mm}$ & $\geq 19 \mathrm{~mm}$ \\
\hline Cefalotina & $\leq 14 \mathrm{~mm}$ & $15-17 \mathrm{~mm}$ & $\geq 18 \mathrm{~mm}$ \\
\hline Cefotaxima & $\leq 14 \mathrm{~mm}$ & $15-22 \mathrm{~mm}$ & $\geq 23 \mathrm{~mm}$ \\
\hline Ertapenem & $\leq 19 \mathrm{~mm}$ & $20-22 \mathrm{~mm}$ & $\geq 23 \mathrm{~mm}$ \\
\hline Ácido Nalidíxico & $\leq 13 \mathrm{~mm}$ & $14-18 \mathrm{~mm}$ & $\geq 19 \mathrm{~mm}$ \\
\hline Enrofloxacina & $\leq 16 \mathrm{~mm}$ & $17-22 \mathrm{~mm}$ & $\geq 23 \mathrm{~mm}$ \\
\hline Cotrinoxazol & $\leq 10 \mathrm{~mm}$ & $11-15 \mathrm{~mm}$ & $\geq 16 \mathrm{~mm}$ \\
\hline Ciprofloxacina & $\leq 15 \mathrm{~mm}$ & $16-20 \mathrm{~mm}$ & $\geq 21 \mathrm{~mm}$ \\
\hline Ceftiofur & $\leq 17 \mathrm{~mm}$ & $18-20 \mathrm{~mm}$ & $\geq 21 \mathrm{~mm}$ \\
\hline
\end{tabular}

*Valores de referência obtidos através das normas do CLSI 
Quadro 10 - Resultados individuais para sensibilidade a antibióticos em amostras de origem ambiental (pt. 1)

\begin{tabular}{|c|c|c|c|c|c|c|c|c|c|c|c|c|}
\hline & $\begin{array}{c}\text { ICB } 22 \\
\text { Kosakonia }\end{array}$ & $\begin{array}{c}\text { ICB } 101 \\
\text { Enterobacter }\end{array}$ & $\begin{array}{c}\text { ICB } 105 \\
\text { Enterobacter }\end{array}$ & $\begin{array}{c}\text { ICB } 115 \\
\text { Klebsiella }\end{array}$ & $\begin{array}{c}\text { ICB } 117 \\
\text { Enterobacter }\end{array}$ & $\begin{array}{c}\text { ICB } 118 \\
\text { Enterobacter }\end{array}$ & $\begin{array}{c}\text { ICB } 365 \\
\text { Klebsiella }\end{array}$ & $\begin{array}{c}\text { ICB } 369 \\
\text { Klebsiella }\end{array}$ & $\begin{array}{c}\text { ICB } 375 \\
\text { Klebsiella }\end{array}$ & $\begin{array}{c}\text { ICB } 477 \\
\text { Klebsiella }\end{array}$ & $\begin{array}{c}\text { ICB } 481 \\
\text { Enterobacter }\end{array}$ & $\begin{array}{c}\text { ICB } 484 \\
\text { Enterobacter }\end{array}$ \\
\hline Gentamicina & DD 20mm(S) & $\mathrm{DD} 20 \mathrm{~mm}(\mathrm{~S})$ & DD 20mm(S) & $\mathrm{DD} 20 \mathrm{~mm}(\mathrm{~S})$ & DD 20mm(S) & DD $18 \mathrm{~mm}(\mathrm{~S})$ & $20 \mathrm{~mm}(\mathrm{~S})$ & 20mm (S) & $21 \mathrm{~mm}(\mathrm{~S})$ & $19 \mathrm{~mm}(\mathrm{~S})$ & $18 \mathrm{~mm}(\mathrm{~S})$ & 20mm (S) \\
\hline Nitrofurantoína & $\begin{array}{l}\text { DD } 7 \mathrm{~mm}(\mathrm{R}) \\
\text { CIM } 32,0\end{array}$ & $\begin{array}{l}\text { DD } 15 \mathrm{~mm} \text { (I) } \\
\text { CIM } 8,0\end{array}$ & $\begin{array}{l}\text { DD13mm(R) } \\
\text { CIM 32,0 }\end{array}$ & DD 20mm(S) & DD 13mm(S) & $\begin{array}{l}\text { DD12mm(R) } \\
\text { CIM } 32,0\end{array}$ & $22 \mathrm{~mm}(\mathrm{~S})$ & $\begin{array}{l}\text { DD10mm(R) } \\
\text { CIM 64,0 }\end{array}$ & $21 \mathrm{~mm}(\mathrm{~S})$ & $23 \mathrm{~mm}(\mathrm{~S})$ & $\begin{array}{l}\text { DD } 19 \mathrm{~mm} \text { (I) } \\
\text { CIM } 32,0\end{array}$ & $21 \mathrm{~mm}(\mathrm{~S})$ \\
\hline Estreptomicina & DD 19mm(S) & DD $18 \mathrm{~mm}(\mathrm{~S})$ & DD $18 \mathrm{~mm}(\mathrm{~S})$ & DD 15mm(S) & $\mathrm{DD} 18 \mathrm{~mm}(\mathrm{~S})$ & DD 18mm(S) & $18 \mathrm{~mm}(\mathrm{~S})$ & $18 \mathrm{~mm}(\mathrm{~S})$ & $17 \mathrm{~mm}(\mathrm{~S})$ & $18 \mathrm{~mm}(\mathrm{~S})$ & $18 \mathrm{~mm}(\mathrm{~S})$ & $17 \mathrm{~mm}(\mathrm{~S})$ \\
\hline Tetraciclina & DD 25mm(S) & DD 25mm(S) & DD 27mm(S) & DD 25mm(S) & DD 30mm(S) & DD 30mm(S) & $27 \mathrm{~mm}(\mathrm{~S})$ & 26mm (S) & $25 \mathrm{~mm}(\mathrm{~S})$ & $23 \mathrm{~mm}(\mathrm{~S})$ & $25 \mathrm{~mm}(\mathrm{~S})$ & $22 \mathrm{~mm}(\mathrm{~S})$ \\
\hline Cefalotina & DD 30mm(S) & DD 30mm(S) & DD 30mm(S) & DD 27mm(S) & DD 30mm(S) & DD 30mm(S) & $29 \mathrm{~mm}(\mathrm{~S})$ & $28 \mathrm{~mm}(\mathrm{~S})$ & $29 \mathrm{~mm}(\mathrm{~S})$ & $27 \mathrm{~mm}(\mathrm{~S})$ & $\begin{array}{l}\text { DD 7mm (R) } \\
\text { CIM > } 256,0\end{array}$ & $\begin{array}{c}\text { DD1 } 1 \mathrm{~mm}(\mathrm{R}) \\
\text { CIM } 1,5\end{array}$ \\
\hline Cefotaxima & $\mathrm{DD} 40 \mathrm{~mm}(\mathrm{~S})$ & $\mathrm{DD} 40 \mathrm{~mm}(\mathrm{~S})$ & $\mathrm{DD} 40 \mathrm{~mm}(\mathrm{~S})$ & DD 35mm(S) & $\mathrm{DD} 40 \mathrm{~mm}(\mathrm{~S})$ & $\mathrm{DD} 40 \mathrm{~mm}(\mathrm{~S})$ & $38 \mathrm{~mm}(\mathrm{~S})$ & $35 \mathrm{~mm}(\mathrm{~S})$ & $36 \mathrm{~mm}(\mathrm{~S})$ & $35 \mathrm{~mm}(\mathrm{~S})$ & $35 \mathrm{~mm}(\mathrm{~S})$ & $33 \mathrm{~mm}(\mathrm{~S})$ \\
\hline Ertapenem & $\mathrm{DD} 40 \mathrm{~mm}(\mathrm{~S})$ & $\mathrm{DD} 40 \mathrm{~mm}(\mathrm{~S})$ & $\mathrm{DD} 40 \mathrm{~mm}(\mathrm{~S})$ & DD 35mm(S) & DD 35mm(S) & DD 39mm(S) & $33 \mathrm{~mm}(\mathrm{~S})$ & 36mm (S) & $31 \mathrm{~mm}(\mathrm{~S})$ & $35 \mathrm{~mm}(\mathrm{~S})$ & 30mm (S) & 33mm (S) \\
\hline $\begin{array}{c}\text { Ácido } \\
\text { Nalidíxico }\end{array}$ & $\mathrm{DD} 25 \mathrm{~mm}(\mathrm{~S})$ & $\mathrm{DD} 28 \mathrm{~mm}(\mathrm{~S})$ & DD 30mm(S) & $\mathrm{DD} 25 \mathrm{~mm}(\mathrm{~S})$ & $\mathrm{DD} 24 \mathrm{~mm}(\mathrm{~S})$ & $\mathrm{DD} 28 \mathrm{~mm}(\mathrm{~S})$ & $25 \mathrm{~mm}(\mathrm{~S})$ & $26 \mathrm{~mm}(\mathrm{~S})$ & $25 \mathrm{~mm}(\mathrm{~S})$ & $26 \mathrm{~mm}(\mathrm{~S})$ & $\begin{array}{l}\text { DD } 14 \mathrm{~mm} \text { (I) } \\
\text { CIM } 4,0\end{array}$ & 20mm (S) \\
\hline Enrofloxacina & $\mathrm{DD} 40 \mathrm{~mm}(\mathrm{~S})$ & $\mathrm{DD} 42 \mathrm{~mm}(\mathrm{~S})$ & DD $41 \mathrm{~mm}(\mathrm{~S})$ & DD 30mm(S) & $\mathrm{DD} 45 \mathrm{~mm}(\mathrm{~S})$ & $\mathrm{DD} 40 \mathrm{~mm}(\mathrm{~S})$ & 30mm (S) & $40 \mathrm{~mm}(\mathrm{~S})$ & $31 \mathrm{~mm}(\mathrm{~S})$ & $28 \mathrm{~mm}(\mathrm{~S})$ & $25 \mathrm{~mm}(\mathrm{~S})$ & $32 \mathrm{~mm}(\mathrm{~S})$ \\
\hline Cotrinoxazol & DD 30mm(S) & $\mathrm{DD} 28 \mathrm{~mm}(\mathrm{~S})$ & DD $25 \mathrm{~mm}(\mathrm{~S})$ & $\mathrm{DD} 28 \mathrm{~mm}(\mathrm{~S})$ & DD 30mm(S) & $\mathrm{DD} 25 \mathrm{~mm}(\mathrm{~S})$ & 30mm (S) & $31 \mathrm{~mm}(\mathrm{~S})$ & $31 \mathrm{~mm}(\mathrm{~S})$ & 30mm (S) & $29 \mathrm{~mm}(\mathrm{~S})$ & $28 \mathrm{~mm}(\mathrm{~S})$ \\
\hline Ciprofloxacina & $\mathrm{DD} 45 \mathrm{~mm}(\mathrm{~S})$ & $\mathrm{DD} 40 \mathrm{~mm}(\mathrm{~S})$ & $\mathrm{DD} 43 \mathrm{~mm}(\mathrm{~S})$ & DD 30mm(S) & $\mathrm{DD} 40 \mathrm{~mm}(\mathrm{~S})$ & $\mathrm{DD} 40 \mathrm{~mm}(\mathrm{~S})$ & 30mm (S) & $35 \mathrm{~mm}(\mathrm{~S})$ & $32 \mathrm{~mm}(\mathrm{~S})$ & $29 \mathrm{~mm}(\mathrm{~S})$ & $25 \mathrm{~mm}(\mathrm{~S})$ & $32 \mathrm{~mm}(\mathrm{~S})$ \\
\hline Ceftiofur & DD 32mm(S) & DD $34 \mathrm{~mm}(\mathrm{~S})$ & DD 33mm(S) & $\mathrm{DD} 27 \mathrm{~mm}(\mathrm{~S})$ & $\mathrm{DD} 38 \mathrm{~mm}(\mathrm{~S})$ & DD 33mm(S) & 30mm (S) & $30 \mathrm{~mm}(\mathrm{~S})$ & $31 \mathrm{~mm}(\mathrm{~S})$ & $28 \mathrm{~mm}(\mathrm{~S})$ & $28 \mathrm{~mm}(\mathrm{~S})$ & $27 \mathrm{~mm}(\mathrm{~S})$ \\
\hline
\end{tabular}

Legenda - DD: Difusão em Disco e CIM: Concentração Inibitória Mínima 
Quadro 11 - Resultados individuais para sensibilidade a antibióticos em amostras de origem ambiental (pt. 2)

\begin{tabular}{|c|c|c|c|c|c|c|c|c|c|c|c|c|}
\hline & $\begin{array}{c}\text { ICB } 561 \\
\text { Kosakonia }\end{array}$ & $\begin{array}{c}\text { ICB } 565 \\
\text { Kosakonia }\end{array}$ & $\begin{array}{c}\text { ICB } 567 \\
\text { Kosakonia }\end{array}$ & $\begin{array}{c}\text { ICB } 572 \\
\text { Klebsiella }\end{array}$ & $\begin{array}{c}\text { ICB } 573 \\
\text { Kosakonia }\end{array}$ & $\begin{array}{c}\text { ICBR } 63 \\
\text { Enterobacter }\end{array}$ & $\begin{array}{c}\text { ICBR } 79 \\
\text { Kosakonia }\end{array}$ & $\begin{array}{l}\text { ICBR } 174 \\
\text { Klebsiella }\end{array}$ & $\begin{array}{l}\text { ICBR } 183 \\
\text { Klebsiella }\end{array}$ & $\begin{array}{c}\text { ICBR } 188 \\
\text { Enterobacter }\end{array}$ & $\begin{array}{l}\text { ICBR } 199 \\
\text { Klebsiella }\end{array}$ & $\begin{array}{l}\text { ICBR } 210 \\
\text { Enterobacter }\end{array}$ \\
\hline Gentamicina & $23 \mathrm{~mm}(\mathrm{~S})$ & $21 \mathrm{~mm}(\mathrm{~S})$ & $21 \mathrm{~mm}(\mathrm{~S})$ & $18 \mathrm{~mm}(\mathrm{~S})$ & $21 \mathrm{~mm}(\mathrm{~S})$ & $19 \mathrm{~mm}(\mathrm{~S})$ & 20mm (S) & 20mm (S) & $18 \mathrm{~mm}(\mathrm{~S})$ & $16 \mathrm{~mm}(\mathrm{~S})$ & 20mm (S) & 20mm (S) \\
\hline Nitrofurantoína & $\begin{array}{l}\text { DD } 7 \mathrm{~mm}(\mathrm{R}) \\
\text { CIM } 48,0\end{array}$ & $\begin{array}{l}\text { DD } 8 \mathrm{~mm}(\mathrm{R}) \\
\text { CIM } 64,0\end{array}$ & $\begin{array}{l}\text { DD } 10 \mathrm{~mm}(\mathrm{R}) \\
\text { CIM } 24,0\end{array}$ & $\begin{array}{l}\text { DD } 15 \mathrm{~mm} \text { (I) } \\
\text { CIM } 6,0\end{array}$ & $\begin{array}{c}\text { DD } 8 \mathrm{~mm}(\mathrm{R}) \\
\text { CIM } 32,0\end{array}$ & $\begin{array}{l}\text { DD } 12 \mathrm{~mm}(\mathrm{R}) \\
\text { CIM } 16,0\end{array}$ & $\begin{array}{l}\text { DD } 8 \mathrm{~mm}(\mathrm{R}) \\
\text { CIM } 8,0\end{array}$ & $\begin{array}{c}\text { DD 8mm (R) } \\
\text { CIM } 2,0\end{array}$ & $\begin{array}{l}\text { DD } 15 \mathrm{~mm} \text { (I) } \\
\text { CIM } 8,0\end{array}$ & $\begin{array}{l}\text { DD } 10 \mathrm{~mm}(\mathrm{R}) \\
\text { CIM } 32,0\end{array}$ & $\begin{array}{l}\text { DD } 12 \mathrm{~mm}(\mathrm{R}) \\
\text { CIM } 16,0\end{array}$ & $\begin{array}{c}\text { DD } 10 \mathrm{~mm}(\mathrm{R}) \\
\text { CIM } 32,0\end{array}$ \\
\hline Estreptomicina & 19mm (S) & 19mm (S) & $19 \mathrm{~mm}(\mathrm{~S})$ & 17mm (S) & 19mm (S) & 15mm (S) & $35 \mathrm{~mm}(\mathrm{~S})$ & $15 \mathrm{~mm}(\mathrm{~S})$ & $16 \mathrm{~mm}(\mathrm{~S})$ & $15 \mathrm{~mm}(\mathrm{~S})$ & $15 \mathrm{~mm}(\mathrm{~S})$ & $19 \mathrm{~mm}(\mathrm{~S})$ \\
\hline Tetraciclina & $31 \mathrm{~mm}(\mathrm{~S})$ & 28mm (S) & 27mm (S) & $23 \mathrm{~mm}(\mathrm{~S})$ & 26mm (S) & 20mm (S) & $25 \mathrm{~mm}(\mathrm{~S})$ & 27mm (S) & $23 \mathrm{~mm}(\mathrm{~S})$ & $\begin{array}{l}\text { DD } 15 \mathrm{~mm} \text { (I) } \\
\text { CIM } 3,0\end{array}$ & $\begin{array}{l}15 \mathrm{~mm}(\mathrm{I}) \\
\text { CIM } 2,0\end{array}$ & 29mm (S) \\
\hline Cefalotina & 35mm (S) & 27mm (S) & 30mm (S) & $23 \mathrm{~mm}(\mathrm{~S})$ & 29mm (S) & $\begin{array}{l}\text { DD } 6 \mathrm{~mm} \text { (R) } \\
\text { CIM >256,0 }\end{array}$ & 27mm (S) & 28mm (S) & $25 \mathrm{~mm}(\mathrm{~S})$ & $\begin{array}{l}\text { DD } 6 \mathrm{~mm}(\mathrm{R}) \\
\text { CIM }>256,0\end{array}$ & $\begin{array}{l}\text { DD } 6 m m \text { (R) } \\
\text { CIM >256,0 }\end{array}$ & 30mm (S) \\
\hline Cefotaxima & $41 \mathrm{~mm}(\mathrm{~S})$ & $35 \mathrm{~mm}(\mathrm{~S})$ & $38 \mathrm{~mm}(\mathrm{~S})$ & $35 \mathrm{~mm}(\mathrm{~S})$ & $35 \mathrm{~mm}(\mathrm{~S})$ & 30mm (S) & $35 \mathrm{~mm}(\mathrm{~S})$ & $35 \mathrm{~mm}(\mathrm{~S})$ & $35 \mathrm{~mm}(\mathrm{~S})$ & $27 \mathrm{~mm}(\mathrm{~S})$ & 30mm (S) & 40mm (S) \\
\hline Ertapenem & $43 \mathrm{~mm}(\mathrm{~S})$ & $40 \mathrm{~mm}(\mathrm{~S})$ & 40mm (S) & 30mm (S) & $40 \mathrm{~mm}(\mathrm{~S})$ & 30mm (S) & $\begin{array}{c}\text { DD } 17 \mathrm{~mm}(\mathrm{R}) \\
\text { CIM } 0,004\end{array}$ & 35mm (S) & 35mm (S) & 30mm (S) & 30mm (S) & 40mm (S) \\
\hline $\begin{array}{c}\text { Ácido } \\
\text { Nalidíxico }\end{array}$ & $31 \mathrm{~mm}(\mathrm{~S})$ & 29mm (S) & $26 \mathrm{~mm}(\mathrm{~S})$ & 20mm (S) & 30mm (S) & $\begin{array}{l}\text { DD } 14 \mathrm{~mm} \text { (I) } \\
\text { CIM } 6,0\end{array}$ & $25 \mathrm{~mm}(\mathrm{~S})$ & $25 \mathrm{~mm}(\mathrm{~S})$ & $22 \mathrm{~mm}(\mathrm{~S})$ & $\begin{array}{l}\text { DD } 15 \mathrm{~mm} \text { (I) } \\
\text { CIM } 4,0\end{array}$ & $\begin{array}{l}\text { DD } 11 \mathrm{~mm}(\mathrm{R}) \\
\text { CIM } 8,0\end{array}$ & $27 \mathrm{~mm}(\mathrm{~S})$ \\
\hline Enrofloxacina & $31 \mathrm{~mm}(\mathrm{~S})$ & 40mm (S) & 40mm (S) & 30mm (S) & 40mm (S) & 30mm (S) & 40mm (S) & 40mm (S) & $28 \mathrm{~mm}(\mathrm{~S})$ & 30mm (S) & 30mm (S) & 35mm (S) \\
\hline Cotrinoxazol & 35mm (S) & 34mm (S) & 30mm (S) & 30mm (S) & 38mm (S) & 22mm (S) & 30mm (S) & 30mm (S) & $25 \mathrm{~mm}(\mathrm{~S})$ & $23 \mathrm{~mm}(\mathrm{~S})$ & $23 \mathrm{~mm}(\mathrm{~S})$ & $31 \mathrm{~mm}(\mathrm{~S})$ \\
\hline Ciprofloxacina & 45mm (S) & 38mm (S) & $42 \mathrm{~mm}(\mathrm{~S})$ & 30mm (S) & 40mm (S) & $23 \mathrm{~mm}(\mathrm{~S})$ & 40mm (S) & $43 \mathrm{~mm}(\mathrm{~S})$ & 30mm (S) & $33 \mathrm{~mm}(\mathrm{~S})$ & 30mm (S) & 39mm (S) \\
\hline Ceftiofur & 39mm (S) & $29 \mathrm{~mm}(\mathrm{~S})$ & $33 \mathrm{~mm}(\mathrm{~S})$ & $28 \mathrm{~mm}(\mathrm{~S})$ & 30mm (S) & $23 \mathrm{~mm}(\mathrm{~S})$ & 30mm (S) & 30mm (S) & $25 \mathrm{~mm}(\mathrm{~S})$ & $25 \mathrm{~mm}(\mathrm{~S})$ & $25 \mathrm{~mm}(\mathrm{~S})$ & $33 \mathrm{~mm}(\mathrm{~S})$ \\
\hline
\end{tabular}

Legenda - DD: Difusão em Disco e CIM: Concentração Inibitória Mínima 
Quadro 12 - Resultados individuais para sensibilidade a antibióticos em amostras de Klebsiella de origem clínica

\begin{tabular}{|c|c|c|c|c|c|c|c|c|c|}
\hline & $\begin{array}{c}\text { C23 } \\
\text { Klebsiella }\end{array}$ & $\begin{array}{c}\text { C26 } \\
\text { Klebsiella }\end{array}$ & $\begin{array}{c}\text { C183 } \\
\text { Klebsiella }\end{array}$ & $\begin{array}{c}\text { C42 } \\
\text { Klebsiella }\end{array}$ & $\begin{array}{c}\text { C4900 } \\
\text { Klebsiella }\end{array}$ & $\begin{array}{c}\text { KPC732 } \\
\text { Klebsiella }\end{array}$ & $\begin{array}{c}\text { KPC-RJ } \\
\text { Klebsiella }\end{array}$ & $\begin{array}{c}\text { C381150 } \\
\text { Klebsiella }\end{array}$ & $\begin{array}{c}\text { C44K } \\
\text { Klebsiella }\end{array}$ \\
\hline Gentamicina & 19mm (S) & 19mm (S) & $19 \mathrm{~mm}(\mathrm{~S})$ & $20 \mathrm{~mm}(\mathrm{~S})$ & 19mm (S) & $\begin{array}{c}\text { DD 6mm (R) } \\
\text { CIM } 1,0\end{array}$ & $\begin{array}{l}\text { DD 14mm (I) } \\
\text { CIM 1,0 }\end{array}$ & $20 \mathrm{~mm}(\mathrm{~S})$ & $20 \mathrm{~mm}(\mathrm{~S})$ \\
\hline Nitrofurantoína & $18 \mathrm{~mm}(\mathrm{~S})$ & $19 \mathrm{~mm}(\mathrm{~S})$ & $21 \mathrm{~mm}(\mathrm{~S})$ & $17 \mathrm{~mm}(\mathrm{~S})$ & $\begin{array}{l}\text { DD } 7 \mathrm{~mm}(\mathrm{R}) \\
\text { CIM } 48,0\end{array}$ & $25 \mathrm{~mm}(\mathrm{~S})$ & $\begin{array}{c}\text { DD 8mm (R) } \\
\text { CIM 64,0 }\end{array}$ & $\begin{array}{l}\text { DD 9mm (R) } \\
\text { CIM } 32,0\end{array}$ & DD $17 \mathrm{~mm}(\mathrm{~S})$ \\
\hline Estreptomicina & $\begin{array}{c}\text { DD 6mm (R) } \\
\text { CIM 128,0 }\end{array}$ & $15 \mathrm{~mm}(\mathrm{~S})$ & $\begin{array}{l}\text { DD 6mm (R) } \\
\text { CIM 96,0 }\end{array}$ & $\begin{array}{l}\text { DD } 6 \mathrm{~mm}(\mathrm{R}) \\
\text { CIM 64,0 }\end{array}$ & $15 \mathrm{~mm}(\mathrm{~S})$ & $\begin{array}{l}\text { DD 6mm (R) } \\
\text { CIM } 16,0\end{array}$ & DD 15mm (S) & $\begin{array}{l}\text { DD 9mm (R) } \\
\text { CIM } 12,0\end{array}$ & DD $16 \mathrm{~mm}(\mathrm{~S})$ \\
\hline Tetraciclina & $23 \mathrm{~mm}(\mathrm{~S})$ & $22 \mathrm{~mm}(\mathrm{~S})$ & $24 \mathrm{~mm}(\mathrm{~S})$ & $25 \mathrm{~mm}(\mathrm{~S})$ & $\begin{array}{l}\text { DD } 6 \mathrm{~mm} \text { (R) } \\
\text { CIM >256,0 }\end{array}$ & $26 \mathrm{~mm}(\mathrm{~S})$ & $\begin{array}{l}\text { DD } 6 \mathrm{~mm}(\mathrm{R}) \\
\mathrm{CIM}>256,0\end{array}$ & $\begin{array}{c}\text { DD } 11 \mathrm{~mm}(\mathrm{R}) \\
\text { CIM }>256,0\end{array}$ & DD $23 \mathrm{~mm}(\mathrm{~S})$ \\
\hline Cefalotina & $\begin{array}{l}\text { DD } 6 \mathrm{~mm}(\mathrm{R}) \\
\text { CIM >256,0 }\end{array}$ & $25 \mathrm{~mm}(\mathrm{~S})$ & $\begin{array}{l}\text { DD } 6 \mathrm{~mm}(\mathrm{R}) \\
\text { CIM }>256,0\end{array}$ & $\begin{array}{l}\text { DD } 6 \mathrm{~mm}(\mathrm{R}) \\
\mathrm{CIM}>256,0\end{array}$ & $\begin{array}{l}\text { DD } 6 \mathrm{~mm}(\mathrm{R}) \\
\text { CIM }>256,0\end{array}$ & $\begin{array}{l}\text { DD } 7 \mathrm{~mm}(\mathrm{R}) \\
\text { CIM }>256,0\end{array}$ & $\begin{array}{l}\text { DD } 6 \mathrm{~mm}(\mathrm{R}) \\
\text { CIM }>256,0\end{array}$ & $\begin{array}{c}\text { DD } 10 \mathrm{~mm} \text { (R) } \\
\text { CIM }>256,0\end{array}$ & DD $27 \mathrm{~mm}(\mathrm{~S})$ \\
\hline Cefotaxima & $\begin{array}{l}\text { DD } 11 \mathrm{~mm}(\mathrm{R}) \\
\text { CIM }>256,0\end{array}$ & $34 \mathrm{~mm}(\mathrm{~S})$ & $\begin{array}{l}\text { DD } 12 \mathrm{~mm}(\mathrm{R}) \\
\text { CIM }>256,0\end{array}$ & $\begin{array}{l}\text { DD } 9 \mathrm{~mm}(\mathrm{R}) \\
\mathrm{CIM}>256,0\end{array}$ & $\begin{array}{l}\text { DD } 6 \mathrm{~mm}(\mathrm{R}) \\
\text { CIM }>256,0\end{array}$ & $\begin{array}{l}\text { DD } 6 \mathrm{~mm} \text { (R) } \\
\text { CIM > } 256,0\end{array}$ & $\begin{array}{l}\text { DD } 6 \mathrm{~mm}(\mathrm{R}) \\
\mathrm{CIM}>256,0\end{array}$ & $\begin{array}{l}\text { DD } 6 \mathrm{~mm}(\mathrm{R}) \\
\text { CIM }>256,0\end{array}$ & DD $35 \mathrm{~mm}(\mathrm{~S})$ \\
\hline Ertapenem & $28 \mathrm{~mm}(\mathrm{~S})$ & $33 \mathrm{~mm}(\mathrm{~S})$ & $30 \mathrm{~mm}(\mathrm{~S})$ & $29 \mathrm{~mm}(\mathrm{~S})$ & $\begin{array}{l}\text { DD } 13 \mathrm{~mm}(\mathrm{R}) \\
\text { CIM } 2,0\end{array}$ & $\begin{array}{c}\text { DD } 13 \mathrm{~mm}(\mathrm{R}) \\
\text { CIM } 8,0\end{array}$ & $\begin{array}{l}\text { DD } 11 \mathrm{~mm} \\
\text { (R) CIM 4,0 }\end{array}$ & $\begin{array}{l}\text { DD } 14 \mathrm{~mm}(\mathrm{R}) \\
\text { CIM } 3,0\end{array}$ & DD $35 \mathrm{~mm}(\mathrm{~S})$ \\
\hline $\begin{array}{c}\text { Ácido } \\
\text { Nalidíxico }\end{array}$ & $\begin{array}{l}\text { DD } 6 \mathrm{~mm}(\mathrm{R}) \\
\mathrm{CIM}>256,0\end{array}$ & $\begin{array}{l}\text { DD } 6 \mathrm{~mm}(\mathrm{R}) \\
\mathrm{CIM}>256,0\end{array}$ & $\begin{array}{l}\text { DD } 6 \mathrm{~mm}(\mathrm{R}) \\
\mathrm{CIM}>256,0\end{array}$ & $\begin{array}{l}\text { DD } 6 \mathrm{~mm}(\mathrm{R}) \\
\mathrm{CIM}>256,0\end{array}$ & $\begin{array}{l}\text { DD } 6 \mathrm{~mm}(\mathrm{R}) \\
\text { CIM }>256,0\end{array}$ & $\begin{array}{l}\text { DD } 6 \mathrm{~mm}(\mathrm{R}) \\
\mathrm{CIM}>256,0\end{array}$ & $\begin{array}{l}\text { DD } 6 \mathrm{~mm} \text { (R) } \\
\text { CIM }>256,0\end{array}$ & $\begin{array}{c}\text { DD } 6 \mathrm{~mm} \text { (R) } \\
\text { CIM }>256,0\end{array}$ & DD 20mm (S) \\
\hline Enrofloxacina & $\begin{array}{l}\text { DD 8mm (R) } \\
\text { CIM } 12,0\end{array}$ & $\begin{array}{l}\text { DD } 18 \mathrm{~mm} \text { (I) } \\
\text { CIM } 8,0\end{array}$ & $\begin{array}{l}\text { DD } 12 \mathrm{~mm}(\mathrm{R}) \\
\text { CIM } 32,0\end{array}$ & $\begin{array}{l}\text { DD } 6 \mathrm{~mm}(\mathrm{R}) \\
\text { CIM } 32,0\end{array}$ & $\begin{array}{l}\text { DD } 12 \mathrm{~mm}(\mathrm{R}) \\
\text { CIM } 32,0\end{array}$ & $\begin{array}{l}\text { DD 8mm (R) } \\
\text { CIM 32,0 }\end{array}$ & $\begin{array}{l}\text { DD } 6 \mathrm{~mm}(\mathrm{R}) \\
\text { CIM } 32,0\end{array}$ & $\begin{array}{l}\text { DD 8mm (R) } \\
\text { CIM 32,0 }\end{array}$ & DD 30mm (S) \\
\hline Cotrinoxazol & $\begin{array}{c}\text { DD 6mm (R) } \\
\text { CIM > 64,0 }\end{array}$ & $28 \mathrm{~mm}(\mathrm{~S})$ & $\begin{array}{c}\text { DD 6mm (R) } \\
\text { CIM > 64,0 }\end{array}$ & $\begin{array}{c}\text { DD } 6 \mathrm{~mm}(\mathrm{R}) \\
\text { CIM }>64,0\end{array}$ & $\begin{array}{c}\text { DD } 6 \mathrm{~mm}(\mathrm{R}) \\
\text { CIM }>64,0\end{array}$ & $30 \mathrm{~mm}(\mathrm{~S})$ & $\begin{array}{c}\text { DD } 6 \mathrm{~mm}(\mathrm{R}) \\
\text { CIM > }\end{array}$ & $\begin{array}{c}\text { DD } 6 \mathrm{~mm}(\mathrm{R}) \\
\text { CIM }>64,0\end{array}$ & DD $27 \mathrm{~mm}(\mathrm{~S})$ \\
\hline Ciprofloxacina & $\begin{array}{l}\text { DD } 11 \mathrm{~mm} \\
\text { (R) CIM 3,0 }\end{array}$ & $21 \mathrm{~mm}(\mathrm{~S})$ & $\begin{array}{l}\text { DD } 14 \mathrm{~mm}(\mathrm{R}) \\
\text { CIM } 16,0\end{array}$ & $\begin{array}{l}\text { DD } 13 \mathrm{~mm} \\
\text { (R) CIM 32,0 }\end{array}$ & $\begin{array}{l}\text { DD } 7 \mathrm{~mm}(\mathrm{R}) \\
\text { CIM } 32,0\end{array}$ & $\begin{array}{l}\text { DD } 7 \mathrm{~mm}(\mathrm{R}) \\
\text { CIM }>256,0\end{array}$ & $\begin{array}{l}\text { DD } 7 \mathrm{~mm}(\mathrm{R}) \\
\text { CIM } 32,0\end{array}$ & $\begin{array}{l}\text { DD } 10 \mathrm{~mm}(\mathrm{R}) \\
\text { CIM } 32,0\end{array}$ & DD 30mm (S) \\
\hline Ceftiofur & $\begin{array}{c}\text { DD } 6 \mathrm{~mm}(\mathrm{R}) \\
\text { CIM }>64,0\end{array}$ & $27 \mathrm{~mm}(\mathrm{~S})$ & $\begin{array}{c}\text { DD } 12 \mathrm{~mm}(\mathrm{R}) \\
\text { CIM }>64,0\end{array}$ & $\begin{array}{c}\text { DD } 9 \mathrm{~mm}(\mathrm{R}) \\
\text { CIM }>64,0\end{array}$ & $\begin{array}{c}\text { DD 7mm (R) } \\
\text { CIM }>64,0\end{array}$ & $\begin{array}{c}\text { DD } 6 \mathrm{~mm}(\mathrm{R}) \\
\text { CIM }>64,0\end{array}$ & $\begin{array}{c}\text { DD } 6 \mathrm{~mm}(\mathrm{R}) \\
\text { CIM }>64,0\end{array}$ & $\begin{array}{c}\text { DD } 6 \mathrm{~mm}(\mathrm{R}) \\
\mathrm{CIM}>64,0\end{array}$ & DD $28 \mathrm{~mm}(\mathrm{~S})$ \\
\hline
\end{tabular}

Legenda - DD: Difusão em Disco e CIM: Concentração Inibitória Mínima 
Quadro 13 - Resultados individuais para sensibilidade a antibióticos em amostras de Enterobacter e Pluralibacter de origem clínica.

\begin{tabular}{|c|c|c|c|c|c|c|}
\hline & $\begin{array}{c}\text { MARCO } \\
\text { Enterobacter }\end{array}$ & $\begin{array}{c}\text { C301903 } \\
\text { Enterobacter }\end{array}$ & $\begin{array}{c}\text { CEG2 } \\
\text { Pluralibacter }\end{array}$ & $\begin{array}{c}\text { CEA39 } \\
\text { Enterobacter }\end{array}$ & $\begin{array}{c}\text { CEA4 } \\
\text { Enterobacter }\end{array}$ & $\begin{array}{c}\text { CEC1 } \\
\text { Enterobacter }\end{array}$ \\
\hline Gentamicina & $\begin{array}{l}\text { DD 8mm (R) } \\
\text { CIM } 0,50\end{array}$ & DD $20 \mathrm{~mm}(\mathrm{~S})$ & $\begin{array}{l}\text { DD 6mm(R) } \\
\text { CIM 16,0 }\end{array}$ & DD 18mm (S) & DD 18mm (S) & DD 15mm (S) \\
\hline Nitrofurantoína & $\begin{array}{l}\text { DD 6mm (R) } \\
\text { CIM } 6,0\end{array}$ & $\begin{array}{l}\text { DD } 15 \mathrm{~mm} \text { (I) } \\
\text { CIM } 24,0\end{array}$ & $\begin{array}{l}\text { DD } 8 \mathrm{~mm}(\mathrm{R}) \\
\text { CIM } 16,0\end{array}$ & $\begin{array}{l}\text { DD 6mm (R) } \\
\text { CIM 32,0 }\end{array}$ & $\begin{array}{l}\text { DD 7mm (R) } \\
\text { CIM 32,0 }\end{array}$ & DD 20mm (S) \\
\hline Estreptomicina & $\begin{array}{l}\text { DD } 13 \mathrm{~mm} \text { (I) } \\
\text { CIM } 6,0\end{array}$ & DD $18 \mathrm{~mm}(\mathrm{~S})$ & $\begin{array}{l}\text { DD } 6 m m(R) \\
\text { CIM } 128,0\end{array}$ & DD 15mm (S) & DD $15 \mathrm{~mm}(\mathrm{~S})$ & DD $15 \mathrm{~mm}(\mathrm{~S})$ \\
\hline Tetraciclina & $\begin{array}{l}\text { DD } 11 \mathrm{~mm} \\
\text { (R) CIM 2,0 }\end{array}$ & $\begin{array}{l}\text { DD } 13 \mathrm{~mm} \\
\text { (R) CIM 16,0 }\end{array}$ & $\begin{array}{l}\text { DD } 8 m m(R) \\
\text { CIM } 16,0\end{array}$ & $\begin{array}{l}\text { DD } 13 \mathrm{~mm} \\
\text { (R) CIM 8,0 }\end{array}$ & DD 20mm (S) & DD 20mm (S) \\
\hline Cefalotina & $\begin{array}{l}\text { DD } 6 \mathrm{~mm}(\mathrm{R}) \\
\mathrm{CIM}>256,0\end{array}$ & $\begin{array}{l}\text { DD } 6 \mathrm{~mm}(\mathrm{R}) \\
\text { CIM }>256,0\end{array}$ & $\begin{array}{l}\text { DD } 6 \mathrm{~mm}(\mathrm{R}) \\
\mathrm{CIM}>256,0\end{array}$ & $\begin{array}{l}\text { DD } 6 \mathrm{~mm}(\mathrm{R}) \\
\mathrm{CIM}>256,0\end{array}$ & $\begin{array}{l}\text { DD } 6 \mathrm{~mm}(\mathrm{R}) \\
\mathrm{CIM}>256,0\end{array}$ & $\begin{array}{l}\text { DD } 6 \mathrm{~mm}(\mathrm{R}) \\
\mathrm{CIM}>256,0\end{array}$ \\
\hline Cefotaxima & $\begin{array}{l}\text { DD 6mm (R) } \\
\text { CIM >256,0 }\end{array}$ & $\begin{array}{c}\text { DD 7mm (R) } \\
\text { CIM } 128,0\end{array}$ & $\begin{array}{l}\text { DD 6mm (R) } \\
\text { CIM >256,0 }\end{array}$ & DD $31 \mathrm{~mm}(\mathrm{~S})$ & $\begin{array}{l}\text { DD 6mm (R) } \\
\text { CIM >256,0 }\end{array}$ & $\begin{array}{l}\text { DD 6mm (R) } \\
\text { CIM >256,0 }\end{array}$ \\
\hline Ertapenem & $\begin{array}{l}\text { DD 6mm (R) } \\
\text { CIM 0,50 }\end{array}$ & $\mathrm{DD} 25 \mathrm{~mm}(\mathrm{~S})$ & $\begin{array}{l}\text { DD 6mm (R) } \\
\text { CIM 32,0 }\end{array}$ & $\begin{array}{l}\text { DD 6mm (R) } \\
\text { CIM 0,50 }\end{array}$ & $\begin{array}{l}\text { DD 6mm (R) } \\
\text { CIM 32,0 }\end{array}$ & $\begin{array}{l}\text { DD 12mm } \\
\text { (R) CIM 8,0 }\end{array}$ \\
\hline $\begin{array}{c}\text { Ácido } \\
\text { Nalidíxico }\end{array}$ & $\begin{array}{l}\text { DD } 15 \mathrm{~mm} \\
\text { (R) CIM 2,0 }\end{array}$ & $\begin{array}{l}\text { DD } 15 \mathrm{~mm} \text { (I) } \\
\text { CIM } 16,0\end{array}$ & $\begin{array}{l}\text { DD } 6 \mathrm{~mm}(\mathrm{R}) \\
\text { CIM >256,0 }\end{array}$ & $\begin{array}{l}\text { DD } 18 \mathrm{~mm} \text { (I) } \\
\text { CIM } 8,0\end{array}$ & $\begin{array}{l}\text { DD } 6 \mathrm{~mm} \text { (R) } \\
\text { CIM >256,0 }\end{array}$ & $\begin{array}{l}\text { DD } 6 \mathrm{~mm}(\mathrm{R}) \\
\text { CIM }>256,0\end{array}$ \\
\hline Enrofloxacina & DD 30mm (S) & $\mathrm{DD} 25 \mathrm{~mm}(\mathrm{~S})$ & $\begin{array}{l}\text { DD 6mm (R) } \\
\text { CIM 32,0 }\end{array}$ & DD 28mm (S) & $\begin{array}{l}\text { DD 6mm (R) } \\
\text { CIM 32,0 }\end{array}$ & $\mathrm{DD} 23 \mathrm{~mm}(\mathrm{~S})$ \\
\hline Cotrinoxazol & DD 20mm (S) & $\mathrm{DD} 24 \mathrm{~mm}(\mathrm{~S})$ & $\begin{array}{c}\text { DD 6mm (R) } \\
\text { CIM >64,0 }\end{array}$ & DD 22mm (S) & $\begin{array}{c}\text { DD 6mm (R) } \\
\text { CIM > }>4,0\end{array}$ & $\begin{array}{c}\text { DD 6mm (R) } \\
\text { CIM >64,0 }\end{array}$ \\
\hline Ciprofloxacina & DD 23mm (S) & $\mathrm{DD} 28 \mathrm{~mm}(\mathrm{~S})$ & $\begin{array}{l}\text { DD } 7 \mathrm{~mm}(\mathrm{R}) \\
\text { CIM } 32,0\end{array}$ & DD 30mm (S) & $\begin{array}{l}\text { DD } 6 m m(R) \\
\text { CIM } 32,0\end{array}$ & DD 30mm (S) \\
\hline Ceftiofur & $\begin{array}{l}\text { DD } 6 \mathrm{~mm}(\mathrm{R}) \\
\text { CIM }>64,0\end{array}$ & $\begin{array}{l}\text { DD } 11 \mathrm{~mm} \\
\text { (R) CIM } \\
>64,0\end{array}$ & $\begin{array}{l}\text { DD } 6 m m(R) \\
\text { CIM }>64,0\end{array}$ & DD 25mm (S) & $\begin{array}{l}\text { DD 6mm (R) } \\
\text { CIM >64,0 }\end{array}$ & $\begin{array}{c}\text { DD 6mm }(\mathrm{R}) \\
\text { CIM }>64,0\end{array}$ \\
\hline
\end{tabular}

Legenda - DD: Difusão em Disco e CIM: Concentração Inibitória Mínima 


\subsection{Transformação e teste de estabilidade de plasmídios}

Os resultados obtidos para o teste de difusão em disco das duas linhagens ambientais selvagens e transformadas, podem ser encontrados no quadro 14.

Quadro 14 - Transformação e teste de estabilidade dos plasmídios

\begin{tabular}{|c|c|c|c|c|}
\hline Antibiótico & $\begin{array}{c}\text { Linhagem de } \\
\text { Enterobacter } \\
\text { selvagem ICB117 }\end{array}$ & $\begin{array}{c}\text { Linhagem de } \\
\text { Enterobacter } \\
\text { transformada } \\
\text { ICB117+Plasmídio }\end{array}$ & $\begin{array}{c}\text { Linhagem de } \\
\text { Klebsiella selvagem } \\
\text { ICB } 375\end{array}$ & $\begin{array}{c}\text { Linhagem de } \\
\text { Klebsiella } \\
\text { transformada } \\
\text { ICB375+Plasmídio }\end{array}$ \\
\hline $\begin{array}{c}\text { Gentamicina } \\
\text { (Aminoglicosídeo) }\end{array}$ & $20 \mathrm{~mm}(\mathrm{~S})$ & $20 \mathrm{~mm}(\mathrm{~S})$ & $21 \mathrm{~mm}(\mathrm{~S})$ & $20 \mathrm{~mm}(\mathrm{~S})$ \\
\hline $\begin{array}{c}\text { Cefalotina } \\
\left(\beta \text {-Lactâmico } 1^{\mathrm{a}} \mathrm{g} .\right)\end{array}$ & $30 \mathrm{~mm}(\mathrm{~S})$ & $25 \mathrm{~mm}(\mathrm{~S})$ & $29 \mathrm{~mm}(\mathrm{~S})$ & $30 \mathrm{~mm}(\mathrm{~S})$ \\
\hline $\begin{array}{c}\text { Nitrofurantoína } \\
\text { (Nitrofurano) }\end{array}$ & $13 \mathrm{~mm}(\mathrm{~S})$ & $13 \mathrm{~mm}(\mathrm{~S})$ & $21 \mathrm{~mm}(\mathrm{~S})$ & $19 \mathrm{~mm}(\mathrm{~S})$ \\
\hline $\begin{array}{c}\text { Ácido Nalidíxico } \\
\text { (Quinolona) }\end{array}$ & $29 \mathrm{~mm}(\mathrm{~S})$ & $29 \mathrm{~mm}(\mathrm{~S})$ & $25 \mathrm{~mm}(\mathrm{~S})$ & $25 \mathrm{~mm}(\mathrm{~S})$ \\
\hline $\begin{array}{c}\text { Ciprofloxacina } \\
\text { (Quinolona) }\end{array}$ & $40 \mathrm{~mm}(\mathrm{~S})$ & $40 \mathrm{~mm}(\mathrm{~S})$ & $32 \mathrm{~mm}(\mathrm{~S})$ & $32 \mathrm{~mm}(\mathrm{~S})$ \\
\hline $\begin{array}{l}\text { Tetraciclina } \\
\text { (Tetraciclina) }\end{array}$ & $30 \mathrm{~mm}(\mathrm{~S})$ & $28 \mathrm{~mm}(\mathrm{~S})$ & $25 \mathrm{~mm}(\mathrm{~S})$ & $25 \mathrm{~mm}(\mathrm{~S})$ \\
\hline $\begin{array}{c}\text { Enrofloxacina } \\
\text { (Quinolona) }\end{array}$ & $45 \mathrm{~mm}(\mathrm{~S})$ & $40 \mathrm{~mm}(\mathrm{~S})$ & $31 \mathrm{~mm}(\mathrm{~S})$ & $31 \mathrm{~mm}(\mathrm{~S})$ \\
\hline $\begin{array}{c}\text { Ceftiofur } \\
\left(\beta \text {-Lactâmico } 3^{\mathrm{a}} \text { g. }\right)\end{array}$ & $38 \mathrm{~mm}(\mathrm{~S})$ & $35 \mathrm{~mm}(\mathrm{~S})$ & $31 \mathrm{~mm}(\mathrm{~S})$ & $29 \mathrm{~mm}(\mathrm{~S})$ \\
\hline $\begin{array}{c}\text { Ertapenem } \\
\text { (Carbapêmico) }\end{array}$ & $35 \mathrm{~mm}(\mathrm{~S})$ & $35 \mathrm{~mm}(\mathrm{~S})$ & $31 \mathrm{~mm}(\mathrm{~S})$ & $34 \mathrm{~mm}(\mathrm{~S})$ \\
\hline $\begin{array}{c}\text { Cotrinoxazol } \\
(\text { Sulfa })\end{array}$ & $30 \mathrm{~mm}(\mathrm{~S})$ & $25 \mathrm{~mm}(\mathrm{~S})$ & $31 \mathrm{~mm}(\mathrm{~S})$ & $30 \mathrm{~mm}(\mathrm{~S})$ \\
\hline $\begin{array}{c}\text { Estreptomicina } \\
\text { (Aminoglicosídeo) }\end{array}$ & $18 \mathrm{~mm}(\mathrm{~S})$ & $18 \mathrm{~mm}(\mathrm{~S})$ & $17 \mathrm{~mm}(\mathrm{~S})$ & $17 \mathrm{~mm}(\mathrm{~S})$ \\
\hline $\begin{array}{c}\text { Cefotaxima } \\
\left(\left(\beta \text {-Lactâmico } 3^{\mathrm{a} g .}\right)\right.\end{array}$ & $40 \mathrm{~mm}(\mathrm{~S})$ & $40 \mathrm{~mm}(\mathrm{~S})$ & $36 \mathrm{~mm}(\mathrm{~S})$ & $37 \mathrm{~mm}(\mathrm{~S})$ \\
\hline
\end{tabular}

Legenda: (S) Sensível

Tanto para a linhagem de Enterobacter ou Klebsiella não houve alterações significativas no perfil de resistência. Para todos os antibióticos testados, as linhagens permaneceram sensíveis.

Porém, pode-se observar que há uma diminuição no tamanho do halo de inibição para os antibióticos Gentamicina, Cefalotina, Nitrofurantoína, Tetraciclina, Enrofloxacina, Ceftiofur e Cotrimoxazol. 


\subsection{Solubilização de Fosfato inorgânico}

Todas as linhagens foram avaliadas quanto à solubilização de fosfato inorgânico em meio sólido $\mathrm{Ca}_{3}\left(\mathrm{PO}_{4}\right)_{2}$. A formação de um halo incolor em torno das colônias foi tomada como resultado positivo (figura 15).

Oitenta por cento de todas as amostras foram capazes de solubilizar fosfatos inorgânicos. Não houve diferença na solubilização quanto à origem (ambiental ou clínica) neste aspecto. Porém, em relação aos gêneros estudados, todas as linhagens do gênero Enterobacter e Pluralibacter produziram ácidos orgânicos capazes de solubilizar o fosfato inorgânico.

Os resultados de cada amostra podem ser verificados no quadro 15.

Figura 13 - Solubilização de fostato inorgânico - amostra de origem clínica CEG2

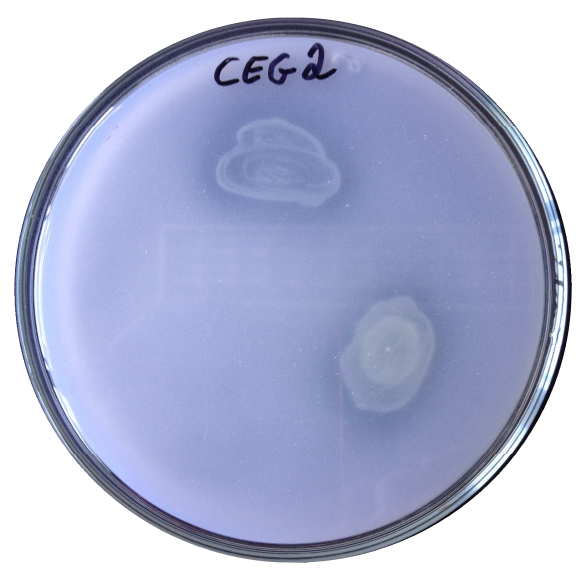

5.9 Determinação da atividade de endoglicanase e pectinase.

Todas as linhagens foram avaliadas quanto à produção de endoglicanase e pectinase. A formação de um halo amarelo em torno das colônias foi tomada como resultado positivo (figuras 16-19).

Um isolado ambiental ICBR 210 (Klebsiella) e um clínico CEG2 (Pluralibacter) foram capazes de produzir endoglicanase. Trinta e três por cento das amostras ambientais e $46 \%$ das amostras clínicas produziram pectinase. Os resultados individuais obtidos nestes experimentos podem ser encontrados no quadro 15. 
Figura 16 - Atividade pectinolítica Controles

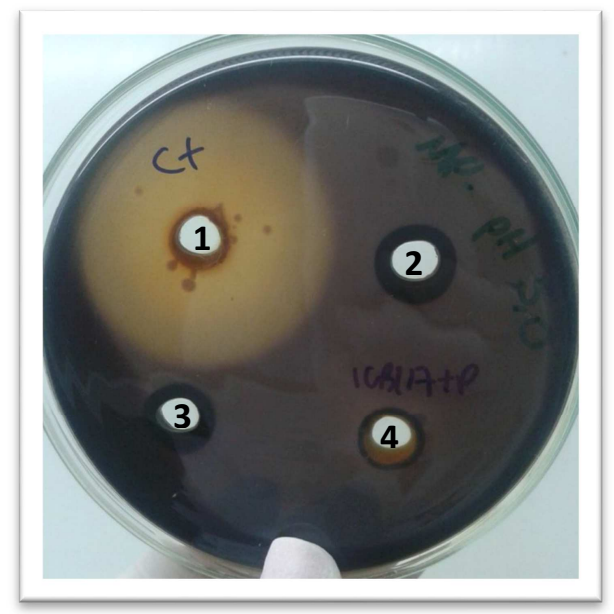

1 - Controle positivo; 2, 3 - vazio; 4 - Controle negativo

Figura 18 - Atividade CMC Controles

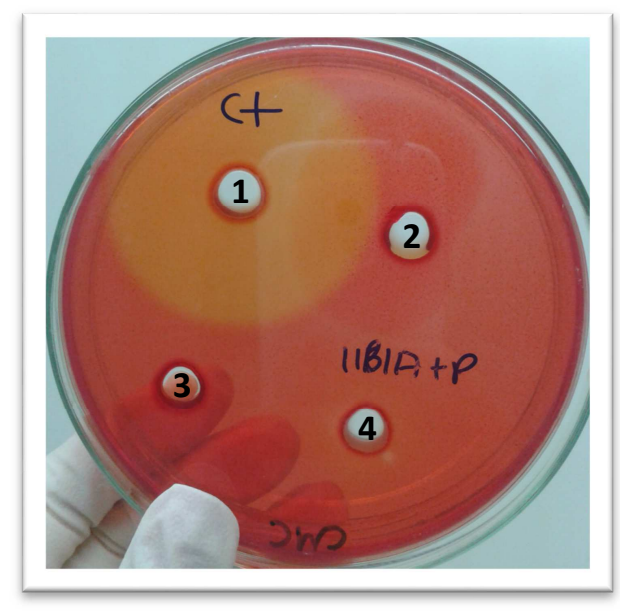

1 - Controle positivo; 2, 3 - vazio; 4 - Controle negativo
Figura 17 - Atividade pectinolítica Amostras

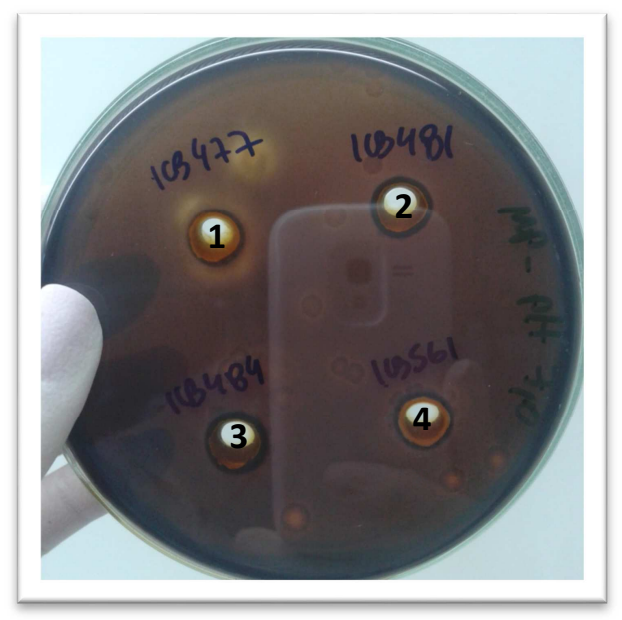

1 - ICB477 (+); 2 - ICB481 (-);

3 - ICB484 (-); 4 - ICB561 (-).

Figura 19 - Atividade CMC Amostras

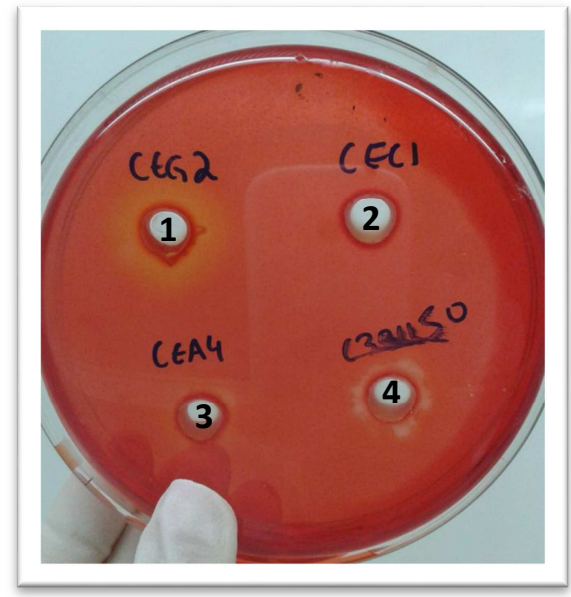

1 - CEG2 (+); 2 - CEC1 (-); 3 - CEA4 (-); 4 - C381150 (-).

Como controle positivo dos dois experimentos foi utilizada a cepa Xanthomonas citri e como controle negativo uma amostra utilizada em trabalhos anteriores (ICB117) e já conhecida como não produtora de pectinase e CMC. 


\subsection{Atividade hemolítica}

Todas as linhagens foram submetidas a uma avaliação da atividade hemolítica. As amostras que formaram um halo em torno da colônia foram classificadas como "Produtoras de hemolisina tipo $\alpha$ " ou "Produtoras de hemolisina tipo $\beta$ ", conforme exemplo mostrado nas figuras 20 e 21.

Figura 20 - Controle $\alpha$ hemólise

$$
\text { Figura } 21 \text { - Controle } \beta \text { hemólise }
$$

Figura 22 - Amostra Clínica C23
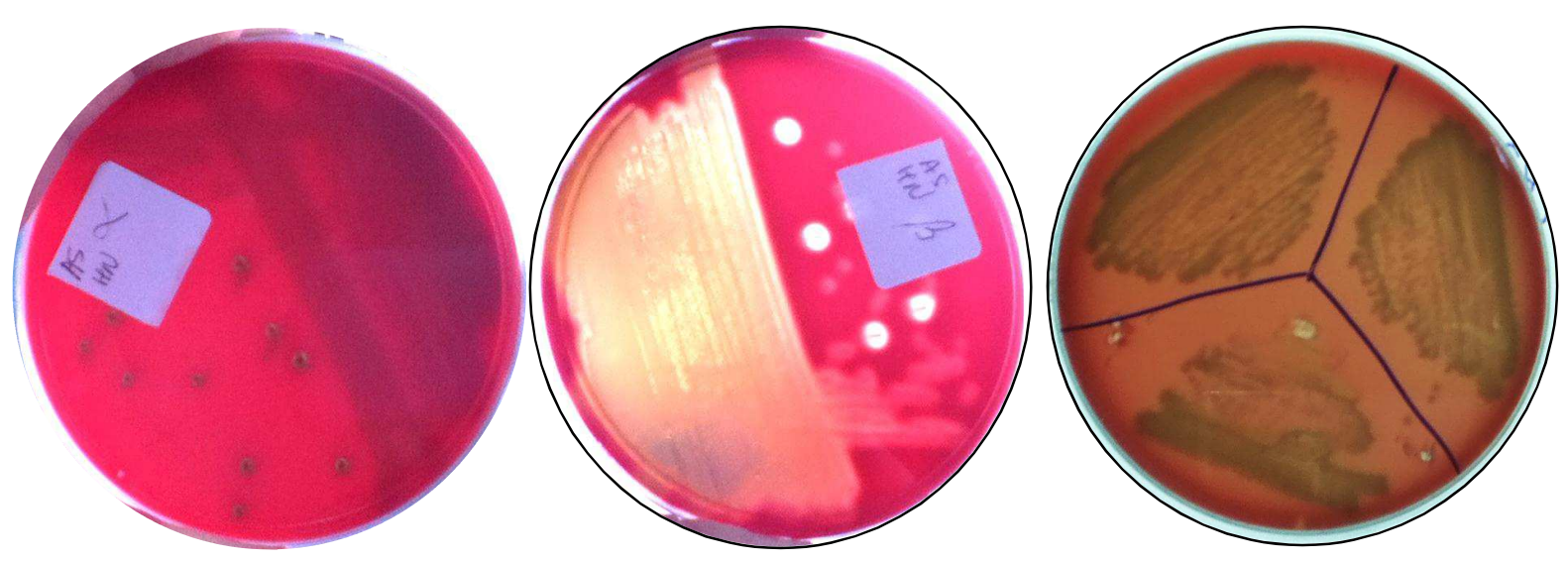

O controle Streptococcus salivarius apresentou o perfil de hemólise tipo $\alpha$ (Figura ). O controle Streptococcus pyogenes apresentou perfil de hemólise tipo $\beta$ (Figura ).

Todas as amostras (Clínicas e Ambientais) foram classificadas como "Produtoras de hemolisina tipo $\alpha "$ (figura 22).

\subsection{Produção de AIA}

A figura 23 mostra a quantidade de AIA liberado in vitro. Oitenta e três por cento das amostras ambientais foram capazes de produzir e liberar este fitormônio, enquanto todas as amostras clínicas o fizeram.

As amostras ambientais que tiveram resultado negativo são da espécie Enterobacter sacchari. Em relação aos gêneros estudados, a cepa Pluralibacter gergoviae foi a melhor 
produtora, enquanto as cepas clínicas do gênero Enterobacter produziram uma menor quantidade deste fitormônio.

Figura 14 - Produção de AIA

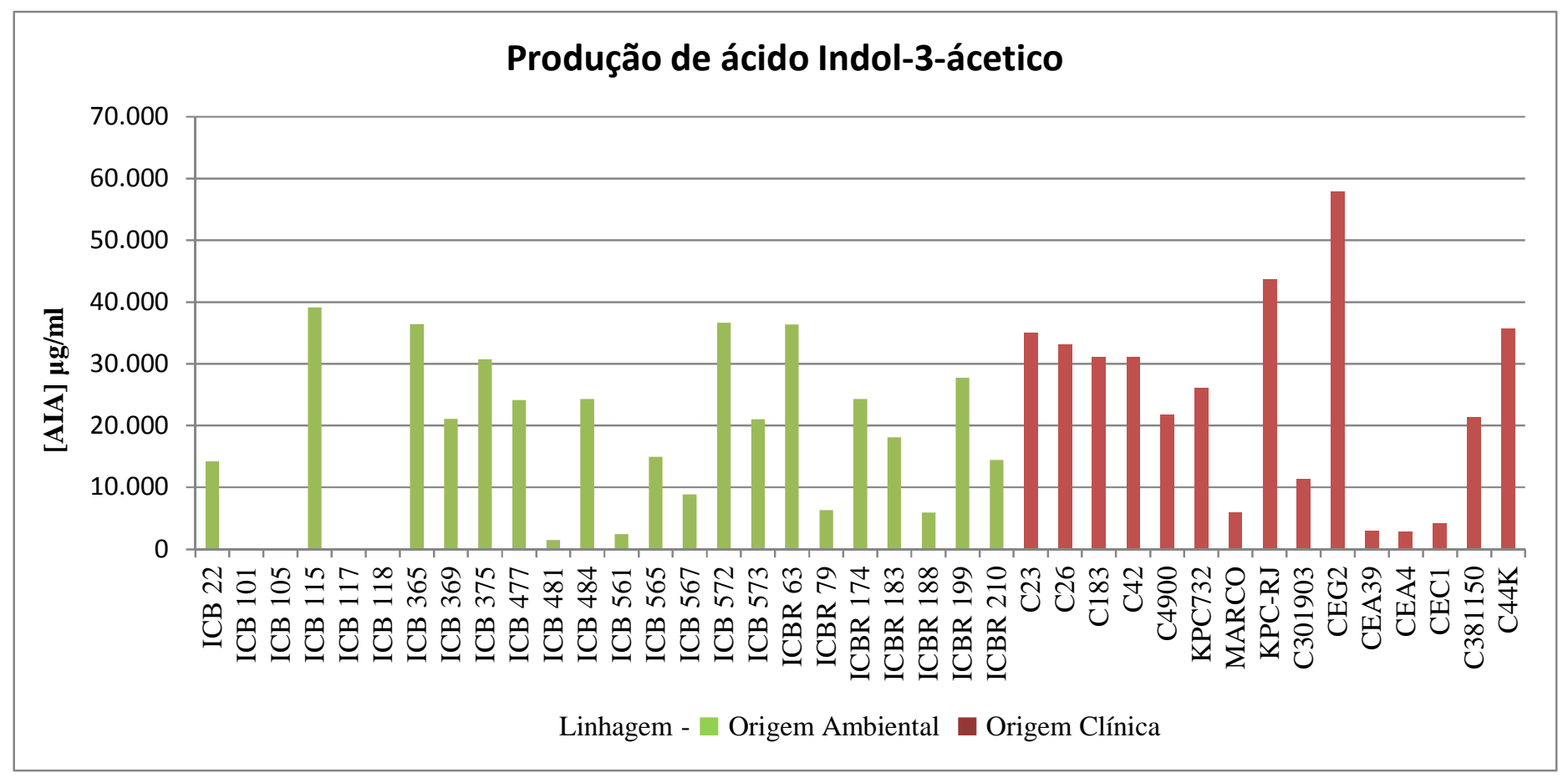

Após análise estatística (figura 24), pode-se verificar que não há diferença significativa na produção de AIA em isolados ambientais ou clínicos.

Figura 15 - Análise estatística - Produção de AIA

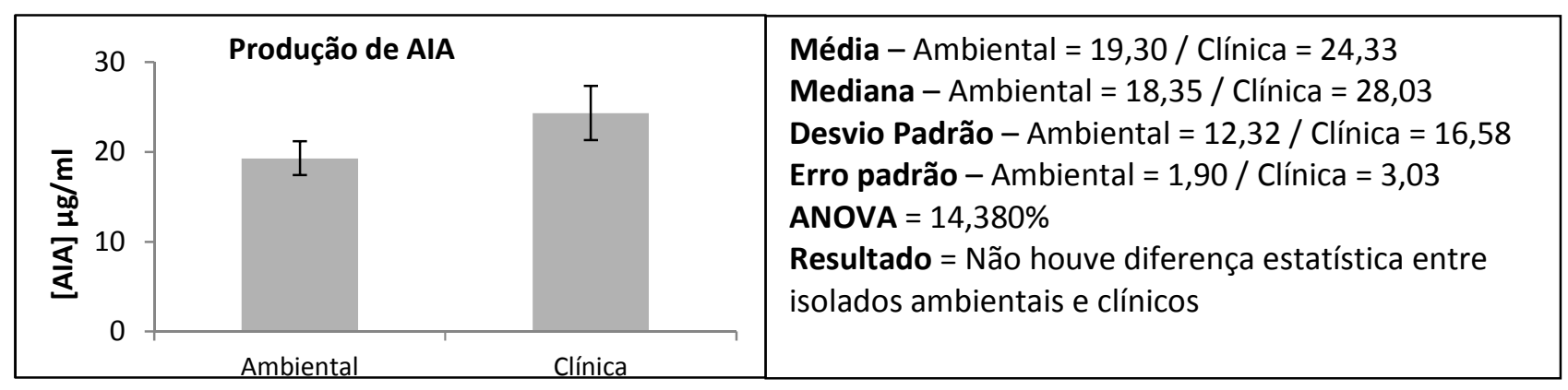

Os valores individuais para cada isolado para efeito de comparação podem ser encontrados no quadro 15. 
Quadro 15 - Determinação da atividade enzimática

\begin{tabular}{|c|c|c|c|c|c|c|c|c|}
\hline \multirow[b]{2}{*}{ Linhagem } & \multirow[b]{2}{*}{ Gênero } & \multirow[b]{2}{*}{ Origem } & \multirow{2}{*}{$\begin{array}{c}\text { Solubilização } \\
\text { de Fosfato } \\
\text { inorgânico }\end{array}$} & \multirow{2}{*}{$\begin{array}{c}\text { Endo- } \\
\text { glicanase }\end{array}$} & \multicolumn{2}{|c|}{ Pectinase } & \multirow[b]{2}{*}{ Hemolisina } & \multirow{2}{*}{$\begin{array}{l}\text { [AIA] } \\
\mu \mathrm{g} / \mathrm{ml}^{-1}\end{array}$} \\
\hline & & & & & $\begin{array}{l}\text { pH } \\
\mathbf{5 , 0}\end{array}$ & $\begin{array}{l}\text { pH } \\
7,0\end{array}$ & & \\
\hline ICB 22 & Kosakonia & Ambiental & + & - & - & - & tipo $\alpha$ & 14.173 \\
\hline ICB 101 & Enterobacter & Ambiental & + & - & - & - & tipo $\alpha$ & 0 \\
\hline ICB 105 & Enterobacter & Ambiental & + & - & - & - & tipo $\alpha$ & 0 \\
\hline ICB 115 & Klebsiella & Ambiental & + & - & + & + & tipo $\alpha$ & 39.139 \\
\hline ICB 117 & Enterobacter & Ambiental & + & - & - & - & tipo $\alpha$ & 0 \\
\hline ICB 118 & Enterobacter & Ambiental & + & - & - & - & tipo $\alpha$ & 0 \\
\hline ICB 365 & Klebsiella & Ambiental & + & - & + & + & tipo $\alpha$ & 36.432 \\
\hline ICB 369 & Klebsiella & Ambiental & + & - & + & - & tipo $\alpha$ & 21.114 \\
\hline ICB 375 & Klebsiella & Ambiental & + & - & + & + & tipo $\alpha$ & 30.764 \\
\hline ICB 477 & Klebsiella & Ambiental & + & - & + & + & tipo $\alpha$ & 24.122 \\
\hline ICB 481 & Enterobacter & Ambiental & + & - & - & - & tipo $\alpha$ & 1.482 \\
\hline ICB 484 & Enterobacter & Ambiental & + & - & - & - & tipo $\alpha$ & 24.289 \\
\hline ICB 561 & Kosakonia & Ambiental & - & - & - & - & tipo $\alpha$ & 2.471 \\
\hline ICB 565 & Kosakonia & Ambiental & + & - & - & - & tipo $\alpha$ & 14.956 \\
\hline ICB 567 & Kosakonia & Ambiental & + & - & - & - & tipo $\alpha$ & 8.893 \\
\hline ICB 572 & Klebsiella & Ambiental & - & - & + & + & tipo $\alpha$ & 36.629 \\
\hline ICB 573 & Kosakonia & Ambiental & + & - & - & - & tipo $\alpha$ & 21.046 \\
\hline ICBR 63 & Klebsiella & Ambiental & - & - & - & - & tipo $\alpha$ & 36.356 \\
\hline ICBR 79 & Kosakonia & Ambiental & + & - & - & - & tipo $\alpha$ & 6.318 \\
\hline ICBR 174 & Klebsiella & Ambiental & - & - & + & - & tipo $\alpha$ & 24.292 \\
\hline ICBR 183 & Klebsiella & Ambiental & - & - & + & + & tipo $\alpha$ & 18.095 \\
\hline ICBR 188 & Klebsiella & Ambiental & + & - & - & - & tipo $\alpha$ & 5.934 \\
\hline ICBR 199 & Klebsiella & Ambiental & + & - & - & - & tipo $\alpha$ & 27.766 \\
\hline ICBR 210 & Klebsiella & Ambiental & + & + & - & - & tipo $\alpha$ & 14.441 \\
\hline C23 & Klebsiella & Clínica & + & - & + & + & tipo $\alpha$ & 35.069 \\
\hline $\mathrm{C} 26$ & Klebsiella & Clínica & - & - & + & + & tipo $\alpha$ & 33.177 \\
\hline C183 & Klebsiella & Clínica & + & - & + & + & tipo $\alpha$ & 31.227 \\
\hline C42 & Klebsiella & Clínica & + & - & + & + & tipo $\alpha$ & 31.193 \\
\hline C4900 & Klebsiella & Clínica & - & - & + & + & tipo $\alpha$ & 21.813 \\
\hline KPC732 & Klebsiella & Clínica & + & - & + & + & tipo $\alpha$ & 26.098 \\
\hline MARCO & Enterobacter & Clínica & + & - & - & - & tipo $\alpha$ & 6.032 \\
\hline KPC-RJ & Klebsiella & Clínica & + & - & + & + & tipo $\alpha$ & 43.775 \\
\hline C301903 & Enterobacter & Clínica & + & - & - & - & tipo $\alpha$ & 11.327 \\
\hline CEG2 & Pluralibacter & Clínica & + & + & - & - & tipo $\alpha$ & 58.005 \\
\hline CEA39 & Enterobacter & Clínica & + & - & - & - & tipo $\alpha$ & 2.982 \\
\hline CEA4 & Enterobacter & Clínica & + & - & - & - & tipo $\alpha$ & 2.892 \\
\hline CEC1 & Enterobacter & Clínica & + & - & - & - & tipo $\alpha$ & 4.220 \\
\hline C381150 & Klebsiella & Clínica & - & - & - & - & tipo $\alpha$ & 21.384 \\
\hline C44K & Klebsiella & Clínica & + & - & - & - & tipo $\alpha$ & 35.746 \\
\hline
\end{tabular}




\section{DISCUSSÃO}

\subsection{Identificação bacteriana}

Intervenções clínicas dependem diretamente da identificação rápida e precisa de patógenos bacterianos, tornando esse, um objetivo fundamental na microbiologia clínica (Tang et al., 1998). A identificação de agentes patógenos diretamente de culturas de sangue por MALDI TOF-MS pode ser uma ferramenta valiosa para melhorar o tratamento de pacientes que sofrem de septicemia e bacteremia (Jung et al., 2014).

A melhor precisão da identificação de amostras bacterianas através deste método, depende principalmente da variedade de perfis contidos no banco de dados. Neste trabalho, todas as amostras de origem clínica, identificadas por MALDI TOF-MS apresentaram resultados iguais aos obtidos por análise filogenética (100\% correlação), indicando que há um grande potencial nesta metodologia para casos de interesse clínico. No entanto, tal método não apresentou resultados similares para as amostras ambientais, exibindo $75 \%$ de correlação com os resultados obtidos por análise filogenética. Este fato está relacionado diretamente com o banco de dados deste equipamento, pois a maior parte dos perfis utilizados para identificação são provenientes de amostras de origem clínica. $\mathrm{O}$ fato de apenas parte dessas amostras terem sido identificadas pelo MALDI TOF-MS, sugere que outros métodos devem ser utilizados quando houver a necessidade de uma identificação bacteriana mais precisa.

$\mathrm{O}$ sequenciamento do gene $16 \mathrm{~S}$, que compõe parte da subunidade $30 \mathrm{~S}$ do RNA ribossômico, é um método amplamente utilizado para identificar gêneros bacterianos isolados dos mais diversos ambientes. Este gene se manteve conservado durante a evolução sendo, por isso, utilizado para identificação taxonômica (Zhang et al., 2008). No entanto, a classificação em função de um único marcador filogenético, em particular, o gene de $16 \mathrm{~S}$ rRNA, não é muito confiável para espécies da família Enterobacteriaceae, em particular, no gênero Enterobacter, pois o gênero em si, ainda não está totalmente definido; portanto, com o objetivo de se obter maior precisão, foi realizado o sequenciamento de mais dois genes, obtendo-se, assim, uma identificação mais confiável (Mollet et al., 1997). Para tanto, foram utilizados dois genes "housekeeping", гроB е gapA. Os genes "housekeeping" controlam processos essenciais para a manutenção da célula (Foss et al., 1998; Schmittgen, Zakrajsek, 2000). O gene rpoB codifica a 
sub-unidade beta da RNA polimerase e a utilização de sequencias deste gene foi descrita para a identificação de membros da família Enterobacteriaceae (Mollet et al., 1997). O gene gapA codifica a subunidade A da enzima gliceraldeido-3-fosfato desidrogenase, que cataliza a transformação do gliceraldeido-3-fosfato a 1,3-bisfosfoglicerato e é essencial para as vias de degradação de açúcares ou síntese de glicose (Toyoda et al., 2008).

As sequências dos três genes obtidas, mostram similaridades com sequências já depositadas, confirmando o alinhamento obtido nas árvores filogenéticas quando comparadas com linhagens tipo. Os percentuais de similaridade variaram de 98 a $100 \%$ e as análises permitiram a classificação das bactérias estudadas neste trabalho em quatro gêneros: Klebsiella, Enterobacter, Kosakonia e Pluralibacter.

O gênero Klebsiella é o grupo com maior número de isolados, sendo 8 de origem clínica e 8 de origem ambiental. Em contraste com muitas outras bactérias patogênicas, K. pneumoniae é onipresente na natureza e vários estudos descrevem, desde a década de 70, que isolados de origem ambiental são quase idênticos aos clínicos no que diz respeito a propriedades fenotípicas (Matsen et al., 1974; Podschun, 1990; Podschun, Sahly, 1991; Podschun, Ullmann, 1996; Seidler et al., 1975).

O gênero Enterobacter é o segundo maior grupo, com 9 isolados ambientais e 5 isolados clínicos. A identificação fenotípica de Enterobacter, especialmente dos que pertencem ao "complexo E. cloacae ", é difícil e, geralmente incerta (Kämpfer et al., 2008).

Seis amostras ambientais foram classificadas como pertencentes ao gênero Kosakonia. Brady et al. (2013) cita que espécies deste gênero podem ser encontradas a partir de amostras clínicas e ambientais, incluindo solo e árvores. Além disso, algumas espécies podem promover o crescimento vegetal através da fixação biológica de nitrogênio.

Um isolado de origem clínica foi classificado como Pluralibacter gergoviae. Este gênero foi recentemente reclassificado, pois, anteriormente pertencia ao gênero Enterobacter, porém, devido a características fenotípicas e moleculares, foi realocado em um novo grupo (Brady et al., 2013).

Aparentemente, os quatro gêneros se caracterizam por sua versatilidade, podendo se adaptar e adquirir características que permitem seu estabelecimento em ambientes variados. Esta capacidade de adaptação é dependentes da aquisição de genes novos, o que permite entender porque a caracterização fenotípica não é confiável. 
Em relação às técnicas utilizadas, fingerprinting por ERIC-PCR é uma técnica que permite detectar rearranjos cromossomais causados por elementos móveis, enquanto o MLST analisa sete genes housekeeping, sendo assim mais apropriado para estabelecer filogenias e epidemiologias em larga escala. Perfis genômicos detectados por ERIC-PCR podem ter diferentes "sequence typing" por MLST (Vimont et al., 2008). Um exemplo disso está na linhagem KPC-RJ, que, no teste de clonalidade pelo método ERIC-PCR, foi considerada clone da cepa C381150, porém sua análise pelo método MLST não confirmou essa informação, mas, demonstrou que esta amostra é mais próxima da cepa C4900.

\subsection{Fixação biológica de nitrogênio (FBN)}

Quanto à caracterízação das bactérias em relação à promoção de crescimento vegetal, foi avaliado o potencial para fixação do $\mathrm{N}_{2}$ atmosférico inicialmente pela capacidade de crescimento dos microrganismos em meio de cultura livre de nitrogênio combinado (Kuss et al., 2007) e, posteriormente, pela atividade de redução de acetileno (Pariona-Llanos et al., 2010). O ensaio de redução de acetileno (ARA) é um método amplamente utilizado por causa de sua simplicidade e baixo custo. Sua grande limitação se dá ao fato de utilizar o acetileno como substrato, e não o substrato natural $\left(\mathrm{N}_{2}\right)$; além disso não revela se esse nitrogênio pode ser incorporado pela planta (Boddey, 1987; Boddey, 1995). Sabe-se que existem quatro tipos de nitrogenases: a clássica Molibdo-nitrogenase (Mo-Nase), a Vanadio-nitrogenase (V-Nase) a Ferro-nitrogenase (Fe-Nase) e a ainda pouco estudada nitrogenase super-óxido dependente (sdn) (Dilworth, 2004; Gadkari, 2004). A Fe-Nase e a Va-Nase têm menor afinidade pelo acetileno (Hales et al., 2004) enquanto a sdn não reduz esse substrato.

O gene nifH codifica a sub-unidade Fe-proteína que faz parte do complexo nitrogenase (Teixeira, 1997). Este gene, presente na maioria das bactérias diazotróficas, apresenta uma sequiência de bases bastante conservada, que permite sua utilização nos estudos de diversidade destas bactérias (Poly et al., 2001). Wang et al. (2013) transferiram os genes nif de Azotobacter para uma linhagem de E. coli e concluiram que, dos 20 genes nif, somente 9 são necessários para sintetizar uma nitrogenase ativa.

Neste trabalho, todos os isolados de Kosakonia radicincitans apresentaram atividade da enzima nitrogenase e amplificaram o gene nifH, confirmando que há interação de bactérias deste 
grupo com plantas promovendo a promoção de crescimento vegetal, conforme descrito por (Kämpfer et al., 2005).

Todos os isolados do gênero Klebsiella que tiveram atividade da nitrogenase também amplificaram o gene nifH com os "primers" utilizados, entretanto, duas linhagens de Enterobacter foram consideradas positivas para a atividade da nitrogenase mas não amplificaram o gene nifH com nenhum dos dois pares de "primers". Este resultado indica que há a necessidade de buscar "primers" específicos para o gênero estudado. Os "primers" utilizados neste trabalho foram originalmente descritos por Poly et al. (2001) baseados nas sequências de Azotobacter vinelandii. Por exemplo, em Klebsiella oxytoca, os vinte genes nif estão localizados próximos uns dos outros, em um cluster de aproximadamente $24 \mathrm{~kb}$, enquanto em Azotobacter vinelandii os genes nif estão distribuídos em dois clusters no genoma (Arnold et al., 1988; Setubal et al., 2009). Esta alteração da posição do genes nif no genoma pode confirmar a necessidade de se obter "primers" específicos para o gênero estudado.

Um resultado não esperado neste trabalho foi a evidenciação da atividade da nitrogenase e a presença do gene nifH em amostras de origem clínica. Na literatura, não foi encontrado nenhum outro trabalho que estudasse a fixação de nitrogênio em bactérias de origem clínica. Entretanto, a hipótese de que estas linhagens vieram de um mesmo ancestral comum e que ainda possuem os genes necessários para a expressão da enzima nitrogenase, pode ser considerada.

\subsection{Produção de Etileno}

O etileno foi produzido por 36 das 39 bactérias estudadas (92\%). As concentrações variaram entre 6,77 e 97,67 $\eta$ mol.ml ${ }^{-1}$. Os gêneros Enterobacter e Klebsiella de origem ambiental foram previamente descritos como produtores de etileno (Ferrara, 2010; Fukuda et al., 1993).

O fitormônio etileno possui várias funções nos vegetais e a presença de bactérias produtoras poderia contribuir de diversas formas, dependendo de sua localização e estágio de desenvolvimento da planta. Em determinadas plantas, como a cana-de-açúcar, os efeitos do etileno são importantes por causarem diminuição do alongamento celular e crescimento lateral das células que promovem aumento do conteúdo de açúcares. Em cana-de-açúcar o elevado acúmulo de sacarose valoriza sua cultura. A presença das bactérias que produzem etileno 
endofiticamente também poderia contribuir para a regulação do crescimento vegetal e aumento da concentração de açúcar num processo que atualmente é induzido por produtos industrializados chamado maturação (Li, Solomon, 2003). O etileno é funcional na planta em concentrações de até 4,4 ๆg. $1^{-1}$, menores que as encontradas neste trabalho. Entretanto, aqui, devido às condições experimentais, o etileno acumulou-se no frasco de ensaio, produzido por uma população possívelmente diferente daquela que há na planta, não refletindo o que ocorre in vivo. Na planta, caso este fosse produzido, seria dispersado pelos tecidos.

Por outro lado, não foi possível saber quais os efeitos que traria o etileno para humanos ou animais. Não foram encontrados na literatura dados sobre a relação entre o etileno e a patogenicidade.

\subsection{Sensibilidade a antibióticos e Concentração Inibitória Minima (CIM)}

No início da era da antibioticoterapia, embora existente, a resistência a antibióticos em bactérias causadoras de infecções humanas era pouco frequente. A expansão do problema coincidiu com a introdução e ampla utilização de inúmeros antimicrobianos novos, a partir da década de 1960 (Tavares, 1996).

Sabe-se que para prescrever um antimicrobiano, é indispensável determinar, a princípio, se a bactéria isolada é sensível ou resistente. A sensibilidade dos microrganismos à ação das drogas antimicrobianas pode ser determinada in vitro.

Através da pressão seletiva, as bactérias criaram vários mecanismos bioquímicos de resistência, tais como: inativação da droga por enzimas; alteração da permeabilidade bacteriana à droga; alteração de sistema de transporte na célula; retirada ativa da droga do meio intracelular; alteração do receptor da droga; modificação do sistema metabólico ativo para a droga e síntese de vias metabólicas alternativas (Murray et al., 1999).

Neste trabalho, foi verificado que as amostras de origem clínica diferem das amostras ambientais em relação à resistência a um grande número de antibióticos de classes diferentes, assim como na concentração inibitória mínima (CIM). Como exemplo, pode-se observar que os valores obtidos para CIM do antibiótico Cefalotina são significantemente maiores nas amostras de origem clínicas, sugerindo que a aquisição de plasmídios de resistência a este antibiótico é 
rápida e eficaz. As amostras ambientais isoladas da rizosfera de cana-de-açúcar também apresentaram valores altos de resistência a este antibiótico.

A Amostra clínica Pluralibacter gergoviae foi resistente a todos antibióticos testados. Na literatura; Stock e Wiedemann (2002) já haviam reportado que esta espécie apresenta resistência natural ao antibiótico Cefoxitima, e que expressa em baixos níveis uma $\beta$-lactamase mais ou menos específica para este antimicrobiano. Também foi reportada a atividade em baixo nível de uma AmpC- $\beta$-Lactamase em três linhagens desta espécie (Pitout et al., 1997).

Em relação às amostras ambientais, houve resistência a oito dos doze antibióticos testados, enquanto nas amostras de origem clínica, houve resistência a todos os antibióticos, porém, somente para a Nitrofurantoína, houve resultados equivalentes entre cepas de ambas origens.

Os nitrofuranos foram muito utilizados em bovinos, suínos e aves como componentes do tratamento de infecções gastrointestinais, causadas pelas enterobacterias Escherichia coli e Salmonella . Estas substâncias também eram utilizadas como promotores de crescimento destes animais podendo ser utilizada por administração intravenosa e também adicionada diretamente na ração (Wang et al., 2006). Em 1995, a Comissão Européia proibiu a utilização de nitrofuranos em animais, tendo reforçado e restringido ainda mais em 2003 (Vass et al., 2008). Este resultado demonstra a importância no controle e restrição da utilização deste antibiótico em campo, tendo em vista que, atualmente, é utilizado em humanos para tratamento de infecções urinárias (Comissão de controle de infecção hospitalar - CCIH). Este trabalho sugere que os resultados aqui obtidos estão relacionados com a antibioticoterapia passada e que os genes capazes de conferir resistência permanecem e são expressos nos microrganismos, demonstrando que são necessárias as devidas precauções no uso de antibióticos.

\subsection{Transformação e estabilidade dos plasmídios}

Com a finalidade de verificar se os isolados ambientais, em contato com isolados clínicos seriam capazes de receber plasmídios de resistência a antimicrobianos, foi realizado o teste de estabilidade dos plasmídios através da transformação $\mathrm{O}$ resultado obtido, após o teste de susceptibilidade a antimicrobianos, não evidenciou a transferência e expressão de genes de resistência para as linhagens selvagens, entretando, pode-se observar uma diminuição no halo de 
inibição para alguns antibióticos. Para trabalhos futuros, a repetição deste experimento por conjugação, pode ser relevante.

\subsection{Solubilização de fosfato inorgânico}

O fósforo é um elemento essencial para todos os seres vivos. Na natureza, grandes porções de fosfato inorgânico ficam livres no solo, mas não podem ser prontamente utilizados. (Nautiyai, 1999). Os microrganismos desempenham um papel central no ciclo natural do fósforo, liberando ácidos orgânicos, responsáveis pela solubilização mineral de fosfatos (Rodriguez, Fraga, 1999).

Neste trabalho, $76 \%$ dos isolados ambientais e $80 \%$ dos de origem clínica foram capazes de solubilizar fosfatos, sugerindo que esta característica seja comum a estes gêneros bacterianos. A solubilização de fosfato inorgânico deve-se à produção de ácidos orgânicos e inorgânicos pelas bactérias. Algumas espécies dos gêneros Rhizobium, Pseudomonas e Bacillus estão entre os microrganismos mais eficientes em solubilizar fosfatos (Rodriguez, Fraga, 1999).

Ferramentas moleculares têm sido utilizadas para se entender a base genética da solubilização de fosfato, característica fenotípica conferida pelo gene mps (mineral phosphate solubilization). Bactérias gram-negativas que possuem a capacidade de solubilizar fosfato de cálcio ou rocha apresentam este fenótipo ( $m p s$ ). Recentemente, mostrou-se que este gene, expresso por Erwinia herbicola e Pseudomonas cepacea está associado com a produção de ácidos orgânicos, como por exemplo, o ácido glicônico, que é responsável pela dissolução do fosfato de cálcio (Babu-Khan et al., 1995). No entanto, não se pode esperar que a solubilização de fosfato seja expressa por um único gene e também seja comum a todos os microrganismos solubilizadores (Narloch, 2002). Os dados aqui apresentados mostram que há uma equivalência entre as amostras clínicas e ambientais na liberação de ácidos. É interessante que, sendo enterobactérias, todos os isolados aqui estudados são fermentadores (fermentação ácido mista) e nem todos solubilizaram fosfatos o que indica que não são os produtos ácidos da fermentação os responsáveis pela dissolução de fosfato. 


\subsection{Pectinase e carboximetilcelulase}

As enzimas são compostos bioativos que regulam algumas alterações químicas em organismos vivos. Celulases e pectinases são responsáveis pela hidrólise de polímeros componentes dos vegetais. A parede das plantas consiste principalmente de celulose, enquanto que a lamela média é formada por pectina. A enzima pectinase pode degradar substâncias pécticas e é sintetizada por microrganismos e plantas superiores (Fogarty et al., 1990). Baseado no $\mathrm{pH}$ ótimo para a atividade enzimática, as pectinas podem ser classificadas em enzimas ácidas ou alcalinas. Pectinas alcalinas, são predominandemente produzidas por bactérias, e já foram encontradas em: Bacillus spp., Erwinia spp., Klebsiella spp.,Yersinia spp. e Pseudomonas spp. (Yuan et al., 2011). Neste trabalho, 33\% das amostras ambientais e 16\% das amostras clínicas produziram pectinase, entretanto, em relação aos gêneros estudados, somente amostras do gênero Klebsiella produziram pectinase.

Celulose é o polissacarídeo mais abundante da terra e o principal constituinte da parede celular das plantas (Recouvreux et al., 2005). É um polímero linear de unidades de glicose, unidas entre si por ligações glicosídicas $\beta-1,4$. A celulose é insoluvel e, portanto, seu aproveitamento depende de sua degradação em monômeros. Celulose tem uma estrutura compacta e sua hidrólise exige um sistema complexo de enzimas celulolíticas, que podem ser nomeadas de endoglicanases (carboximetilcelulase e endo-1,4- $\beta$-glicanase) ou exoglicanases (exo-1,4- $\beta$-glicanase e $\beta$-glicosidase) (Arantes, Saddler, 2010; Wood, 1989). As endoglicanases são responsáveis pela rápida solubilização do polímero celulósico, devido à sua fragmentação em oligossacarídeos (Lynd et al., 2002). Neste trabalho, somente um isolado ambiental do gênero Klebsiella e um isolado clínico do gênero Pluralibacter produziram endoglicanase.

Este resultado indica que a produção de celulases e pectinases não é exclusiva para isolados ambientais, e também não caracteriza a capacidade de invasão no hospedeiro vegetal. A produção de pectinases e celulases por organimos simbióticos ou fitopatogênicos já havia sido descrita anteriormente, entretanto, estudos da produção destas enzimas em cepas de origem clínica não foram encontrados. 


\subsection{Atividade hemolítica}

No presente estudo, o teste de hemólise de sangue de carneiro in vitro foi empregado para a avaliação da atividade hemolítica em todas as linhagens de origem ambiental e clínica.

Todas as amostras apresentaram o mesmo perfil de hemolisina, sendo classificadas como produtoras de hemolisina do tipo $\alpha$. O termo $\alpha$-hemolisina foi introduzido por Smith (1963) para hemolisinas que podem ser obtidas livres da célula bacteriana em culturas líquidas filtradas. Outra hemolisina, denominada $\beta$-hemolisina não pode ser separada de células bacterianas (Short, Kurtz, 1971; Smith, 1963). Cepas bacterianas podem ser descritas como $\alpha$-hemolíticas, $\beta$ hemolíticas ou ambas (Smith, 1963).

Albesa et al. (1985) relataram espécies de Klebsiella como produtoras de hemolisinas, o que reforça os resultados obtidos. O primeiro relato de cepas de Enterobacter produtoras de hemolisina foi descrito por Prada e Beutin (1991). A produção de $\alpha$-hemolisina em E. coli (Su et al., 2013) também foi descrita, o que sugere a troca de material genético entre bactérias da família Enterobacteriaceae.

Em relação às bactérias de origem clínica, por serem patógenos oportunistas, é particularmente difícil identificar fatores de virulência nesses microrganismos (Köthe et al., 2003; Rahme et al., 1995). Neste trabalho, os resultados demonstram que a atividade hemolítica não é um fator determinante de patogenicidade: tanto bactérias ambientais quanto clínicas causaram um tipo de lesão ao sangue. No entanto, esta característica é absolutamente dispensável para os microrganismos ambientais. Outro dado, diz respeito aos dados obtidos para o tipo de hemólise: todas, clínicas e ambientais apresentaram hemólise do tipo $\alpha$, que não caracteriza as bactérias como indicadoras de patogenicidade. Embora haja sugestões de que bactérias $\alpha$ hemolíticas possam ser tóxicas para as células do hospedeiro, as infecções extra-intestinais podem ocorrer também por microrganismos não hemolíticos (Cavalieri et al., 1984).

\subsection{Produção de ácido-indol-3-acético (AIA)}

Este fitormônio é essencial para os vegetais, e deve estar presente em todas as plantas, sem exceção (Taiz, Zieger, 2002). Acredita-se que esta característica, quando presente em bactérias, tenha sido adquirida ao longo do tempo, a partir de suas associações com plantas, provavelmente 
por transferência de genes do vegetal para o microrganismo. Em bactérias, foram encontradas duas vias de síntese principais presentes na grande maioria dos isolados, a da indol-acetamida (IAM) e a do ácido indol-pirúvico (IPA); ambas possuem o triptofano como precursor.

A via de produção do AIA pode ser importante para determinar o efeito de uma bactéria na planta. Manulis et al. (1991) verificaram que cepas fitopatogênicas e não-fitopatogênicas de Erwinia herbicola sintetizam AIA através da via do ácido indol pirúvico. No entanto, apenas a estirpe patogênica, que induz a formação de nódulos em locais ferida em Gypsophilae, pode produzir AIA via indoleacetamida. Se esta última via é inactivada, então a virulência é reduzida. Para trabalhos futuros, o estudo da via de produção do AIA, pode ser realizado para a elaboração da hipótese do efeito do AIA em hospedeiros animais.

Neste trabalho, tanto linhagens de origem ambiental, quanto de origem clínica foram capazes de produzir e liberar AIA in vitro. Dentre os gêneros estudados, Pluralibacter foi o melhor produtor, com $58.005 \mu \mathrm{g} / \mathrm{ml}^{-1}$; seguido de Klebsiella, com a média de valores, 28.000 $\mu \mathrm{g} / \mathrm{ml}^{-1}$, Kosakonia com a média $11.000 \mu \mathrm{g} / \mathrm{ml}^{-1}$ e Enterobacter, com a média de valores, 4.800 $\mu \mathrm{g} / \mathrm{ml}^{-1}$.

Não foi encontrada na literatura o efeito do AIA na patogenicidade em humanos ou animais, entretanto, este estudo foi realizado in vitro, e seu resultado pode não refletir a atividade destes microrganimos quando presentes in vivo.

\section{CONCLUSÕES}


$\checkmark \quad \mathrm{O}$ sequenciamento dos genes "housekeeping" $16 \mathrm{~S}$ e $\operatorname{rpoB}$ confirmou a identificação obtida através do MALDI TOF-MS somente para as linhagens de origem clínica;

$\checkmark \quad$ análise de perfis alélicos e ST's por MLST em Klebsiella demonstraram a formação de dois grupos distintos. E além disso, mostrou a similaridade de um isolado clínico (C44K) com os ambientais, assim como a similaridade de um isolado ambiental (ICBR199) com os clínicos;

o teste de clonalidade por ERIC-PCR também formou grupos distintos e confirmou a similaridade obtida através do MLST nos dois isolados citados acima;

$\checkmark \quad$ os isolados ambientais são mais sensíveis aos antibióticos testados em relação aos isolados clínicos, exceto para o antibiótico Nitrofurantoína;

$\checkmark \quad$ isolados ambientais apresentaram maiores valores de fixação de $\mathrm{N}_{2}$ em relação aos isolados clínicos;

$\checkmark \quad$ ensaios de produção de etileno, AIA, solubilização de fosfato inorgânico, produção de pectinase, celulase e hemolisina não foram distintivos para isolados de origem ambiental ou clínica. 


\section{REFERÊNCIAS*}

Albesa I, Barberis LI, Pajaro MC, Farnochi MC, Eraso AJ. A thiol-activated hemolysin in Gram-negative bacteria. Canadian Journal of Microbiology. 1985;31:297-300.

Alonso A, Martinez JL. Environmental and clinical isolates of Pseudomonas aeruginosa show pathogenic and biodegradative properties irrespective their origin. Environmental Microbiology. 1999;31:421-30.

Andrade SP. Manual de terapêutica veterinária. $2^{\mathrm{a}}$ ed. São Paulo: Rocca; 2002.

Arantes V, Saddler JN. Access to cellulose limits the efficiency of enzymatic hydrolysis: the role of amorphogenesis. Biotechnology for Biofuels. 2010;3:4

Arnold W, Rump A, Klipp W, Priefer UB, Pühler A. Nucleotide sequence of a 24,206 base pair fragment carrying the entire nitrogen fixation gene cluster of Klebsiella pneumoniae. Journal of Molecular Biology. $1988 ; 203: 715-38$.

Babu-Khan S, Yeo TC, Martin WL, Duron MR, Rogers RD, Goldstein AH. Cloning of a mineral phosphate-solubilizing gene from Pseudomonas cepacia. Applied and Environmental Microbiology. 1995;61:972-8.

Bagley S, Seidler RJ, Brenner DJ. Klebsiella planticola sp. nov.: a new species of Enterobacteriaceae found primarily in nonclinical environments. Current Microbiology. 1981;6:105-9.

Barbosa FHF, Barbosa LPJL, Bambirra LHS, Aburjaile FF. Produção de substâncias envolvidas no fenômeno de antagonismo bacteriano. Biologia e Ciências da Terra. 2011;11:1.

Barbosa HR, et al. Counting of viable cluster-forming and non-cluster-forming bacteria: a comparison between the drop and the spread methods. Journal of Microbology Methods. 1995; 22:39-50.

Bell JM, Chitsaz C, Turnidge JD, Barton M, Walters LJ, Jones RN. Prevalence and Significance of a Negative Extended-Spectrum $\beta$-Lactamase Confirmation Test Result after a Positive ESBL Screening Test Result for isolates of Escherichia coli and Klebsiella pneumoniae:Results from the SENTRY AsiaPacific Surveillan Program. Journal of Clinical Microbiology. 2007;45:1478-82.

Belyavska NA, Kozyrovska NO, Kucherenko LA, Kordyum VA. Interrelations of Klebsiella with the plant. Electron-microscopy analysis of interaction of the endophytic microorganisms with rice seedling roots. Biopolymery i Klityna. 1995;11:55-61.

Ben-David D, Maor Y, Keller N, Regev-Yochay G, Tal I, Shachar D. Potential role of active surveillance in the control of a hospital-wide outbreak of carbapenem-resistant Klebsiella pneumoniae infection. Infection Control and Hospital Epidemiology. 2010;31:620-6.

*De acordo com:

International Committee of Medical Journal Editors. [Internet]. Uniform requirements for manuscripts submitted to Biomedical Journal: sample references. [updated 2011 Jul 15]. Available from: http://www.icmje.org 
Berg G, Eberl L, Hartmann A. The Rhizosphere as a reservoir for opportunistic human pathogenic bacteria. Environmental Microbiology. 2005;7:1673-85.

Beutin L. The different hemolysins of Escherichia coli. Medical Microbiology and Immunology 1991; 180:167-82.

Boddey RM. Methods for the quantification of nitrogen fixation associated with gramineae. CRC Critical Reviews in Plant Sciences. 1987;6:209-66.

Boddey RM, Resende CP, Pereira JM, Cantarutti RB, Alves BJR, Ferreira E, Richter M, Cadisch G, Urquiaga $\mathrm{S}$. The nitrogen cycle in pure grass and grass/legume pastures: Evaluation of pasture sustainability. In Nuclear Techniques in Soil-Plant Studies for Sustainable Agriculture and Environmental Preservation. 1995;319:307-19.

Boddey RM, Urquiaga S, Alves BJR, Reis V. Endophytic nitrogen fixation in sugarcane: present knowledge and future applications. Plant and Soil. 2003; 252:139-49.

Bolmström A. Susceptibility testing of anaerobes with Etest. Clinical Infectious Diseases. 1993; 16:S36770.

Borer A, Saidel-Odes L, Riesenberg K, Eskira S, Peled N, Nativ R. Attributable mortality rate for carbapenem-resistant Klebsiella pneumoniae bacteremia. Infection Control and Hospital Epidemiology. 2009; 30:972-6.

Brady C, Cleenwerck I, Venter S, Coutinho T, De Vos P. Taxonomic evaluation of the genus Enterobacter based on multilocus sequence analysis MLSA. Systematic and Applied Microbiology. 2013;39:309-19.

Bratu S, Landman D, Haag R, Recco R, Eramo A, Alam M. Rapid spread of carbapenem-resistant Klebsiella pneumoniae in New York City: a new threat to our antibiotic armamentarium. Archives of Internal Medicine. 2005; 165:1430-5.

Brenner DJ, McWhorter AC, Kai A, Steigerwalt AG, Farmer JJ. Enterobacter asburiae sp. nov., a new species found in clinical specimens, and reassignment of Erwinia dissolvens and Erwinia nimipressuralis to the genus Enterobacter as Enterobacter dissolvens comb. nov. and Enterobacter nimipressuralis. Journal of Clinical Microbiology. 1986; 23:1114-20.

Brooks GF, Butel JS, Morse SA. Microbiologia médica. 21 ${ }^{\text {a }}$ ed. Rio de Janeiro: Guanabara Koogan; 2000.

Buchanan B, Guissem W, Jones R. Biochemistry \& Molecular Biology of plants. American Society of Plant Biologists. 2002:1408.

Cavalieri SJ, Bohach GA, Snyder IS. Escherichia coli alpha-hemolysin: Characteristics and Probable Role in Pathogenicity. Microbiological reviews. 1984: 326-343.

Chelius MK, Triplett EW. Immunolocalization of dinitrogenasereductase produced by Klebsiella pneumoniae in association with Zea mays. Applied and Environmental Microbiology. 2000; 66:783-787. 
Chimetto LA, Brocchi M, Thompson CC, Martins RCR, Barbosa HR, Thompson FL. Vibrios dominate as culturable nitrogen-fixing bacteria of the Brazilian coral Mussismilia hispida. Systematic and Applied Microbiology. 2008; 31:312-319.

Chudasama KS, Thaker VS. Biological control of phytopathogenic bacteria Pantoea agglomerans and Erwinia chrysanthemi using 100 essential oils. Archives of Phytopathology And Plant Protection. 2014.

Clinical and Laboratory Standards Institute. Performance Standards for Antimicrobial Disk Dilution Susceptibility Tests for Bacteria Isolated From Animals. CLSI Document M31-A3: Approved StandardThird Edition, 2009.

CLSI. Normas de desempenho para testes de sensibilidade a agentes antimicrobianos por diluição para crescimento de bactérias aeróbias. Vols. M100-S15. Wayne, PA: Clinical and Laboratory Standards Institute, 2005.

Coelho JU, Baretta GAP, Okawa L. Seleção e uso de antibióticos em infecções intra-abdominais. Arquivos de Gastroenterologia. 2007;44:85-90.

Diancourt L, Passet V, Verhoef J, Grimont PA, Brisse S. Multilocus sequence typing of Klebsiella pneumoniae nosocomial isolates. Journal of Clinical Microbiology. 2005; 43:4178-4182.

Dickey RS, Zumoff CH. Emended description of Enterobacter cancerogenus comb. nov. formerly Erwinia cancerogenus. International Journal of Systematic and Evolutionary Microbiology. 1988; 38:371-374.

Dilworth MJ. Assay methods for products of nitrogenase action on substrates. In: Smith BE, Richard LR, Newton WE (Eds) Catalysts for nitrogen fixation: Nitrogenases, relevant chemical models and commercial processes. Netherlands: Springer. 2004;55-76.

Ding C, He J. Effect of antibiotics in the environment on microbial populations. Applied Microbiology and Biotechnology. 2010; 87:925-941.

Dobbelaere S, Vanderleyden J, Okona Y. Plant growth-promoting effects of diazotrophs in the rhizosphere. Critical Reviews in Plant Sciences. 2003; 22:107-149.

Döbereiner J. Biological Nitrogen Fixation in the tropics: social and economic contributions. Soil Biology \& Biochemistry. 1997;29:771-4.

Döbereiner J, Baldani VL, Baldani JI. Como isolar e identificar bactérias diazotróficas de plantas nãoleguminosas. Brasília: Embrapa; 1995.

Dong Y, et al. Comparisons between two Klebsiella: The plant endophyte K. Pneumoniae 342 and a clinical isolate K. pneumoniae MGH78578. Symbiosis. 2003;35:247-59.

Dörr J, Hurek T, Reinhold-Hurek B. Type IV pili are involved in plant-microbe and fungus-microbe interactions. Molecular Microbiology. 1998; 30:7-17.

Felsenstein J. Confidence limits on phylogenies: An approach using the bootstrap. Evolution. 1985; 39:783-91. 
Ferragut C, Izard D, Gavini F, Kersters F, De Ley J, Leclerc H. Klebsiella trevisanii: a new species from water and soil. International Journal of Systematic and Evolutionary Microbiology. 1983;33:133-42.

Ferrara FIS. Influência do tipo de adubação na produção de aminoácidos e de ácido indol-3-acético, etileno e poliaminas por bactérias fixadoras de nitrogênio isoladas de cana-de-açúcar Saccharum sp. [tese (Doutorado em Microbiologia)]. São Paulo: Instituto de Ciências Biomédicas, Universidade de São Paulo; 2010.

Fogarty WM, Kelly CT. Microbial enzymes and biotechnology. London: Elsevier Applied Science; 1990. $92 \mathrm{p}$.

Foss DL, Baarsch MJ, Murtaugh MP. Regulation of hypoxanthine phosphoribosyltransferase, glyceraldehyde-3-phosphate dehydrogenase and beta-actin mRNA expression in porcine immune cells and tissues. Animal Biotechnology. 1998;9:67-78.

Fravel DR. Role of antibiosis in the biocontrol of plant diseases. Annual Review of Phytopathology. 1988; 26:75-91.

Fukuda H, Ogawa T, Tanase B. Ethylene production by micro-organisms. Advances in Microbial Physiology. 1993;35:275-306.

Garbeva P, Van Veen JA, Van Elsas JD. Microbial diversity in soil: selection of microbial populations by plant and soil type and implications for disease suppressiveness. Annual Review of Phytopathology. 2004;42:243-70.

Gadkari D. Superoxide-dependent nitrogenase. In: Smith BE, Richard LR, Newton WE (Eds) Catalysts for nitrogen fixation: Nitrogenases, relevant chemical models and commercial processes. Netherlands: Springer. 2004;309-32.

Gavini F, Izard D, Grimont PAD, Beji A, Ageron E, Leclerc H. Priority of Klebsiella planticola Bagley, Seidler, and Brenner 1982 over Klebsiella trevisanii Ferragut, Izard, Gavini, Kersters, DeLey, and Leclerc 1983. International Journal of Systematic and Evolutionary Microbiology. 1986;36:486-8.

Gavini F, et al. Transfer of Enterobacter agglomerans Beijerinck 1888 Ewing and Fife 1972 to Pantoea gen. nov. as Pantoea agglomerans comb. nov. and Description of Pantoea dispersa sp. nov. International Journal of Systematic and Evolutionary Microbiology. 1989;39:337-45.

Gavini F, Leclerc H, Lefèbvre B, Ferragut C, Izard D. Etude taxonomique d'entérobactéries appartenant ou apparentées au genre Klebsiella. Annales de l'Institut Pasteur Microbiology. 1977;128b:45-9.

Glick BR, Cheng Z, Czamy J, Duan J. Promotion of plant growth by ACC deaminase-containing soil bacteria. European Journal of Plant Pathology. 2007;119:329-39.

Graciolli LA. Bactérias fixadoras de nitrogênio nas raízes, caules e folhas de cana-de-açúcar Saccharum sp.. Annual Review of Microbiology. 1983;14:191-6.

Hacker J, Hentschel U, Dobrindt U. Prokaryotic chromosomes and diseases. Science. 2003; 301:790-3. 
Hales BJ. Vanadium nitrogenase. In: Smith BE, Richard LR, Newton WE (Eds) Catalysts for nitrogen fixation: Nitrogenases, relevant chemical models and commercial processes. Netherlands: Springer. 2004;255-79.

Hammond-Kosack, Jones JDG. Responses to plant pathogens. In: Buchanan B, Gruissem W, Jones R, editors. Biochemistry and molecular biology of plants, American Society of Plant Physiologists; 2000. $1408 \mathrm{p}$.

Hankin L, Zucher M, Sands DC. Improved solid medium for detection and enumeration of pectolytic bacteria. Applied Microbiology. 1971;22:205-9.

Hardoim PR, Van Overbeek LS, Van Elsas JD. Properties of bacterial endophytes and their proposed role in plant growth. Trends in Microbiology. 2008;16:463-71.

Hinton DM, Bacon CW. Enterobacter cloacae is an endophytic symbiont of corn Mycopathologia. Dordrecht. 1995; 129:117-25.

Hirsch EB, Tam VH. Detection and treatment options for Klebsiella pneumoniae carbapenemases KPCs: an emerging cause of multidrug-resistant infections. Journal of Antimicrobial Chemotherapy. 2010; 65:1119-25.

Hoffmann H, et al. Reassignment of Enterobacter dissolvens to Enterobacter cloacae as E. cloacae subspecies dissolvens comb. nov. and emended description of Enterobacter asburiae and Enterobacter kobei. Systematic and Applied Microbiology. 2005;28:196-205.

Holben WE, Feris KP, Kettunen A, Apajalahti JH. GC fractionation enhances microbial community diversity assessment and detection of minority populations of bacteria by denaturing gradient gel electrophoresis. Applied and Environmental Microbiology. 2004; 70:2263-70.

Hormaeche PR, Edwards A. A proposed genus Enterobacter. Int Bull Bacteriol Nomencl Taxon. 1960; 10:71-4.

Hyle EP, Bilker WB, Gasink LB, Lautenbach E. Impact of different methods for describing the extent of prior antibiotic exposure on the association between antibiotic use and antibiotic-resistant infection. Infection Control and Hospital Epidemiology. 2007;28:647-54.

Ichiwaki S. Efeitos da inoculação de Enterobacter sp. ICB 481 sobre o crescimento e acúmulo protéico em plântulas de cana-de-açúcar Saccharum sp. submetidas a fertilização orgânica e convencional Dissertação de mestrado. São Paulo: Instituto de Ciências Biomédicas, Universidade de São Paulo; 2012.

Iversen C, et al. Cronobacter gen. nov., a new genus to accommodate the biogroups of Enterobacter sakazakii, and proposal of Cronobacter sakazakii gen. nov., comb. nov., Cronobacter malonaticus sp. nov., Cronobacter turicensis sp. nov., Cronobacter muytjensii sp. nov.,... International Journal of Systematic and Evolutionary Microbiology. 2008;58:1442-7.

Izard D, Ferragut C, Gavini F, Kersters K, De Ley J, Leclerc H. Klebsiella terrigena, a new species from soil and water. International Journal of Systematic and Evolutionary Microbiology. 1981;31:116-27. 
Jha PN, Kumar A. Endophytic colonization of Typha australis by a plant growth-promoting bacterium Klebsiella oxytoca strain GR-3. Journal of Applied Microbiology. 2007;103:1311-20.

Jones RN. Global epidemiology of antimicrobial resistance among community-acquired and nosocomial pathogens: a five-year summary from the SENTRY Antimicrobial Surveillance Program 1997-2001. Seminars in Respiratory and Critical Care Medicine. 2003;51:121-34.

Jung JS, Popp C, Sparbier K, Lange C, Kostrzewa M, Schubert S. Evaluation of MALDI-TOF MS for rapid detection of $\beta$-lactam resistance in Enterobacteriaceae derived from blood cultures. Journal of Clinical Microbiology. 2014;52:924-30.

Kämpfer P, et al. Molecular identification of coliform bacteria isolated from drinking water reservoirs with traditional methods and the Colilert-18 system. International Journal of Hygiene and Environmental Health. 2008;211:374-84.

Kämpfer P, Ruppel S, Remus R. Enterobacter radicincitans sp. nov., a plant growth promoting species of the family Enterobacteriaceae. Systematic and Applied Microbiology. 2005;28:213-21.

Kiffer C, et al. Antimicrobial susceptibility of Gram-negative bacteria in Brazilian hospitals: the MYSTIC Program Brazil 2003. Brazilian Journal of Infectious Diseases. 2005;9:216-24.

Kim J, Rees DC. Nitrogenase and biological nitrogen fixation. Biochemistry. 1994;33:379-97.

Kim KY, McDonald GA, Jordan D. Solubilization of hydroxyapatite by Enterobacter agglomerans and cloned Escherichia coli in culture medium. Biology and Fertility of Soils. 1997;24:446-55.

Koga J, Adachi T, Hidaka H. IAA. biosynthesis pathway from tryptophan via indole-3-pyruvic acid in Enterobacter cloacae. Agricultural Biology and Chemistry. 1991;55:701-6.

Korres AMN, Ventura JA, Fernandes PMB. First report of bacteria and yeasts associated with pineapple fruit collapse in espírito santo state, Brazil. Plant Disease 2010;54:1509.

Köthe M, et al. Killing of caenorhabditis elegans by Burkholderia cepacia is controlled by the cep quorum-sensing system. Cellular Microbiology. 2003;5:343-51.

Kowalchuk GA, Buma DS, Boer W, Klinkhamer PGL, van Veen JA. Effects of above-ground plant species composition and diversity on the diversity of soil-borne microorganisms. Antonie van Leeuwenhoek J Microbiol Serol. 2002;81:509-20.

Kuss AV, Kuss VV; Lovato T; Flôres ML. Fixação de nitrogênio e produção de ácido indolacético in vitro por bactérias diazotróficas endofíticas. Pesquisa Agropecuária Brasileira. 2007;42:1459-65.

Lartigue MF, et al. Identification of Streptococcus agalactiae isolates from various phylogenetic lineages by matrix-assisted laser desorption ionization-time of flight mass spectrometry. Journal of Clinical Microbiology. 2009;47:2284-7.

Lavizzari T, Breccia M, Bover-Cid S, Vidal-Carou MC, Veciana-Nogués MT. Histamine, cadaverine, and putrescine produced in vitro by enterobacteriaceae and pseudomonadaceae isolated from spinach. Journal of Food Protection. 2010;73:385-9. 
Li Y, Solomon S. Ethephon: A versatile growth regulator for sugarcane industry. Sugar Tech. 2003;5:213-23.

Liba CM, et al. Nitrogen-fixing chemo-organotrophic bacteria isolated from cyanobacteria-deprived lichens and their ability to solubilize phosphate and to release amino acids and phytohormones. Journal of Applied Microbiology. 2006;101:1076-86.

Lifishitz R, et al. Growth promoting of canola rapessed sedlig by strian of Pseudomonas putida under gnobiotic conditions. Canadian Journal of Microbiology. 1987;33:390-5.

Lincopan N, Leis R, Vianello MA, Araújo MRE, Ruiz AS, Mamizuka EM. Enterobacteria producing extended-spectrum beta-lactamases and IMP-1 metallo-beta-lactamases isolated from Brazilian hospitals. Journal of Medical Microbiology. 2006;55:1611-3.

Lynd LR, Weimer WH, Van ZYL, Pretorius IS. Microbial cellulose utilization: fundamentals and biotechnology. Microbiology and Molecular Biology Reviews, v. 66, p. 506-577, 2002.

Manter DK, Hunter WJ, Vivanco JM. Enterobacter soli sp. nov.: A Lignin-Degrading $\gamma$-Proteobacteria Isolated from Soil. Current Microbiology. 2011;62:1044-9.

Manulis S, Valinski L, Gafni Y, Hershenhorn J. Indole-3-acetic acid biosynthetic pathways in Erwinia herbicola in relation to pathogenicity on Gypsophila paniculata. Physiological and Molecular Plant Pathology. 1991;39:161-71.

Marin VA, Baldani VLD, Teixeira KRS, Baldani JI. Fixação biológica de nitrogênio: bactérias fixadoras de nitrogênio de importância para a agricultura tropical. Abril de 1999.

http://www.infoteca.cnptia.embrapa.br/bitstream/doc/598661/1/doc091.pdf. Acesso em: 21 fev. 2014.

Martins RCR. Resposta de calos de cana-de-açúcar na interação com bactérias endofíticas diazotróficas Tese de Doutorado. São Paulo: Universidade de São Paulo; 2014.

Matsen JM, Spindler JA, Blosser RO. Characterization of Klebsiella isolates from natural receiving waters and comparison with human isolates. Journal of Applied Microbiology. 1974;28:672-8.

Mehnaz C, et al. Isolation and $16 \mathrm{~S}$ rRNA sequence analysis of the beneficial bacteria from the rhizosphere of rice. Canadian Journal of Microbiology. 2001;47:110-7.

Mitchell MA. Enrofloxacin. Journal of Exotic Pet Medicine. 2006;15:66-9.

Mollet C, Drancourt M, Raoult D. $r p o B$ sequence analysis as a novel basis for bacterial identification. Molecular Microbiology. 1997;26:1005-11.

Muller JH, Hinton J. A protein free medicine for primary isolation of onococus and meningococcus. Proceedings of society of experiments. Biology and Medicine. 1941;48:330-3.

Murray PR, Drew WL, Kobayashi GS, Thompson Jr JH. Microbiologia médica. $9^{a}$ ed. Rio de Janeiro: Guanabara Koogan; 1999.

Napier RM, et al. Purification, sequencing and functions of calreticulin from maize. Journal of Experimental Botany. 1995;46:1603-13. 
Narloch C. Interação microrganismos solubilizadores de fosfatos-fungos ectomicorrízicos e o crescimento de Pinus taeda L. Dissertação de Mestrado. Florianópolis: Universidade Federal de Santa Catarina; 2002.

Nautiyal CS. An efficient microbiological growth medium for screening phosphate solubilizing microrganisms. FEMS Microbiology Letters. 1999;170:265-70.

Nguyen T, Ton T, Tarasenko V, Kozyrovska N. Nitrogen-Fixing bacteria colonize the rice root xylem. Biopolymery i Kletka. 1989;5:97-9.

Ohgaki N. Bacterial biofilm in chronic airway infection. Kansenshogaku Zasshi. 1994;68:138-51.

Oliveira ZM. Rizobactérias promotoras de crescimento vegetal isoladas de cana-de-açúcar sob fertilização orgânica e/ou convencional. [tese (Doutorado)]. São Paulo: Instituto de Ciências Biomédicas, Universidade de São Paulo; 2009.

Opelt K, Berg G. Diversity and antagonistic potential of bacteria associated with bryophytes from nutrient poor habitats of the Baltic Sea Coast. Applied and Environmental Microbiology. 2004; 70:6569 - 6579.

Paradis S, et al. Phylogeny of the Enterobacteriaceae based on genes. International Journal of Systematic and Evolutionary Microbiology. 2005; 55:2013-2025.

Pariona-Llanos R, Ferrara FIS, Gonzales HS, Barbosa HR. Influence of organic fertilization on the number of culturable diazotrophic endophytic bacteria isolated from sugarcane. European Journal of Soil Biology. 2010;46:387-93.

Parke JL, Gurian-Sherman D. Diversity of the Burkholderia cepacia complex and implications for risk assessment of biological control strains. Annual Reviews Phytopathology. 2001;39:225-58.

Patten CL, Glick BR. Bacterial Biosyntesis of indole-3-acetic acid. Canadian Journal of Microbiology. 1996; 42:207-20.

Pham HN., et al. Phylogeny and species identification of the family Enterobacteriaceae based on dnaJ sequences. Diagnostic Microbiology and Infectious Disease. 2007;58:153-61.

Pierik R, Tholen D, Poorter H, Visser EJW, Voesenek LACJ. The Janus face of ethylene: growth inhibition and stimulation. Trends in Plant Sciences. 2006;11:176-83.

Pitout JD, Moland ES, Sanders CC, Thomson KS, Fitzsimmons SR. Beta-lactamases and detection of beta-lactam resistance in Enterobacter spp. Antimicrob Agents Chemother. 1997:35-9.

Podschun R. Phenotypic properties of Klebsiella pneumoniae and K. oxytoca isolated from different sources. Zentralbl Hyg Umweltmed. 1990;189:527-35.

Podschun R, Sahly H. Hemagglutinins of Klebsiella pneumoniae and $K$. oxytoca isolated from different sources. Zentralbl Hyg Umweltmed. 1991;191:46-52.

Podschun R, Ullmann U. Bacteriocin typing of Klebsiella spp. isolated from different sources. Zentralbl Hyg Umweltmed. 1996;198:258-64. 
Poirel L, Héritier C, Podglajen I, Sougakoff W, Gutmann L, Nordmann P. Emergence in Klebsiella pneumoniae of a chromosome-encoded SHV beta-lactamase that compromises the efficacy of imipenem. Antimicrobial Agents and Chemotherapy. 2003;47:755-8.

Poly F, Monrozier LJ, Bally R. Improvement in the RFLP procedure for studying the diversity of nifH genes in communities of nitrogen fixers in soil. Microbiological research. 2001;152:95-103.

Prada J, Beutin L. Detection of Escherichia coli alpha-heamolysin genes and their expression in a human faecal strain of Enterobacter cloacae. FEMS Microbiology Letters. 1991;63:111-4.

Rahme LG, Stevens EJ, Wolfort SB, Shoa J, Tompkins RG, Ausubel FM. Common virulence factors for bacterial pathogenicity in plants and animals. Science. 1995;268:1899-902.

Rajkumar M, Ae N, Prasad MNV, Freitas H. Potential of siderophore-producing bactéria for improving heavy metal phytoextraction. Trends in Biotecnology. 2010;28:142-9.

Recouvreux DOS, Carminatti CA, Pitlovanciv DGA, Miqueleto AP, Oliveira IL, Antonio RV, Porto LM. Evidências da presença de celulose no Biofilme formado por Chromobacterium violaceum. 2005. Disponível em: < http://repositorio.ufsc.br/xmlui/handle/123456789/87780 > Acesso em: março 2014.

Rodriguez H, Fraga R. Phosphate solubilizing bacteria and their role in plant growth promotion. Biotechnology Advances. 1999;17:319-39.

Ryu JR, Patten CL. Aromatic Amino Acid-Dependent Expression of Indole-3-Pyruvate Decarboxylase Is Regulated by TyrR in Enterobacter cloacae UW5. Journal of Bacteriology. 2008; 190:7200-8.

Sakazaki R, Tamura K, Kosako Y, Yoshizaki E. Klebsiella ornithinolytica sp. nov., formerly known as ornithine-positive Klebsiella oxytoca. Current Microbiology. 1989; 18:201-6.

Salzman TC, Klemm L. Transferable drug resistance R factors in Enterobacterlaceae: relationship to nosocomial infections. Antimicrobial Agents and Chemotherapy. 1967:212-20.

Sanders Jr WE, Sanders CC. Enterobacter spp.: Pathogens Poised To Flourishat the Turn of the Century. Clinical Microbiology Reviews. 1997;10:220-41.

Schmittgen TD, Zakrajsek BA. Effect of experimental treatment on housekeeping gene expression: validation by real-time, quantitative RT-PCR. Journal of Biochemical and Biophysical Methods. 2000; 46:69-81.

Seidler RJ, Knittel MD, Brown C. Potential pathogens in the environment: cultural reactions and nucleic acid studies on Klebsiella pneumoniae from clinical and environmental sources. Journal of Applied Microbiology. 1975; 29:819-25.

Setubal JC, dos Santos P, Goldman BS, Ertesvå H, Espin G. Genome Sequence of Azotobacter vinelandii, an obligate aerobe specialized to support diverse anaerobic metabolic processes. Journal of Bacteriology. 2009;191:4534-45.

Shen BF, Zhu HR, Li J. Response of rice to inoculation with genetic engineered strains of associative diazotrophics. Chinese Rice Research Newsletter. 1996;4:4-5. 
Short EC, Kurtz HJ. Properties of the hemolytic activities of Escherichia coli. Infection and Immunity. 1971;3:678.

Smalla K, Wieland G, Buchner A, Zock A, Parzy J, Roskot N. Bacterial bulk and rhizosphere communities studied by denaturing gradient gel electrophoresis of PCR-amplified fragments of $16 \mathrm{~S}$ rRNA genes - plant dependent enrichment and seasonal shifts revealed. Applied and Environmental Microbiology. 2001;67:4742-51.

Smith HW. The haemolysins of Escherichia coli. Journal of Pathology \& Bacteriology. 1963;85:197.

Sneath PHA, Sokal RR. Numerical taxonomy. San Francisco: Freeman; 1973.

Spaepen S, Vanderleyden J, Remans R. Indole-3-acetic acid in microbial and microorganism-plant signaling. FEMS Microbiology Reviews. 2007;31:425-48.

Spinosa HS, Górniak SL, Bernardi MM. Considerações gerais sobre os antimicrobianos. In: Farmacologia aplicada à medicina veterinária. Rio de Janeiro: Guanabara Koogan; 2002. p. 379-85.

Steinkamp G, et al. Prospective evaluation of emerging bacteria in cystis fibrosis. Journal of Cystic Fibrosis. 2005;4:41-8.

Stock I, Wiedemann B. Natural antibiotic susceptibility of Enterobacter amnigenus, Enterobacter cancerogenus, Enterobacter gergoviae and Enterobacter sakazakii strains. Clinical Microbiology and Infection. 2002;8:564-78.

Struve C, Krogfelt KA. Pathogenic potential of environmental Klebsiella pneumoniae isolates. Environmental Microbiology. 2004;6:584-90.

Su L, Chen S, Wu J. Advance on Escherichia coli alpha-hemolysin secretion pathway-a review. Wei Sheng Wu Xue Bao. 2013;53:1011-7.

Taiz L, Zeiger E. Plant Physiology. $3^{\mathrm{a}}$ ed. Sunderland: Sinauer Associates. 2002.

Tamura K, Stecher G, Peterson D, Filipski A, Kumar S. MEGA6: Molecular Evolutionary Genetics Analysis version 6.0. Molecular Biology and Evolution. 2013;30:2725-9.

Tamura K, Nei M, Kumar S. Prospects for inferring very large phylogenies by using the neighbor-joining method. Proceedings of the National Academy of Sciences. 2004;101:11030-5.

Tan MW, Rahme LG, Sternberg JA, Tompkind RG, Ausubel FM. Pseudomonas aeruginosa killing of Caenorhabditis elegans used to identify $P$. aeruginosa virulence factors. Proceedings of the National Academy of Sciences. 1999; 96:2408-13.

Tang YW, Ellis NM, Hopkins MK, Smith DH, Dodge DE, Persing DH. Comparison of Phenotypic and Genotypic Techniques for Identification of Unusual Aerobic Pathogenic Gram-Negative Bacilli. Journal of Clinical Microbiology. 1998; 36:3674-3679.

Tavares W. Manual de antibióticos e quimioterápicos antiinfecciosos. 2a ed. São Paulo: Atheneu; 1996. 
Teather RM, Wood PJ. Use of congo red-polysaccharide interactions in enumeration and characterization of cellulotic bacteria from the bovine rumen. Applied and Environmental Microbiology. 1982; 43:777-80.

Teixeira KR. Bases moleculares e genética da fixação biológica de nitrogênio. Embrapa-CNPAB. Documentos. 1997;32:26.

Thuler DS, Floh EI, Handro W, Barbosa HR. Beijerinckia derxii releases plant growth regulators and amino acids in synthetic media independent of nitrogenase activity. Journal of Applied Microbiology. 2003; 95:799-806.

Thuler DS, Floh EI, Handro W, Barbosa HR. Plant growth regulators and amino acids released by Azospirillum sp in chemically defined media. Letters in Applied Microbiology. 2003;37:174-8.

Toth IK, Pritchard L, Birch PR. Comparative genomics reveals what makes an enterobacterial plant pathogen. Annual Review of Phytopathology. 2006; 44:305-36.

Toyoda et al. Expression of the gapA gene encoding glyceraldehyde-3-phosphate dehydrogenase of Corynebacterium glutamicum is regulated by the global regulator SugR. Applied Microbiology and Biotechnology. 2008;81:291-301.

Trabulsi LR, Alterthum F, Martinez MB, Campos LC, Gompertz OF, Rácz ML. Microbiologia. $4^{\mathrm{a}}$ ed. São Paulo: Atheneu; 2005.

van Baar BL. Characterisation of bacteria by matrix-assisted laser desorption/ionisation and electrospray mass spectrometry. FEMS Microbiology Reviews. 2000;24:193-219.

Van Loon LC, Bakker PA, Pieterse CM. Systemic resistance induced by rhizosphere bacteria. Annual Review of Phytopathology. 1998; 36:453-83.

Varon NF, Alangaden GJ. Emerging trends in infections among renal transplant recipients. Expert Review of Anti-infective Therapy. 2004;2:95-109.

Vass M, Hruska K, Franek M. Nitrofuran antibiotics: a review on the application, prohibition and residual analysis. Veterinarni Medicina. 2008;53:469-500.

Verma SC, Lahda JK, Tripathi AK. Evaluation of plant growth promoting and colonization ability of endophytic diazotrophs from deep water rice. Journal of Bacteriology. 2001; 91:127-41.

Versalovic J, Koeuth T, Lupski JR. Distribution of repetitive DNA sequences in eubacteria and application to fingerprinting of bacterial genomes. Nucleic Acids Research. 1991;91:6823-31.

Vimont S, Mnif B, Fevre C, Brisse S. Comparison of PFGE and multilocus sequence typing for analysis of Klebsiella pneumoniae isolates. Journal of Medical Microbiology. 2008;57:1308-10.

Wang JR, Zhang LY. Simultaneous Determination and Identification of Furazolidone, Furaltadone, Nitrofurazone, and Nitrovin in Feeds by HPLC and LC-MS. Journal of Liquid Chromatography \& Related Technologies. 2006; 29:377-90.

Wang L, et al. A Minimal Nitrogen Fixation Gene Cluster from Paenibacillus sp. WLY78 Enables Expression of Active Nitrogenase in Escherichia coli. PLoS Genetics. 2013:9. 
Wei, H, et al. Fatal infection in human flora-associated piglets caused by the opportunistic pathogen Klebsiella pneumoniae from an apparently healthy human donor. The Journal of Veterinary Medical Science. 2008;70:715-7.

Weisburg WG, Barns SM, Pelletier DA, Lane DJ. 16S ribosomal DNA amplification for phylogenetic study. Journal of Bacteriology. 1991; 173:697-703.

Whipps J. Microbial interactions and biocontrol in the rhizosphere. Journal os experimental Botany. 2001;52:487-511.

Wood WA, Kellog ST. Biomass Part A. Cellulose and Hemicellulose. Methods in Enzymology. $1988 ; 160$.

Yuan P, et al. A novel low-temperature active alkaline pectate lyase from Klebsiella sp. Y1 with potential in textile industry. Process Biochemistry. 2011;46:1921-6.

Zhang GX, et al. Diverse endophytic nitrogen-fixing bacteria isolated from wild rice Oryza rufipogon and description of Phytobacter diazotrophicus gen. nov. sp. nov. Archives of Microbiology. 2008;189:431-9.

Zhao Y, Bian S, Zhou H, Huang J. Diversity of Nitrogenase Systems in Diazothophs. Journal of Integrative Plant Biology. 2006;48:745-55.

Zhu B, et al. Enterobacter sacchari sp. nov., a nitrogen-fixing bacterium associated with sugarcane Saccharum officinarum L.. International Journal of Systematic and Evolutionary Microbiology. 2013; 63:2577-82. 